\title{
EFFECTS OF A NON-STEROIDAL AROMATASE INHIBITOR ON OVARIAN FUNCTION IN CATTLE
}

\author{
A Thesis submitted to the College \\ of Graduate Studies and Research \\ in Partial Fulfilment of the Requirements \\ for the Degree of Master of Science \\ in the Department of Veterinary Biomedical Sciences \\ University of Saskatchewan \\ Saskatoon
}

By

Maria Jimena Yapura

(C) Copyrights Maria Jimena Yapura, July 2009. All rights reserved 


\title{
PERMISSION TO USE POSTGRADUATE THESIS
}

In presenting this thesis in partial fulfillment of the requirements for a Postgraduate degree from the University of Saskatchewan, I agree that the Libraries of this University may take it freely available for inspection. I further agree that permission for copying of this thesis in any manner, in whole or in part, for scholarly purposes may be granted by the professor or professors who supervised my thesis work or, in their absence, by the Head of the Department or the Dean of the College in which my thesis work was done. It is understood that any copying or publication or use of this thesis or parts thereof for financial gain shall not be allowed without my written permission. It is also understood that due recognition shall be given to me and to the University of Saskatchewan in any scholarly use which may be made of any material in my thesis.

Request for permission to copy or to make other use of material in this thesis in whole or part should be addressed to:

\author{
Head of Department of Veterinary Biomedical Sciences \\ Western College of Veterinary Medicine \\ 52 Campus Drive \\ University of Saskatchewan \\ Saskatoon, Saskatchewan \\ S7N 5B4 Canada
}




\begin{abstract}
Two studies were designed to characterize the effects of a non-steroidal aromatase inhibitor, letrozole, on ovarian function in cattle. The specific objective was to test the hypothesis that letrozole will arrest dominant follicle growth resulting in emergence of a new follicular wave at a predictable interval post-treatment. In a first experiment, postpubertal beef heifers were assigned randomly to four treatment groups and given phosphate-buffered saline (controls; $n=10$ ), or letrozole at a dose of $500(n=9), 250(n=10)$, or $125(n=10) \mu g / k g$ intravenously 4 days after follicular ablation ( 2.5 days after wave emergence). In a second study, postpubertal beef heifers were assigned randomly to four treatment groups. One group received no treatment (control; $\mathrm{n}=17)$ and the other groups $(\mathrm{n}=9-10)$ were given $85 \mu \mathrm{g} / \mathrm{kg}$ of letrozole per day $(250 \mu \mathrm{g} / \mathrm{kg}$ total dose), from Days 1 to 3 , Days 3 to 5 , or Days 5 to 7 (Day $0=$ pre-treatment ovulation,) corresponding to the periods before, during and after selection of the dominant follicle, respectively. Follicular dynamics were monitored ultrasonically and blood samples were collected for endocrine assays. Follicle diameter profiles and plasma LH, FSH, and estradiol concentrations were analyzed. Additionally, during the second trial, CL diameter profiles and plasma progesterone concentrations were measured. In both studies, the diameter profile of the dominant follicle was larger in heifers treated with letrozole than in control heifers $(\mathrm{P}<0.05)$ and the intervals to new wave emergence and onset of regression of the extant dominant follicle were longer $(\mathrm{P}<0.05)$ in heifers treated with letrozole than in controls, regardless of the dose (high, medium, or low; single vs multiple) and the stage of the follicle wave in which treatments were initiated. Furthermore, during the second experiment, the mean CL diameter was larger in letrozole-treated heifers, although there were no differences in plasma progesterone
\end{abstract}


concentrations between treated and control animals. The effects on dominant follicle and CL diameter profiles appeared to be the result of the significantly increased plasma LH concentrations observed in letrozole-treated animals during both treatment approaches (single vs multiple dose). Incomplete and inconsistent inhibition of estradiol production and the lack of a surge on FSH observed in both experiments may be a result of insufficient circulating levels of letrozole during the treatment period. In summary, a single or multiple dose of letrozole did not induce regression of the extant dominant follicle, nor did it directly affect FSH release. Conversely, letrozole extended the lifespan of the dominant follicle, in association with increased endogenous levels of LH, thereby delaying the next FSH surge and subsequent follicular wave emergence. Results suggest that letrozole has potential as a non-steroidal method for controlling ovarian function in cattle, but further studies are warranted to clarify dosage and timing of treatment to predictably affect follicular wave dynamics in cattle. 


\section{ACKNOWLEDGEMENTS}

I want to express my admiration and gratitude to my supervisor Dr. Gregg P. Adams for his guidance and support throughout my program. I appreciate his efforts to help me become a better researcher and for his endless patience. I also extend my appreciation to my co-supervisor Dr. Jaswant Singh for his inputs, critiques, and for helping me better understand data analysis. I would like to thank Dr. Roger Pierson for his critical inputs and insightful comments.

I will be lifetime grateful to Dr. Reuben Mapletoft for helping the progress of my research, but more importantly for his trust and never ending support. I cannot find the right words to thank him for all his encouragement and dedication.

I am immensely thankful to Dr Gabriel Bo, Dr Humberto Tribulo and Dr Ricardo Tribulo for introducing me to reproductive physiology and for fostering in me the interest and passion for research. They were instrumental part of my training as a vet student and later on as a bovine reproduction specialist and they made it possible for me to come to Canada to pursuit graduate studies.

There are many people that have, directly or indirectly, participated in the completion of this thesis. I thank my friends and colleagues Orleigh Bogle, Mahsa Abrishami, Behzad Toosi, and Fernanda Dias for their help, the great times and their unconditional support. I specially thank the member of the Repro Lab as well as all our summer students for their assistantship at the farm; without their help this work could not have been completed. The interactions with my fellow students and officemates Garry, Rajesh, Pritpal, Dinesh, Sunita, Jennifer, YangFei, and many others were rewarding. I must also thank Dr. Baljit Singh for his positive outlook and for 
being so inspirational every day. I take this opportunity to acknowledge funding from University of Saskatchewan Devolved Scholarship.

I am thankful to Dr Luca Panizzi for being my beloved partner, my best friend and my family during the last few years. His unconditional love and support provided me with the strength and determination to reach my goals and objectives. I thank him for helping me become a better person.

Finally, I thank my sisters Eugenia, Laura and Dolly, my father Alberto and my mother Ana for their unrelenting support during this adventure. I thank them for their love and encouragement and for making my times at home a never-ending celebration. I left a half of my heart in Argentina every time I left them behind. 


\section{DEDICATION}

To my mother, Ana Maria del Jesus Vera, for being my inspiration and unconditional supporter since the beginning of my career. She taught me to persevere and prepared me to face challenges with love and hope. I wish every word in this thesis could pay her back for all the tears I made her shed with my absence.

A mi madre, Ana Maria del Jesús Vera, por ser mi inspiración y mi incondicional seguidora desde los comienzos de mi carrera. Ella me enseño a perseverar y me preparo para enfrentar los desafíos con amor y esperanza. Es mi deseo q cada palabra en esta tesis pueda pagarle por todas las lagrimas q le hice derramar con mi ausencia. 


\section{TABLE OF CONTENTS}

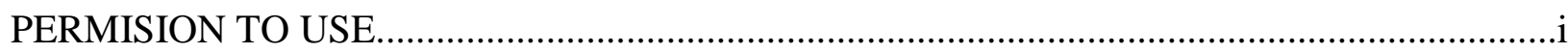

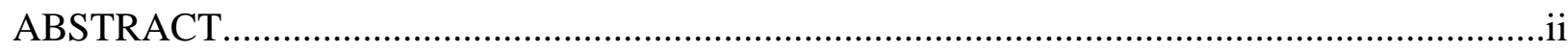

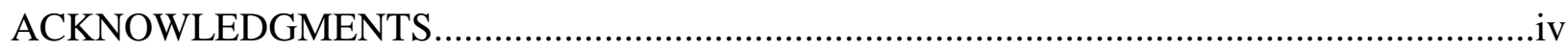

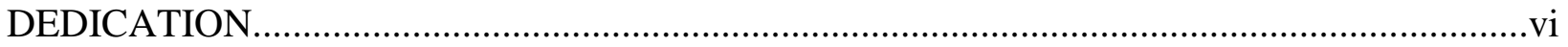

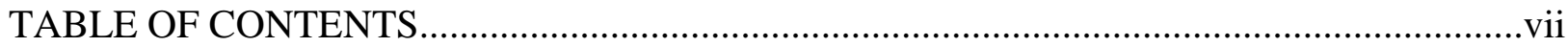

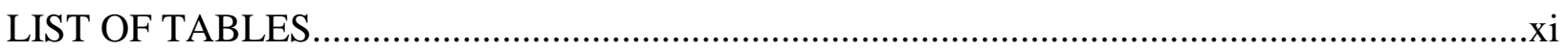

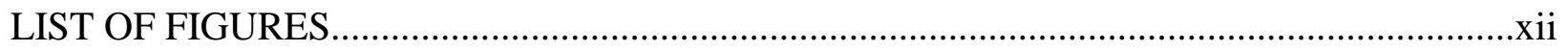

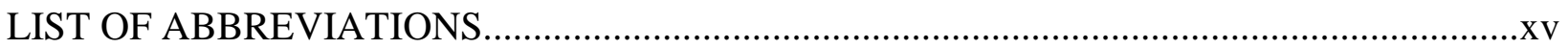

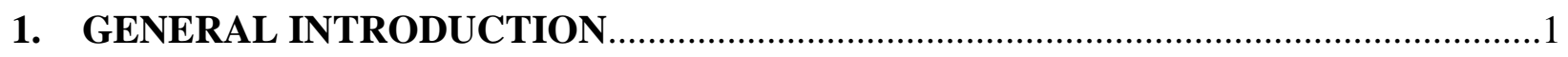

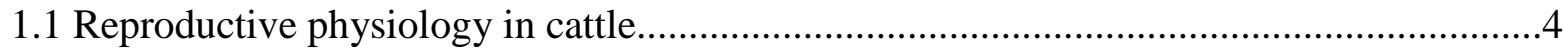

1.1.1 Follicular wave development in cattle...................................................

1.1.2 Role of gonadotrophins in ovarian functions...............................................

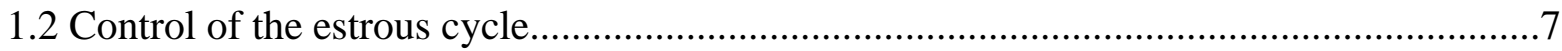

1.2.1 Prostaglandin and GnRH-based protocols for estrus synchronization...................8

1.2.2 Estradiol and progesterone-based protocols................................................10

1.3 Estrogens and other sex steroid hormones......................................................... 12

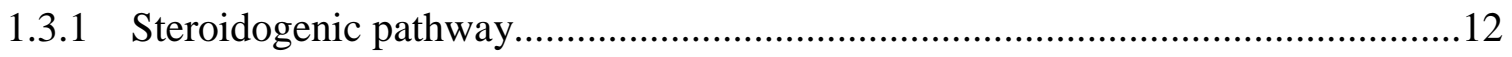

1.3.2 Regulation of steroidogenesis in the bovine ovary.........................................14

1.3.3 Metabolism and elimination of estrogens...................................................15

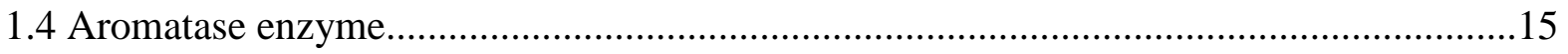

1.4.1 CYP19 gene: Structure and regulation.....................................................16 


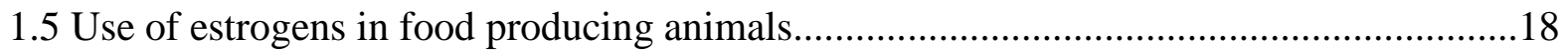

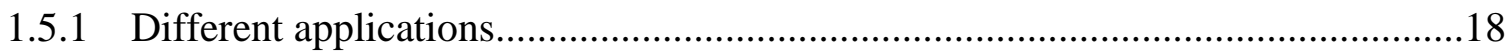

1.5.2 The issue of estrogens in food: Situation in the European Union, USA and

Canada.

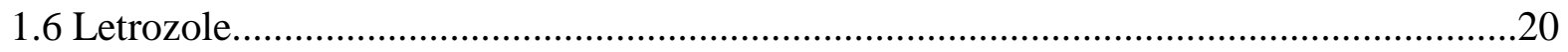

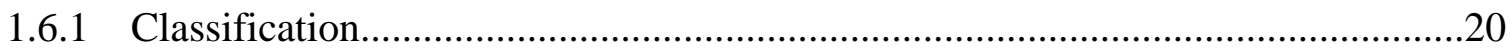

1.6.2 Pharmacology of letrozole in humans......................................................21

1.6.3 Uses of letrozole in cancer therapy..........................................................22

1.6.4 Letrozole in the treatment of infertility in women......................................23

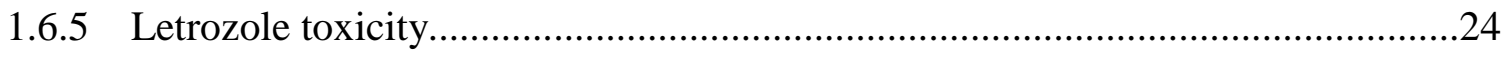

1.7 The bovine model for the study of human reproduction..........................................25

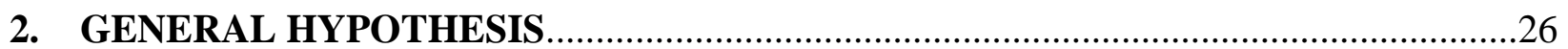

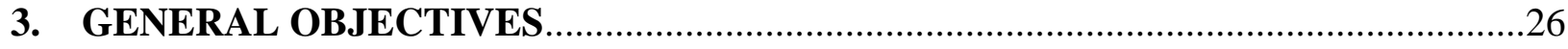

4. EFFECT OF LETROZOLE ON OVARIAN FUNCTION IN CATTLE.....................27

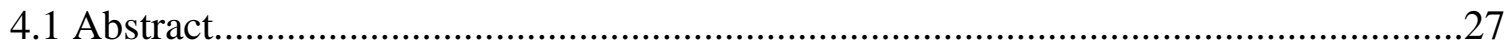

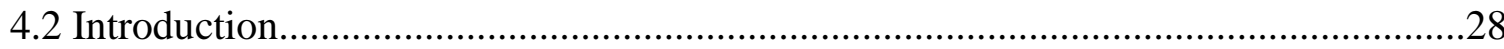

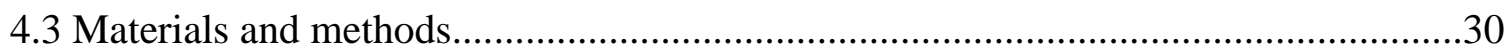

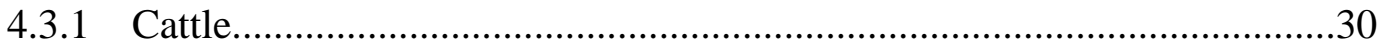

4.3.2 Treatments and examinations........................................................... 30

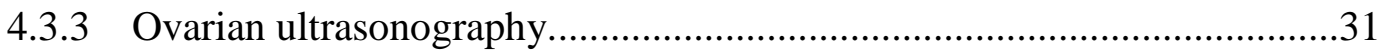

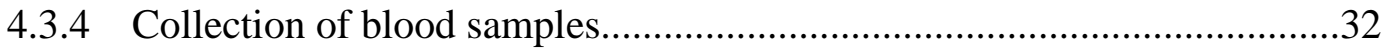

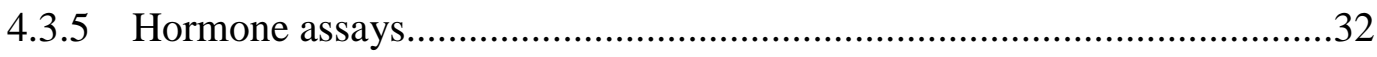

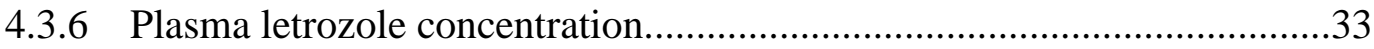




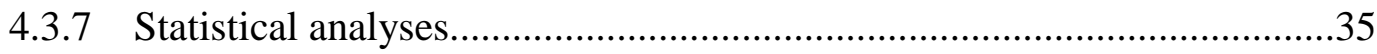

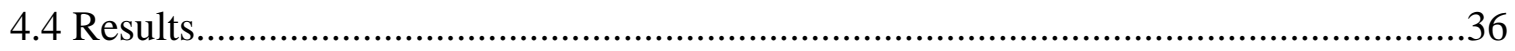

4.4.1 Ovarian function............................................................................ 36

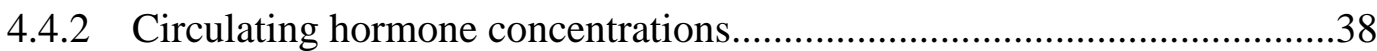

4.4.3 Plasma letrozole concentration....................................................41

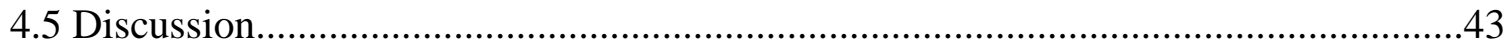

\section{EFFECT OF A 3-DAY REGIMEN OF LETROZOLE ON OVARIAN FUNCTION}

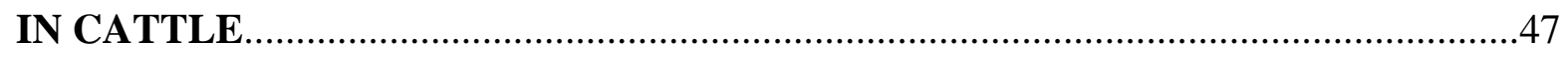

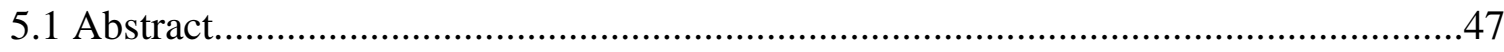

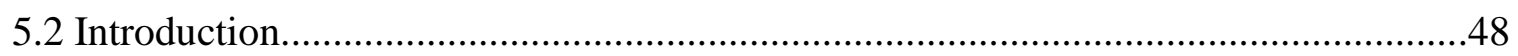

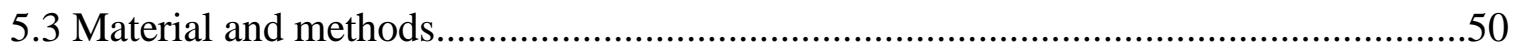

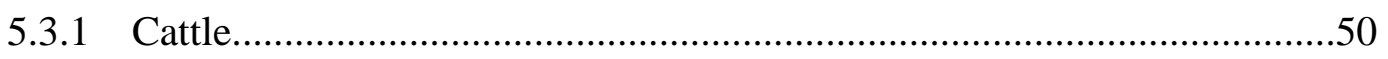

5.3.2 Treatments and examinations......................................................51

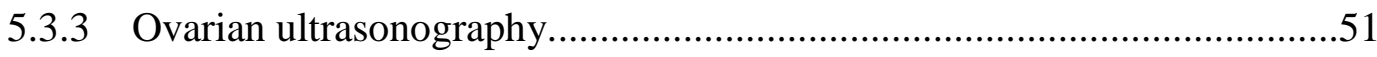

5.3.4 Computer-assisted ultrasound image analysis..................................52

5.3.5 Collection of blood samples........................................................53

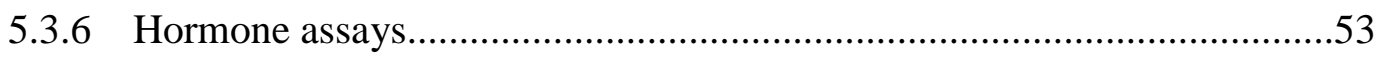

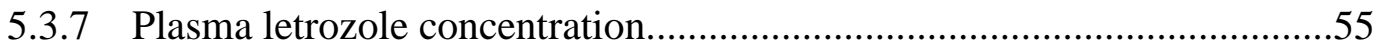

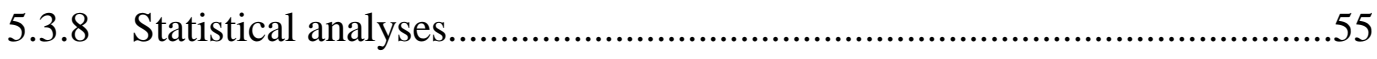

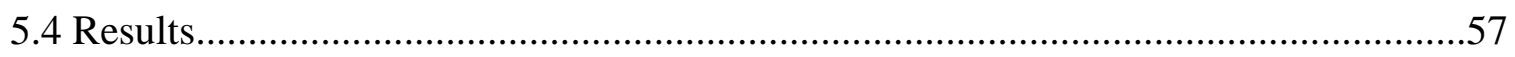

5.4.1 Circulating concentrations of letrozole..............................................57

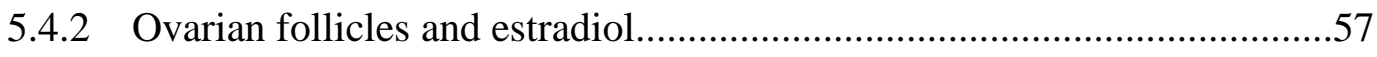

5.4.3 Corpus luteum and plasma progesterone ...........................................60 


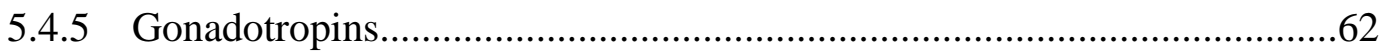

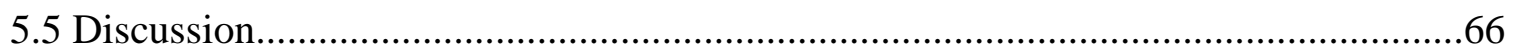

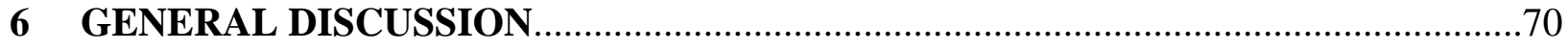

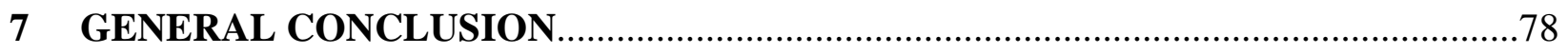

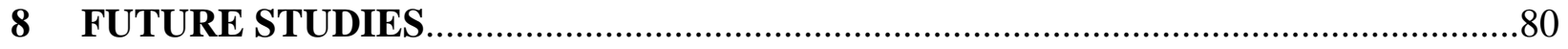

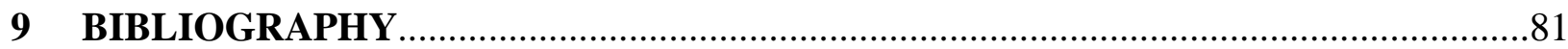

APPENDICES

Appendix 1: Diameter profile (mean \pm SEM) of the dominant follicle in heifers treated with a high- $(\mathrm{n}=9)$, medium- $(\mathrm{n}=10)$ or low-dose $(\mathrm{n}=10)$ of letrozole 4 days after follicular ablation (i.e., 2.5 days after wave emergence), compared to saline-treated controls $(\mathrm{n}=10)$

Appendix 2: Diameter profile (mean $\pm \mathrm{SEM}$ ) of the dominant follicle in heifers treated with letrozole on Days 1 to $3(n=10), 3$ to $5(n=9)$ or 5 to $7(n=9)($ Day $0=$ ovulation) compared to untreated controls $(\mathrm{n}=17)$.

Appendix 3: Determination of plasma estradiol-17 $\beta$ concentrations by high performance liquid chromatography/mass spectrometry (HPLC/MS).

Appendix 4: Comparison of plasma estradiol-17 $\beta$ concentrations as determined by HPLC/MS and ELISA

Appendix 5: Results from computer-assisted image analysis of CL and dominant follicle. 


\section{LIST OF TABLES}

Table 4.1. Effects of letrozole on interval to follicle wave emergence, ovulation, onset of follicular regression and onset of CL regression in cattle. Data from low-, medium- and high-dose treatment groups were combined, and compared to PBS-treated controls. Values are expressed as mean \pm SEM.

Table 4.2. Pharmacokinetics of letrozole after administration of a single intravenous dose of 125,250 , or $500 \mu \mathrm{g} / \mathrm{kg}$ in postpubertal beef heifers, determined by non-compartmental analysis (mean \pm SEM)

Table 5.1. Effects (mean $\pm \mathrm{SEM}$ ) of a 3-day treatment regimen of letrozole given at three different stages of the follicular wave on the intervals to new wave emergence and ovulation in heifers.

Table 5.2. Effect of 3-day letrozole treatment at three different stages of the follicular wave on LH secretory activity compared to corresponding controls as measured in 15 min samples collected over 8 hours 


\section{LIST OF FIGURES}

Figure 1.1. Synthesis of estrogens in ruminant: five main hormones are involved in the enzymatic pathway leading to the synthesis of estrogens from cholesterol.

Figure 1.2. Chemical structure of letrozole: its chemical structure contains a triazole group that selectively binds to the heme group of the aromatase enzyme.

Figure 4.1. Diameter profile (mean \pm SEM) of the dominant follicle in heifers treated with letrozole (high-, medium- and low-dose groups combined; n=29) 4 days after follicular ablation (i.e., 2.5 days after wave emergence), compared to PBS-treated controls $(\mathrm{n}=10)$.

Figure 4.2. Plasma FSH concentrations (percent change after treatment; mean \pm SEM) in heifers treated with letrozole (high-, medium- and low-dose groups combined; $\mathrm{n}=29$, , 4 days after follicular ablation (i.e., 2.5 days after wave emergence), compared to PBS-treated controls $(n=10)$

Figure 4.3. Plasma LH concentrations in heifers (percent change after treatment; mean \pm SEM) during the first 12 hours (left) and for 96 hours (right) after a single intravenous dose of letrozole (high-, medium- and low-dose groups combined; $\mathrm{n}=29$ ) given 4 days after follicular ablation (i.e., 2.5 days after

wave emergence), compared to PBS-treated controls $(n=10)$

Figure 4.4. Plasma estradiol concentrations (mean \pm SEM) in heifers during the first 96 hours after a single intravenous dose of letrozole (high-, medium- and lowdose groups combined; $\mathrm{n}=29$ ) given 4 days after follicular ablation (i.e., 2.5 days after wave emergence), compared to PBS-treated controls $(n=10)$. Within groups, differences in estradiol concentrations between 0 and 24 xii 
hours after treatment were compared by paired t-test.

Figure 4.5. Plasma letrozole concentration (mean \pm SEM) as determined by HPLC/MS after administration of a single intravenous dose of 125,250 , or $500 \mu \mathrm{g} / \mathrm{kg}$ in postpubertal beef heifers. Data from Hour 0 to 12 hours after treatment are represented

Figure 5.1. Plasma letrozole concentration (mean \pm SEM) as determined by HPLC/MS in heifers treated with letrozole $(85 \mu \mathrm{g} / \mathrm{kg} /$ day $)$ from Days 1 to 3, Days 3 to 5 or Days 5 to 7 (Day $0=$ ovulation)

Figure 5.2. Diameter profile (mean \pm SEM) of the dominant follicle in heifers treated with letrozole on Days 1 to 3, 3 to 5 or 5 to 7 (Day $0=$ ovulation; treatment groups combined, $n=28)$ compared to untreated controls $(n=17)$. .58

Figure 5.3. Diameter profile (mean \pm SEM) of the largest subordinate follicle in heifers treated with letrozole on Days 1 to $3(n=10)$, or Days 3 to $5(n=9)$, compared to untreated controls $(n=17)$. Heifers treated with letrozole from Days 5 to 7 were not included in the analysis since the largest subordinate follicle was not longer detectable at initiation of treatment on Day 5 .59

Figure 5.4. Plasma estradiol concentration, expressed as a percent of the mean of two pre-treatment samples (i.e., taken 24 hours before and immediately before treatment; mean \pm SEM); in heifers following daily treatment with letrozole from Days 1 to 3 (a), Days 3 to 5 (b) and Days 5 to 7 (c) of the first follicular wave ( $\mathrm{n}=4-5$ per group; Day $0=$ ovulation $)$. 
Figure 5.5. Diameter profile of the corpus luteum and plasma progesterone concentration (mean $\pm \mathrm{SEM}$ ) in heifers treated with letrozole $(85 \mu \mathrm{g} / \mathrm{kg} / \mathrm{day}$ for 3 days; data from treatment periods of Days 1 to 3,3 to 5 , and 5 to 7 combined; $n=18)$, compared to untreated controls $(n=17)$..

Figure 5.6. Plasma FSH concentration, expressed as a percent of the mean of Days 0 and $1($ mean $\pm S E M)$, in heifers treated with letrozole on Days 1 to $3(n=10)$, Days 3 to $5(n=9)$, or Days 5 to $7(n=9$; Day $0=$ ovulation), compared to untreated controls $(n=17)$

Figure 5.7. Comparison of plasma LH concentrations in heifers for a 60-hour period from the start of treatment and from the end of treatment with letrozole. Values (mean \pm SEM) are expressed as a percent of the mean of Days 0 and 1 in heifers treated with letrozole on Days 1 to $3(n=10)$, Days 3 to $5(n=9)$, or Days 5 to 7 ( $n=9$; Day $0=$ ovulation). Data obtained during the 3 days of letrozole treatment and the 3 days after treatment were analyzed for effects of Treatment (during vs after), Time of data collection (AM vs PM), Day $\left(1^{\text {st }}, 2^{\text {nd }}\right.$, and $\left.3^{\text {rd }}\right)$, and their interactions. 64

Figure 5.8. Effect of letrozole on plasma LH concentrations (expressed as a percent of the mean of Days 0 and 1 post-ovulation; mean \pm SEM) in heifers treated in the morning for 3 consecutive days (letrozole-groups combined $n=28$ ) during the 3 days of treatment and after the 3 days following treatment. 65 


\section{LIST OF ABBREVIATIONS}

\begin{tabular}{|c|c|}
\hline$\mu g$ & micrograms \\
\hline $3 \beta-H S D$ & $3 \beta$-hydroxysteroid dehydrogenase \\
\hline $17 \beta$-HSD & $17 \beta$-hydroxysteroid dehydrogenase \\
\hline A & adenine \\
\hline AI & artificial insemination \\
\hline CIDR & controlled internal drug release \\
\hline CL & corpus luteum \\
\hline DES & diethylstilbestrol \\
\hline DF & dominant follicle \\
\hline $\mathrm{EB}$ & estradiol benzoate \\
\hline $\mathrm{EC}$ & estradiol cypionate \\
\hline E-17 & estradiol-17 beta \\
\hline ELISA & enzyme-linked immunosorbent assay \\
\hline FDA & USA Food and Drug Administration \\
\hline FSH & follicle stimulating hormone \\
\hline FSHr & follicle stimulating hormone receptor \\
\hline FTAI & fixed-time artificial insemination \\
\hline $\mathrm{G}$ & guanine \\
\hline GH & growth hormone \\
\hline GnRH & gonadotrophin releasing hormone \\
\hline $\mathrm{h}$ & hours \\
\hline
\end{tabular}

HPLC/MS High performance liquid chromatography mass spectrometry 


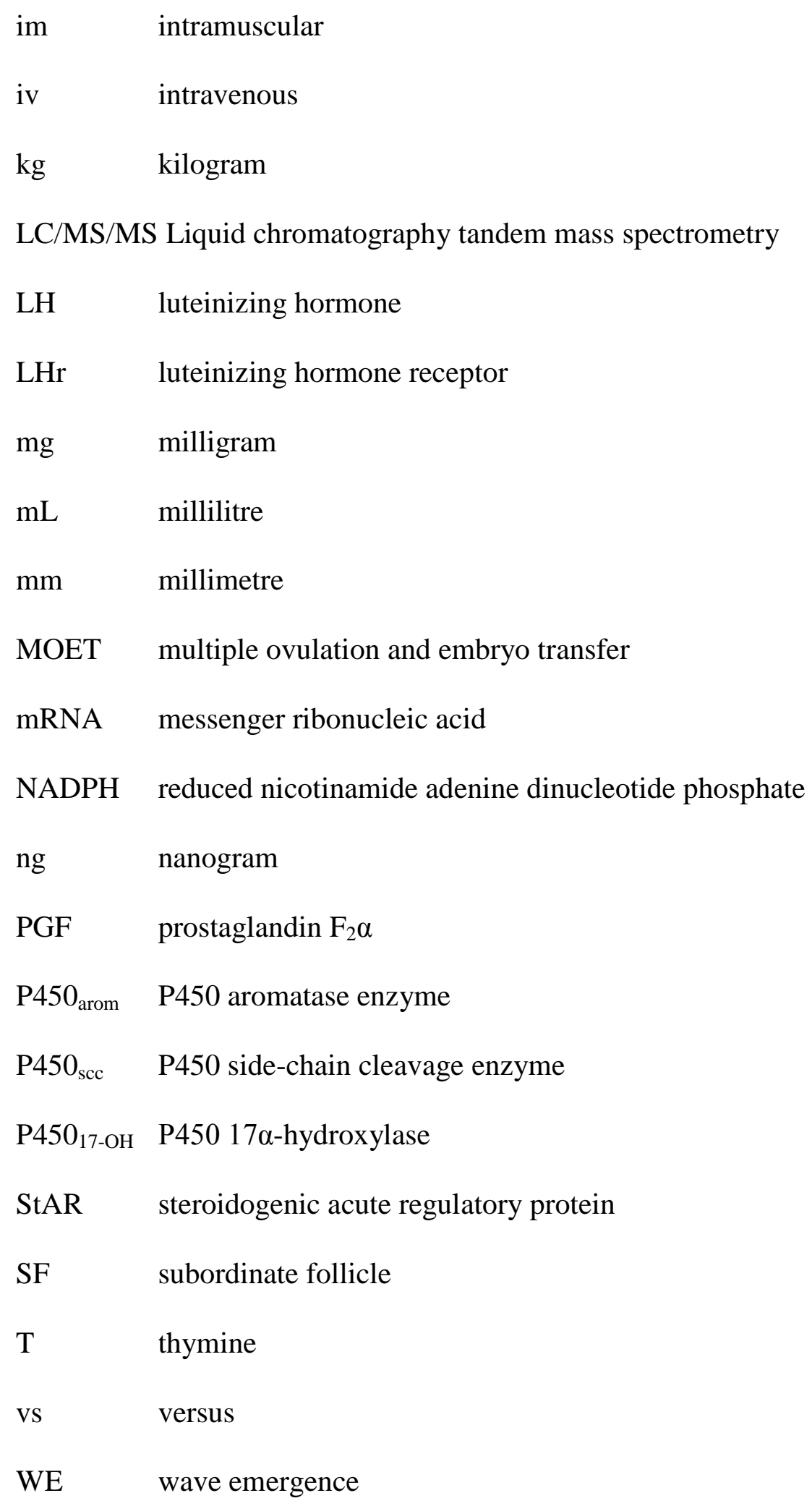




\subsection{GENERAL INTRODUCTION}

Reproductive efficiency is the single most important factor affecting profitability in the cattle industry. Improvements in reproductive efficiency have required years of research aimed at clarifying and describing the patterns and mechanisms governing physiological functions related to reproduction. Key findings such as the occurrence of waves of follicular growth $[1,2]$ and the involvement of gonadotrophins [3-5] and steroid hormones [6, 7] in the control of follicular wave patterns have allowed the development and application of several strategies meant to manipulate the many different events related to ovarian function in cattle. Among those strategies, estrogens in combination with a source of progesterone has been very efficient in synchronizing follicle wave emergence and ovulation [8, 9]. Steroid-induced wave synchronization is associated with regression of the dominant follicle followed by a surge in circulating FSH and subsequent emergence of a new follicular wave at a consistent interval posttreatment. Steroid-induced regression of the dominant follicle is a result of a systemic alteration in feedback of estradiol and progesterone on pituitary release of LH and FSH [10]. Estradiol suppresses FSH release [11] and has been reported to decrease LH pulse amplitude in sheep [12] and cattle [13]. Progesterone has been reported to decrease LH pulse frequency and suppress maximal diameter of the dominant follicle in a dose-dependent manner in cattle [14-19]. Once the suppressive effects of estradiol are removed, FSH surges resulting in the emergence of a new wave of follicular development approximately 4 days after estradiol/progesterone treatment, regardless of the stage of development of the dominant follicle at the time of treatment $[9,20$, 21]. The degree of synchrony achieved with a combination of estradiol and progesterone has reduced or eliminated the need for estrus detection, allowing more efficient use of time and labour, and thereby shortening breeding and calving seasons. Furthermore, the elective control of 
follicle development in cattle has opened the possibility of introducing new technologies that require precise control of luteal function, follicle wave emergence and ovulation such as fixedtime artificial insemination (FTAI) $[22,23]$ and multiple ovulation and embryo transfer (MOET) $[9,24]$.

Estrogens regulate reproductive phenomena and play a key role in many other important physiological functions in vertebrates. Because of their involvement in the determination of secondary sexual characteristics, acceleration of linear growth and closure of epiphyseal plates, and facilitation of fat deposition and vasodilatation [25], estrogen and its synthetic analogs have been used by the beef industry as growth promoting factors for several decades [26]. It has been reported that the anabolic effects of implants containing estrogens can improve growth rate by 10 to $30 \%$ and feed efficiency by 5 to $15 \%[27,28]$.

The concern regarding the toxicity of hormonal preparations used as growth promoters in cattle, and the potential carcinogenic effects of hormonal residues present in meat or milk of treated animals [29-31] was raised in Europe more than 20 years ago. The use of naturally occurring estrogens and synthetic compounds with estrogenic activity in food producing animals has been a subject of considerable controversy (reviewed in [32]). After years of deliberation, and regardless of the lack of convincing scientific support, the European Union (EU) decided to ban the use of estradiol and other steroid hormones as growth promoting agents in animals designated for human consumption in all the member states as of January 1, 1989 [33]. This prohibition also banned the entry into the EU of meat or food products originated from animals in which hormonal growth promoting treatments were applied. As there was some uncertainty among veterinarians regarding the legality of using hormonal treatments for reproductive management in animals designated to human consumption, the EU issued another report, 
officialised on October 14, 2006, in which it was stated that the use of estradiol-17 $\beta$ and its ester derivatives for reproductive management was also prohibited [34]. These legislations led to the ban of the use of estradiol esters in lactating dairy animals in New Zealand and Australia in 2007 [35]. the use of estradiol and estrogen-like compounds as growth promoters is still permitted in the United States [36] and Canada [37]. However, they can only be applied for the purpose of estrus synchronization following prescription and compounding, and compounding of drugs for use in food-producing animals raises additional problems in the USA $[38,39]$. The ban of the use of estrogens in livestock and lack of commercially available of estrogenic preparations negatively impacts the implementation of reproductive biotechnologies in cattle production systems, limiting potential reproductive efficiency and genetic improvement provided by the use of AI or MOET [35]. In this context, the development of alternative methods for controlling ovarian function in cattle, with efficacy and predictability comparable with that of estrogen plus progesterone treatments [21], and with no toxic or harmful effects on human and animal health is needed.

Aromatase inhibitors prevent the body from producing its own estrogens. Thus, they could potentially be applied to the management of estrogen-dependent physiologic functions such as reproduction. Letrozole is a non-steroidal aromatase inhibitor that inactivates the aromatase enzyme by reversibly binding to the heme group of the P450 subunit of the enzyme. It was developed and is prescribed as an adjuvant treatment as well as a first line treatment of hormonal-responsive breast cancer in post-menopausal women [40].

Letrozole has been used in human assisted reproduction to treat sub-fertile and infertile women because of its effectiveness in removing the negative feedback effect of estradiol on gonadotrophin secretion [41]. There is no commercially available formulation of letrozole 
labelled for such purposes; however the protocols have been developed as an off-label instruction. Several authors have reported using of letrozole in a 5-day regimen starting 3 days after the beginning of menses for ovarian stimulation [42-45] and it has also been used in higher or increasing doses to induce ovarian superstimulation in women [46, 47]. It can be hypothesized that letrozole could be applied to the management of ovarian function in cattle, even though the exact mechanism of stimulation of ovarian function by letrozole is not clearly understood.

\subsection{Reproductive Physiology in Cattle}

\subsubsection{Follicular wave development in cattle}

In cattle, ovarian follicles develop in waves $[1,2]$. An ovarian follicular wave begins with the synchronous development of a group of follicles ( 7 to 11$) \geq 4 \mathrm{~mm}$ in diameter. This period is refered to as wave emergence [48]. In monovular species such as cattle, a single follicle is selected from this cohort of follicles to continue growth (dominant follicle) while the other follicles undergo atresia (subordinate follicles) [1, 49-51]. The occurrence of selection is confirmed by the deviation in diameter between the dominant follicle and the largest subordinate follicle which occurs when the dominant follicle is on average $8.5 \mathrm{~mm}$ in diameter. That is, about 3 days after wave emergence [48]. If the dominant follicle grows during the early luteal phase, the follicle becomes an anovulatory follicle and regresses. During anovulatory waves, three different phases of follicular growth have been described: 1) a growing phase during which the dominant follicle grows actively; 2) a static phase during which follicular diameter does not change; and, 3) a regressing phase during which follicular diameter starts to decrease [52]. However, if the dominant follicle is in its growing or early static phase when the regression of 
the corpus luteum begins it will become the ovulatory follicle and it has the potential to trigger the gonadotrophin surge that will lead to ovulation (reviewed in [53]).

Two and three of these waves of follicular development have been commonly reported during an estrous cycle in cattle. There has been some controversy about the frequency of these patterns; some authors reported a higher incidence of animals with two waves of follicular development while other research groups reported that cycles with three waves were more frequently found than those with two waves $[51,52,54,55]$. In animals with two or three waves of follicular development, the first wave can be identified, on average, the day of ovulation. The second wave appears by day 10 after ovulation in two-wave cycles [52] and by day 9 in threewave cycles, and in this last group the third wave is detected by day 16 [56]. Furthermore, it has been shown that estrous cycles composed of two waves are consistently shorter than cycles with three waves of follicular development (19 to 20 days and 22 to 23 days, respectively) [56].

\subsubsection{Role of gonadotrophins in ovarian functions}

Follicle-stimulating hormone (FSH) and luteinizing hormone ( $\mathrm{LH})$ play crucial roles in the regulation of the ovarian follicular dynamics. Emergence of a follicular wave and the selection of the dominant follicle have been temporally associated with an increase and decrease, respectively, in FSH levels. A transient increase in plasma LH concentration has also been reported in relation to the time of follicular deviation (defined as the measure point when a significant difference in diameter between the dominant follicle and the largest subordinate follicle is first identified), besides the well documented peak in LH concentrations that encompasses ovulation $[4,5]$. It has been demonstrated that each wave of follicular development is preceded by a surge in FSH concentration [3]. In this regard, the suppression of the increase in FSH concentration by administration of a proteinaceous fraction of follicular fluid was followed 
by a delay on follicular wave emergence. Moreover, promotion of a surge of FSH by ablation of the extant DF resulted in the emergence of a new wave of follicular development within 2 days. These results also provided evidence that intrafollicular factors were, at least in part, responsible for the changes in plasma FSH concentrations related to follicular dynamics. Further clarification of this concept revealed that increasing plasma concentrations of intrafollicular components (e.g., estradiol, inhibins, insulin-like growth factors, etc), mainly synthesised by the dominant follicle, had a suppressing effect of circulating FSH concentrations and that the decrease in FSH levels was crucial for the selection process and to ensure monovulation by regression of the subordinate follicles [57] (reviewed in [49, 58]). A FSH-follicle coupling system involving all the follicles in a wave is responsible for the initial drop in FSH concentrations observed after wave emergence. When the dominant follicle reaches a critical stage of development (which has been identified as $8.5 \mathrm{~mm}$ [59]) it has the capability to further suppress FSH concentrations to levels that are not compatible with continuous development of the subordinate follicles which then undergo atresia. However, the dominant follicle can continue growing for a longer period of time, even under very low levels of plasma FSH [60]. The acquisition of LH receptors by the thecal and granulosa cells of the dominant follicle contribute in part to the ability of the dominant follicle to remain viable in a low FSH environment [61]. Results of a study involving the suppression of the transient LH rise before, during and after follicular deviation by administration of exogenous progesterone demonstrated that LH was not indispensable for the initiation of deviation; there was no difference in follicle diameters between progesterone-treated and control animals before and during deviation. However, it was observed that the dominant follicle was smaller and grew at a slower rate than dominant follicle of control animals when LH secretion was suppressed after deviation was initiated. [61]. Meanwhile, the active dominant follicle continues to produce 
factors that inhibit plasma FSH secretion ensuring that the emergence of a new wave of follicular development will not occur throughout the dominance period [62]. Once the dominant follicle is at the end of the static phase and starts to regress, plasma concentration of follicular components start to decline removing the FSH-suppressing effects of estradiol. A surge of FSH is observed followed by the development of a new follicular wave.

In summary, follicle wave emergence is preceded by an increase in plasma FSH concentrations. Follicular selection is related to a decline in FSH concentrations caused mainly by the production of estradiol by the dominant follicle under the influence of LH. Low FSH concentrations maintained by the dominant follicle ensure that no further waves of follicular development occur during the period of dominance. When LH pulse frequency is low the dominant follicle losses dominance and regresses, estradiol production declines and FSH increases and a new wave of follicular development is stimulated. However, if the dominant follicle is still viable at the end of the luteal phase, LH pulse frequency increases and stimulates a greater production of estradiol by the dominant follicle that will, in turn, elicit a preovulatory peak of LH and FSH secretion, and ovulation. The disappearance of the dominant follicle after ovulation removes the negative feedback effect of estradiol on FSH secretion and a postovulatory surge of FSH followed by the emergence of a wave of follicular development is observed [63].

\subsection{Control of the estrous cycle}

The advancement in our understanding of reproductive biology in cattle has made it possible to develop several strategies and protocols to manipulate phenomena related to the estrous cycle i.e., wave emergence, selection, luteolysis and ovulation. The ideal method of control of the estrous cycle is the one that is simple, effective and safe. For the purpose of this introduction, 
some aspects of those strategies using prostaglandin $\mathrm{F}_{2 \alpha}(\mathrm{PGF})$ and gonadotrophin releasing hormone $(\mathrm{GnRH})$, and the rationale and implementation of protocols based on the use of estrogens alone or in combination with progesterone releasing devices will be briefly reviewed.

\subsubsection{Prostaglandin and GnRH-based protocols for estrus synchronization}

The identification of PGF as the luteolysin responsible for the regression of the CL in cattle provided a new means for controlling of the length of the luteal phase and ovulation (reviewed in [64]). Several protocols using different doses and intervals between doses of prostaglandins have since been designed $[65,66]$. The state of maturity of the dominant follicle at the time of PGF treatment determines the interval to estrus and ovulation (on average, 3 to 3.4 days). However, if the extant dominant follicle is in the late static or regressing phase at the time of PGF treatment, the dominant follicle of the subsequent follicular wave will grow and reach preovulatory size; the process that may take as much as 4.5 days $[65,66]$. Further, newly formed CL during the first 3 to 4 days after ovulation are refractory to the luteolytic effect of PGF and responsiveness increases as the CL develops [65]. These important sources of variability in interval from treatment to ovulation limit the use of prostaglandin-based protocols for fixed-time artificial insemination (FTAI). A treatment approach using two injections of PGF 11 to 14 days apart is widely accepted and used mainly on dairy farms. The rationale for this approach is that approximately $67 \%$ of the animals (those with a CL 5 days old or older and experiencing natural luteal regression) would respond to the first injection by undergoing luteolysis and ovulating. Therefore, $100 \%$ of the animals would have a functional and responsive CL when the second injection of PGF is administered 11 to 14 days later [50]. However, the use of luteolytic doses of prostaglandin still relies on estrus detection efficiency to provide acceptable outcomes. Consequently, the low rate of submission of animals for artificial insemination (AI) after 
detected estrus, reported to be about 50\% in North America [67], limits the effectiveness of this protocol.

Fixed-time AI eliminates the need for estrus detection but requires synchronous ovulation. The use of FTAI can overcome the negative impact of poor estrus detection efficiency. Pregnancy rates obtained with FTAI are usually comparable to those obtained after AI with high estrus detection rates, because all animals are inseminated regardless of whether or not they showed estrus [68]. Gonadotrophin releasing hormone $(\mathrm{GnRH})$ is commonly used to induce the pituitary release of gonadotrophins (LH and FSH) which will induce ovulation and/or luteinisation of the dominant follicle $[6,69]$; this is followed by the emergence a new wave of follicular development approximately 2 days after GnRH treatment [69]. The use of GnRH is usually combined with a luteolytic dose of PGF 7 days later. The GnRH is intended to synchronize wave emergence and the PGF synchronizes luteolysis. An additional dose of GnRH is used about 48 hours after PGF to induce an LH surge and synchronize ovulation [68, 70]. Finally, animals are inseminated 16 to 20 hours after the second GnRH dose. This protocol is known as the Ovsynch. Several studies in which Ovsynch protocols were used had pregnancy rates similar to those obtained using the two doses of PGF 14 days apart with high estrous detection management in lactating dairy cows (38.9\% versus 37.8\%) [68, 69]. However, when the same protocols were applied to heifers, pregnancy rates following Ovsynch were lower than in controls treated with PGF and inseminated after estrus detection (35.1\% versus $74.4 \%)$. Poor ovulatory response to the first injection of GnRH and consequently poor synchronization of wave emergence were identified as the causes of the lack of success of the Ovsynch protocols in heifers [71]. 


\subsubsection{Estradiol and progesterone-based protocols}

The interval from PGF-induced luteolysis to ovulation and the variability in the ovulatory response among animals to GnRH treatment depends on the status of the ovarian follicle at the time of treatment. Thus, a method that controls ovarian follicle recruitment would provide the advantage of knowing the stage of follicular development when the ovulatory or luteolytic treatment is given and improve the degree and synchrony of the ovulatory response. A synchronized ovulatory response is essential for the efficient use of time, resources, labour and the application of reproductive management techniques such as FTAI $[21,24]$ and MOET [72, 73].

A combination of progesterone and estradiol have been used to hormonally ablate the effects of the dominant follicle and to induce a new wave of follicular development in a predictable interval of time [13,21]. This method of synchronizing wave emergence is based on the negative feedback effects that estradiol has on FSH secretion during the luteal phase [74] or under the influence of an exogenous source of progesterone [9, 20, 21, 73]. Furthermore, exogenous progesterone suppresses LH secretion leading to the regression of the extant dominant follicle. Reducing circulating levels of FSH and LH terminates the growth of both FSH- and LHdependent follicles, and the subsequent increase in FSH results in the emergence of a new wave of follicular development about 4 days after estradiol and progesterone treatment $[9,72]$. The complete protocol includes the insertion of a progesterone releasing device for 7 to 9 days plus a dose of estradiol at the time of device insertion and a dose of PGF at the time of progesterone device removal to ensure luteal regression. Animals are inseminated 55 to 60 hours after progesterone withdrawal [75]. Different forms of estradiol have been applied in these progestinbased protocols. It has been reported that the use of short-acting preparations such as estradiol- 
$17 \beta$ (E-17ß) or estradiol benzoate (EB) results in more synchrony of wave emergence and ovulation than long-acting esters [76]. In a trial in which estradiol cypionate (ECP) was given in combination with a controlled internal drug release device (CIDR) of progesterone to synchronize wave emergence and ovulation [77], synchrony of wave emergence were less precise and the interval to ovulation was more variable than in animals treated with EB or E-17ß. The synchrony associated with ECP was attributed to the longer absorption period from the site of injection and the length of action in the circulation. However, in a later study, the same group reported pregnancy rates after FTAI with ECP that were comparable with those obtained using EB or E-17 (approximately 56.4\%) [24]. It is important to point out that, in this last experiment, an additional dose of ECP or EB used 0 to 24 hours after CIDR removal was used to synchronize ovulation.

The effects of short-acting estradiol preparations in progesterone-treated cows on synchrony of wave emergence and ovulation have been of critical importance for the application of superstimulation protocols for MOET programs [78]. The outcome of a superstimulation treatment is strongly influenced by the stage of follicular development at initiation of treatment. Optimal ovarian responses were obtained when superstimulatory treatments were initiated about the time of follicular wave emergence (day -1 or 0 of the follicular wave) [21], as observed when treating between days 8 and 12 after estrus detection (around the time of emergence of the second follicular wave) [24]. Since progesterone plus estradiol treatments result in precise synchronization of wave emergence (on average 4.3 days after treatment), superstimulatory treatments are initiated on the day of wave emergence (day 4), without the need for estrus detection and the 8- to 12-day waiting period $[9,79]$. 


\subsection{Estrogens and other sex steroid hormones}

\subsubsection{Steroidogenic pathway}

Steroid hormones are cholesterol-derivatives commonly classified in five groups: glucocorticoids, mineralocorticoids, androgens, progestins and estrogens. The last three groups are also referred to as sex steroid hormones, since they are involved in mechanisms that control reproductive physiology in mammals. Estrogens are composed of 18 carbon molecules and are the final product of a complex biosynthetic pathway that, in ruminants, involves five main enzymes. The rate limiting step in the biosynthesis of sex steroids is the incorporation of cholesterol into the mitochondria. Free cholesterol is highly hydrophobic, and although it can cross the cellular membrane by diffusion, this process is extremely slow. Therefore, this step depends on an active mechanism to transverse the hydrophobic mitochondrial wall. This process is mediated by the "steroidogenic acute regulatory protein" (StAR). Once inside the mitochondria, cholesterol is metabolized to pregnenolone by the P450 cholesterol side-chain cleavage enzyme (P450scc). Pregnenolone is the substrate for two different enzymes: $3 \beta$ -

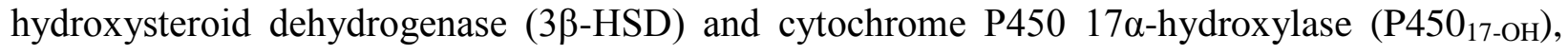
giving rise to progesterone and 17 $\alpha$-hydroxypregnenolone, respectively. In ruminants, granulosa cells only express $3 \beta-\mathrm{HSD}$. Consequently, progesterone is the main product and these cell types cannot metabolize it further. In thecal cells, however, $\mathrm{P} 450_{17-\mathrm{OH}}$ is highly expressed and

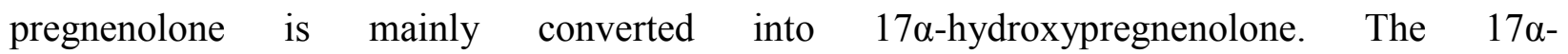
hydroxypregnenolone is then converted into androstenedione by the sequential activities of $\mathrm{P} 450_{17-\mathrm{OH}}$ and $3 \beta-\mathrm{HSD}$ and a small amount of androstenedione is transformed into testosterone

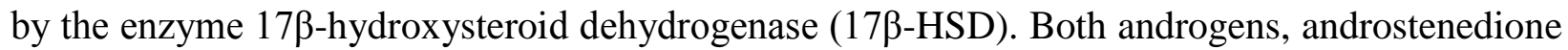
and testosterone, are then available to be either secreted or further converted into estrone and 
estradiol, respectively, by the action of the cytochrome P450 aromatase (P450arom) within the granulosa cells $[80,81]$. The major enzymatic pathway leading to the synthesis of estrogens, irrespective of species or tissue, is summarized in the Figure 1.1.

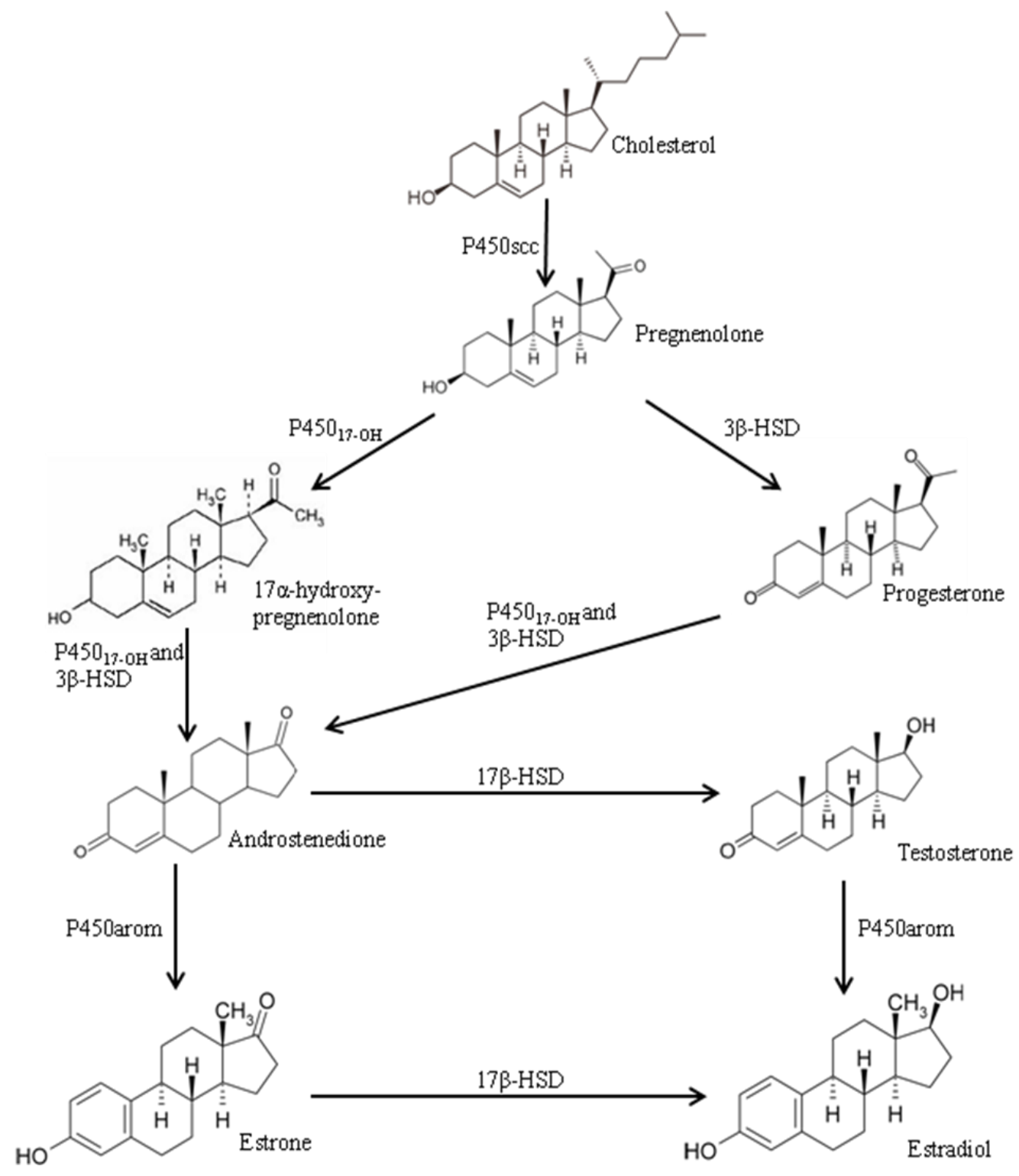

Fig. 1.1. Synthesis of estrogens in ruminants. Five main hormones are involved in the enzymatic pathway leading to the synthesis of estrogens from cholesterol. 


\subsubsection{Regulation of steroidogenesis in bovine ovary}

Timely variations in the expression and number of gonadotrophin receptors (LH receptor LHr, and FSH receptor FSHr) as well as differences in cell responsiveness to the activation of such receptors have been described during folliculogenesis and maturation of ovarian follicles in cattle [82]. Researchers have been able to relate the changes in expression and activity of the gonadotrophin receptors with the control of steroidogenesis in the bovine ovary, and ultimately, with the ovarian follicular dynamics $[80,81]$. It was shown that FSHr mRNA was expressed in granulosa and cumulus cells of pre-recruitment ovarian follicles, although this stage of follicular development has been classified as gonadotrophin-independent. The beginning of recruitment of such follicles into a wave has been associated with the expression of $\mathrm{P} 450_{\text {arom }}$ and $\mathrm{P} 450_{\mathrm{scc}}$ mRNA in their granullosa cells. It is believed that the surge in FSH related to wave emergence [3] could be responsible for the induction of such enzymes in the granulosa cells. As the thecal cells of pre-antral and small antral follicles are already expressing LHr mRNA, P450 ${ }_{\text {scc }}$ mRNA, $3 \beta$-HSD mRNA, StAR mRNA and $\mathrm{P} 450_{17-\mathrm{OH}} \mathrm{mRNA}$, and are therefore producing androgens, recruited follicles begin to synthesize and secrete estradiol.

By the time of dominant follicle selection, several follicles in the cohort begin to express LHr mRNA and 3 $\beta$-HSD mRNA on their granulosa cells. It has been hypothesized that estradiol

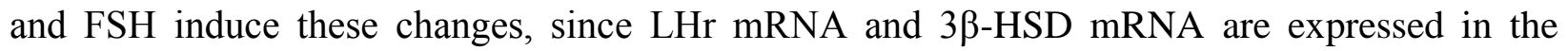
follicles with higher levels of $\mathrm{P} 450_{\text {arom }}$ and $\mathrm{P} 450_{\mathrm{scc}}$ mRNA in granulosa cells (both enzymes induced by FSH for the synthesis of estrogens). Forty eight hours after wave emergence, LHr mRNA and $3 \beta$-HSD mRNA were found in granulosa cells of only the dominant follicle. The dominant follicle of the first follicular wave remains viable for 4 to 5 days, after which most mRNAs begin to decline, except for P450 arom mRNA which begins to decline 2 days later. If 
progesterone levels begin to decrease 6 or 7 days after wave emergence, the dominant follicle becomes preovulatory and mRNA, except $\mathrm{P} 450_{\text {arom }} \mathrm{mRNA}$, increases [83]. These observations could demonstrate that LH pulsatility may be responsible for the expression of steroidogenic enzymes mRNA in the granulosa and thecal cells. The notion is supported by the observation that mRNA expression is suppressed under low pulsatility of LH observed during the luteal phase and increased during the pre-ovulatory increase in LH pulsatility. However, aromatase activity is not the rate limiting step in estradiol production. It is the availability of the androgenic substrates produced by thecal cells that controls estrogen secretion by granulosa cells (reviewed in [80]).

\subsubsection{Metabolism and elimination of estrogens}

Estrogen bioactivity is also regulated through metabolism and elimination. Estrogens can be either inactivated or converted into compounds with lower biological activity before excretion. In ruminants, estradiol-17 $\beta$ is in the most part deactivated in the liver by redox reactions (oxidation, reduction and hydroxylation) and it is later conjugated with glucuronic or sulphuric acid prior to bile excretion. A small amount is also converted into estradiol-17 $\alpha$, which has a very low estrogenic activity. In any case, fecal elimination is the most important route of excretion, although small amounts of estradiol-17 $\alpha$, and the glucuronide and sulphate conjugates can be isolated from the urine [84-86].

\subsection{Aromatase enzyme}

The aromatase enzyme, also called Aromatase $\mathrm{P} 450$ cytochrome enzyme $\left(\mathrm{P} 450_{\text {arom }}\right)$, is an enzymatic complex that belongs to the super-family of $\mathrm{P} 450$ proteins, that includes more than 480 members divided in 74 different families; P450 arom is a unique member of family 19 [87]. 
This enzyme is located in the endoplasmic reticulum of cells that express the $\mathrm{P} 450_{\text {arom }}$ gene (CYP19 gene) such as in adipose tissue, the brain, gonads, fetal tissues, liver and placenta [83, 88-93]. It is responsible for the conversion of androgens into estrogens in the last step in the synthesis of estrogenic compounds. Aromatase enzymes contain a heme group in their structure and are functionally associated with another member of P450 cytochrome family, an NADPH reductase which acts as a donor of reductive equivalents [92].

Estrogens are synthesized in all members of the vertebrate phylum [91, 94]. In more developed species such as primates, it is synthesized in many different locations in the body such as the gonads, adipose tissue, placenta, liver, skin and brain. In ungulates, adipose tissue synthesis of estrogens has not yet been fully demonstrated. In rats, the placenta does not have the capability to synthesize estrogens [94]. Another characteristic of estrogen synthesis is that different tissues can secrete different types of estrogens. For example, the main estrogen produced in the ovaries is estradiol, while estrone is synthesized in adipose tissue and estriol predominates in the placenta. The aromatase enzyme catalyzing these reactions is the same and confirms the idea that the different types of estrogens synthesized in different tissues are not the result of the activity of alternative $\mathrm{P} 450_{\text {arom }}$ enzymes, but rather they result from the presence of different precursors in each location [94].

\subsubsection{CYP19 gene: Structure and regulation}

The aromatase gene (CYP19 gene) is a special case of tissue specific regulation of transcription by alternative use of different promoters. The gene contains nine exons (from exon II to X) that are translated exons. The sequence of ribonucleotides is actually translated in a sequence of amino acids in the protein. The exon $\mathrm{X}$ has the sequence that encodes the heme 
binding region and the $3^{\prime}$ untranslated region with alternative poly-adenylation signals. Moreover, the gene contains several forms of a first untranslated exon (exon I) located distally from the encoding region and is present in the transcripts, but does not encode a sequence of amino acids in the aromatase protein [95]. It is estimated that the gene has around $120 \mathrm{~kb}$, where $30 \mathrm{~kb}$ include the translated exons and their introns and about $90 \mathrm{~kb}$ contains the alternative forms of untranslated exons I and their promoters [87, 89]. Exon I is particular in that it can be differentially spliced among several structures located upstream from the translational start site (exon II). These structures are alternative forms of exon I which include their own regulatory signals and promoter regions and that are activated and spliced out in a tissue specific fashion. For instance, in ovaries exon I is spliced out and the transcripts start with exon II. In adipose tissue exon I.4 is expressed and in the placenta, exon I.1 is expressed. In cancer-associated adipose tissue, exon I.3 and II are expressed [87, 88, 91, 94].

After transcription, mRNA undergoes the process of maturation, where introns are spliced out and exons are arranged together prior to the initiation of translation. In the case of aromatase transcripts, this process is crucial to ensure the translation of the same and unique aromatase protein even when the original transcripts differ among tissues [87, 88, 94]. Independent of the tissue of origin, every alternative exon I expresses, at the $3^{\prime}$ end of its structure, the same splicing donor sequence (GT) that match with the splicing donor sequence (AG) present at the 5 ' end of exon II. This means that during the process of maturation, exons I are closely attached to exon II, regardless of the content or the length of the sequence of ribonucleotides that are between them in the heteronuclear mRNA $[87,88,94]$. The mature aromatase mRNA is then translated into a sequence of amino acids, starting with the translational start signal (ATG) located within exon II. As a result, all the information located upstream from the translation start site is not translated 
into the polypeptide chain and the final protein is the same in all tissues that have the capability to synthesize estrogens.

\subsection{Use of estrogens in food producing animals}

\subsubsection{Different applications}

Estrogens and other sex steroids have been developed for use as growth promoter in food producing animals, in addition to the previously discussed use of sex steroid hormones as a tool for controlling and manipulating reproductive phenomena in cattle and other farm animals [26]. The first compound approved by the USA Food and Drug Administration (FDA) to be used as growth promoter in beef cattle and sheep was diethylstilbestrol (DES), which has estrogenic effects. It was used to improve the efficiency of meat production as well as the proportion of lean meat. Since then, several compounds have been formulated and approved for use in farm animals including estradiol benzoate, progesterone, testosterone, melengestrol acetate and zeranol, among others [26]. Some preparations are still available for oral administration, while others are used as subcutaneous implants. The implants may contain single hormones or combinations of hormones. Estradiol was believed to be the main growth-promoting compound in combined implants and the other hormones used (usually progesterone for steers and testosterone for heifers) were included to enhance the anabolic response by either suppressing excessive estrogenic stimulation or improving estrogen release from the implant [96]. However, further research on the physiologic mechanisms involved revealed that improvements in the anabolic effects are due to a additive or synergistic activity of both hormonal compounds contained in the implant [26, 27, 96, 97]. 
Growth implants can improve growth rate by 10 to $30 \%$ and feed efficiency by 5 to $15 \%$ $[27,28]$. The mechanisms behind this improvement combine the anabolic effects of estrogens with the anti-catabolic actions of androgens. Estrogen receptors have been demonstrated in striated muscle cells. Further, it was observed that estrogens promote growth-hormone (GH) secretion, increase GH receptors in the liver and induce synthesis and secretion of growth factors such as IGF-1 from the liver. In addition, androgen receptors were found in the muscles of cattle, although in much lower concentrations, and androgenic products can also induce release of GH and IGF-1. The reduced glucocorticoid-induced catabolism observed in steers treated with androgenic implants may also contribute to the growth-promoting effect [28].

1.5.2. The issue of estrogens in food: Situation in the European Union, USA and Canada There has been an increasing interest of producers on the positive impact of using anabolic hormones in meat production systems. However, the potential presence of residues of exogenous hormones in meat and other foods originating from treated animals have increased biosafety concerns among consumers and scientists [30, 98-100]. The main issues include the involvement of naturally occurring hormones and synthetic hormonally active compounds on the development of different forms of cancer, abnormal growth of prepubertal children and altered reproductive function $[32,99]$. While several researchers have attributed carcinogenic effects to estrogens and estrogenic compounds (i.e., zeranol), other research groups have failed to replicate those results $[31,101]$.

The acceptable levels of estrogens and other hormones in food originating from treated animals have been under consideration for many years and consensus has not been reached. The controversy revolves around acceptable daily intake (ADI) levels, minimum residual levels (MRL) and no-observed-effect levels (NOEL) for the different hormones under study [29, 102]. 
Factors such as method of quantification, age range and physiologic status of the population under consideration have made it difficult to determine a common tolerance level for estrogens. Further, the impact of the natural occurrence of steroid hormones in food is not completely understood [29].

Despite all the uncertainties around the issue of steroid hormone residue in food originated from treated animals, the international situation evolved towards the banning of steroid hormones and their synthetic analogs for use in food producing animals in all member states of the European Union in January 1989 [103]. The use of E-17ß and its ester derivates for reproductive management was prohibited on October 14, 2006 [34]. This led to the prohibition of the use of estradiol esters in lactating dairy animals in New Zealand and Australia in 2007 [104]. The use of estradiol and zeranol (an estrogen-like compound) as growth promoters is still permitted in the United States [36] and Canada [37]; however, they can only be applied for the purpose of estrus synchronization following prescription and compounding. Compounding has recently come under scrutiny in the USA since the FDA declared that it is illegal to compound analogs of drugs that are banned to be used in food producing animals, which would be the case for $\mathrm{E}-17 \beta$ and its derivatives [38, 39].

\subsection{Letrozole}

\subsubsection{Classification}

Letrozole [4,4'-(1H-1,2,4-triazol- 1-yl-methylene)-bis-benzonitrile] is a type II, very potent non-steroidal aromatase inhibitor. Its chemical structure contains a triazole group (Fig. 1.2) that selectively interacts with the heme group of the $\mathrm{P} 450_{\text {arom }}$ enzyme, thereby reversibly inhibiting the bioactivity of the enzyme [105-107]. Letrozole is highly selective for $\mathrm{P}^{4} 50_{\text {arom }}$ blocking only 
estrogen production without altering progesterone or corticosteroid synthesis [108, 109]. In North America, letrozole is marketed under the name of FEMARA® (Novartis) and it is approved for the treatment of estrogen-dependent breast cancer in postmenopausal women.

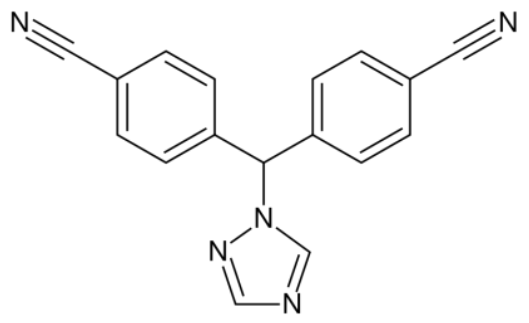

Fig.1.2. Chemical structure of letrozole: its chemical structure contains a triazole group that selectively binds to the heme group of the aromatase enzyme

\subsubsection{Pharmacology of letrozole in humans}

The pharmacokinetics of letrozole in humans have been described in several studies conducted on healthy post-menopausal women, breast cancer patients, and in healthy male volunteers [109-112]. It was reported that letrozole is rapidly and completely absorbed after oral administration [111] and its half-life is approximately 42 hours in healthy subjects [111, 112] and 82 hours in breast cancer patients [110]. Breast cancer patients also have been shown to have higher area under the curve (AUC) values than healthy individuals which may suggest a reduced metabolic clearance and consequently a lower elimination rate [110]. Approximately 60\% of letrozole found in circulation is bound to plasma proteins, mainly albumin $[111,112]$. Letrozole is eliminate mainly via metabolism by P-450 isozymes (CYP3A4 and CYP2A6) into a pharmacologically inactive alcohol metabolite $[110,111]$. The main route of excretion of letrozole is urine, where $6.8 \%$ of the given dose of letrozole was found unchanged [110].

A pharmacodynamic study of letrozole in healthy postmenopausal women in which three different doses of letrozole were used revealed maximal suppression of serum estradiol of $76.5 \%, 78.5 \%$ and $78.8 \%$ from baseline at 72 hours post-treatment with $0.1,0.5$ and $2.5 \mathrm{mg}$ of 
letrozole given in a single dose, respectively [113]. In postmenopausal breast cancer patients, in vivo aromatization and plasma estrogen levels were measured after 0.5 or $2.5 \mathrm{mg}$ of letrozole given daily for at least 6 weeks. Letrozole inhibited aromatase activity by $98.4 \%$ and $>98.9 \%$, respectively. Plasma estradiol concentrations were reduced by $84.1 \%$ and $68.1 \%$, respectively [114]. In a trial conducted in healthy male volunteers, estradiol suppression was about $30 \%$ at the lowest dose (0.02 mg) and 80-90\% at the highest dose (30mg) tested [109].

\subsubsection{Uses of letrozole in cancer therapy}

Seventy-five percent of women suffering from breast cancer have hormone receptor positive (+) disease [115]. This means that circulating hormones, mainly estrogens and progesterone, stimulate the division and growth of the tumour tissue. It was observed that the surgical removal of the ovaries (ovariectomy) was effective in reducing tumor size and survival rates of nonoperable breast cancer patients more than 100 years ago [116]. Years later, this was attributed to estrogen deprivation. However, there were some limitations to the massive use of ovariectomy. Firstly, it is a very invasive and non-conservative procedure to be performed, especially in young patients wishing to conceive after treatment. Secondly, after natural menopause or ovariectomy, peripheral production of estrogens, mainly by adipose tissue, contributes importantly to the total circulating levels of estrogen [117]. Therefore, several systemic methods of treatment have been developed to reduce the effects of estrogens (of any source) on breast cancer growth either by irreversibly binding to tumour-estrogen receptors (antiestrogens) or inhibiting estrogen synthesis at the enzymatic level (aromatase inhibitors) [118]. In 1998, letrozole was approved as secondline treatment. In January 2001, letrozole was approved as a first-line treatment for breast cancer in post-menopausal women by the FDA $[119,120]$. Because of its potent inhibition of estradiol production, high oral bioavailability, selectivity and mild secondary effects, letrozole has become 
a drug of preference for the treatment of breast cancer, either as a first-line treatment or as a neoadjuvant therapy $[40,117,121]$.

Letrozole has also been proposed for the treatment of endometrial cancer and endometriosis $[122,123]$. Both pathologic conditions are steroid hormone-responsive; therefore, letrozole and other aromatase inhibitors could be beneficial and promising results have already been reported [124-126].

\subsubsection{Letrozole in the treatment of infertility in women}

Commercially available letrozole $\left(\right.$ FEMARA $\left.^{\circledR}\right)$ is not labelled for use in any pathologic condition other than hormone-dependent breast cancer in post-menopausal women [40, 127]; however there are numerous reports on the use of letrozole for the treatment of subfertility or infertility in women undergoing ovarian superstimulation, intra-uterine insemination (IUI) or timed intercourse [123, 128, 129]. Although the effects of estrogen deprivation on the reproductive physiology of premenopausal women are not completely elucidated, letrozole has been used in assisted reproduction because of its apparent effect of removing the negative feedback effects of estradiol on gonadotrophin secretion. Theoretically, removal of circulating estradiol should be followed by a surge in FSH levels and this would induce the recruitment of a new wave of follicular development, the final maturation of the oocyte or even the development of more than one ovarian follicle $[41,42]$. Letrozole has been used alone as a single or a 5-day regimen for ovarian stimulation [42, 130, 131], and in higher or increasing doses to induce ovarian superstimulation in women $[46,47]$. Letrozole has also been used in combination with gonadotrophin treatment for ovarian superstimulation prior to IUI. Improvements in the ovarian response of poor responders and a significant decrease in the dose of FSH required to achieve an acceptable stimulatory response have been reported $[44,132]$. 


\subsubsection{Letrozole toxicity}

Letrozole has proven to be a well tolerated drug, lacking of toxic effects when used as indicated for breast cancer treatment in post-menopausal women. Toxicity studies performed for the approval of FEMARA® concluded that repeated dosing caused sexual inactivity in females and atrophy of the reproductive tract in males and females at doses of $0.6,0.1$ and $0.03 \mathrm{mg} / \mathrm{kg}$ in mice, rats and dogs, respectively. Although all the reported toxic effects of letrozole have been observed during long-term treatment (as those used for breast cancer therapy), less is know about its toxic effects when used in a short-term treatment for ovarian stimulation. Letrozole is classified as embryotoxic, and it is contraindicated in premenopausal and pregnant women [40].

In 2005 , the safety of letrozole as a treatment for ovulation induction was seriously challenged by a abstract published by Biljan et al. [133]. In that retrospective study, the authors reported an increased risk for congenital cardiac and bone malformations related to the use of letrozole as an infertility treatment. However, the scientific credibility of that study was strongly questioned based on the number of letrozole-treated cases reported versus the control cases (150 vs 36,050 babies, respectively) and the inadequacy of the comparison made among these groups. Shortly thereafter, another retrospective study reported the absence of teratogenic effects of letrozole when used as an ovulation induction therapy [134]. Recently, a prospective trial was designed to evaluate pregnancy outcomes after ovarian stimulation with aromatase inhibitors. The conclusions drawn from this study further confirmed the safety of aromatase inhibitor as a tool for infertility management in women [135]. 


\subsection{The bovine model for the study of human reproduction}

Based on the similarities between cattle and women regarding ovarian size, follicular size and endocrine regulation of the follicular development, and because of the accessibility and adaptability of the bovine species, a bovine model has been validated as a tool to assess and further investigate human reproductive physiology [49, 136-140]. The description of a wave-like pattern of follicular growth during the estrous cycle in women, as observed in other mammals (cow, mare, sheep) [49, 140], represented a break-through discovery. Two or three waves of follicular development were observed during the follicular as well as the luteal phase of the estrous cycle in healthy female volunteers [138]. It was also shown that the wave-like pattern observed was controlled by the same endocrine mechanisms as described in other monovulatory species such as cattle [137]. Consequently, the bovine model has been successfully implemented

for the study several features of human reproduction including ovarian senescence [141] and oocyte competence after reproductive aging [142]. Therefore, it is plausible that the bovine model could be used to elucidate the effects of letrozole on ovarian function in premenopausal women and to further understand and explore its potential as a treatment for ovarian stimulation. 


\section{GENERAL HYPOTHESIS}

The overall hypothesis tested in this thesis was that letrozole given as a single or multipledose treatment would reduce estradiol production and thus circulating estradiol concentrations. Releasing the pituitary gland from the negative feedback effect of estrogens would elicit a surge in FSH secretion, thus inducing the emergence of a new follicular wave.

\section{GENERAL OBJECTIVES}

The overall objectives of the studies reported herein were to determine the effects of an aromatase inhibitor on endocrine function and follicular dynamics in cattle, and to determine a minimum effective dose of letrozole treatment to predictably induce these changes. In the first experiment, the effect of three different doses of letrozole administered as a single intravenous injection on hormonal profiles and ovarian function were compared to a control group. In the second experiment, the effects of a 3-day treatment regimen of letrozole given at three different stages of follicular development on hormonal profiles and ovarian function were compared to their respective non-treated controls. It was hypothesized that the stage of follicular development would not alter the ovarian response to letrozole treatment. 


\section{EFFECTS OF LETROZOLE ON OVARIAN FUNCTION IN CATTLE}

\subsection{Abstract}

An experiment was designed to determine the effects of a non-steroidal aromatase inhibitor, letrozole, on ovarian function in cattle. The specific objectives were to test the hypothesis that letrozole will arrest growth of the dominant follicle resulting in emergence of a new follicular wave at a predictable interval post-treatment. Beef heifers were assigned randomly to four treatment groups and given phosphate-buffered saline (controls; $n=10)$, or letrozole at a dose of $500(\mathrm{n}=9), 250(\mathrm{n}=10)$, or $125(\mathrm{n}=10) \mu \mathrm{g} / \mathrm{kg}$ intravenously 4 days after follicular ablation $(\sim 21 / 2$ days after wave emergence). Blood samples were collected and ovarian structures were monitored daily by transrectal ultrasonography. The diameter profile of the dominant follicle was larger in heifers treated with letrozole than in control heifers $(\mathrm{P}<0.05)$. The intervals from treatment to new wave emergence and from treatment to onset of regression of the extant dominant follicle were longer $(\mathrm{P}<0.05)$ in heifers treated with letrozole than in controls, although variances in the intervals were not different. A small but significant reduction in circulating estradiol concentrations was observed, and plasma LH concentrations were higher $(\mathrm{P}<0.05)$ in letrozole-treated heifers than in controls. Lower plasma concentrations of FSH in letrozoletreated heifers than in controls $(\mathrm{P}<0.03)$ were interpreted as an indirect effect resulting from prolonged follicular dominance. In summary, a single dose of letrozole did not induce regression of the extant dominant follicle, nor did it directly affect FSH release. Conversely, letrozole extended the lifespan of the dominant follicle, in association with increased endogenous levels of LH, thereby delaying the next FSH surge and subsequent follicular wave emergence. Results suggest that letrozole has potential as a non-steroidal method for controlling ovarian function in 
cattle, but further studies are warranted to clarify mechanism of action, dosage and timing of treatment.

\subsection{Introduction}

Among the strategies used to control ovarian function in cattle, treatment with estrogen in combination with progesterone has been very effective for synchronizing follicle wave emergence and ovulation [9, 21]. Steroid-induced wave synchronization is brought about by regression of the dominant follicle followed by resurgence in circulating FSH and subsequent emergence of a new follicular wave at a consistent interval post-treatment. Steroid-induced regression of the dominant follicle is a result of a systemic alteration in feedback of estradiol and progesterone on pituitary release of LH and FSH [10]. Estradiol suppresses FSH release [11], and decreases LH pulse amplitude in sheep [12] and cattle [13]. Progesterone decreases LH pulse frequency and suppresses growth of the dominant follicle in a dose-dependent manner in cattle [14-19]. After metabolic clearance of exogenous estradiol, endogenous FSH surges therefore resulting in the emergence of a new wave of follicular development approximately 4 days after estradiol/progesterone treatment regardless of the stage of development of the dominant follicle at the time of treatment $[9,20,21]$. The degree of synchrony achieved with protocols involving estradiol and progesterone has permitted effective use of fixed-time artificial insemination in cattle [22, 23, 77], as well as more efficient use of time and labour for multiple ovulation and embryo transfer and conventional breeding management programs $[9,10]$.

The use of natural or synthetic estrogens in food producing animals, however, has been the subject of considerable controversy (reviewed in [32]). Increasing concern regarding the toxicity of hormonal preparations used as growth promotants in cattle and the potential carcinogenic effects of steroid hormone residues in meat or milk [29-31] has led to a prohibition of the use of 
estradiol and other steroid hormones as growth promotants in animals designated for human consumption in all the member states of the European Union as of January 1, 1989 [33]. Furthermore, the use of estradiol-17 $\beta$ and its ester derivatives for purposes of reproductive management was prohibited in the European Union on October 14, 2006 [34]. These actions in Europe led to the subsequence prohibition of the use of estradiol esters in lactating dairy animals in New Zealand and Australia in 2007 [104]. Although the use of estradiol and zeranol (an estrogen-like compound) as growth promotants is still permitted in the United States [36] and Canada [37], they cannot be used for the purpose of estrus synchronization except by prescription and custom-compounding. However, veterinary compounding of pharmaceuticals for food-producing animals has recently come under scrutiny in the US and is discouraged [38, 39]. This situation negatively impacts the implementation of reproductive technologies in cattle production systems, limiting potential reproductive efficiency and genetic improvement provided by the use of artificial insemination and embryo transfer [104].

In this context, the development of alternative methods for controlling ovarian function in cattle, with no toxic or harmful effects on human or animal health, are needed. Aromatase inhibitors prevent the body from producing its own estrogens. Therefore, we proposed that aromatase inhibitors may be an effective alternative to control ovarian follicular development in cattle. Letrozole, a non-steroidal aromatase inhibitor, inactivates the aromatase enzyme by reversibly binding to the heme group of the P450 subunit of the aromatase enzyme. Letrozole is used as an adjuvant treatment for hormone-responsive breast cancer in post-menopausal women [40], and has been used as a fertility therapy for women undergoing assisted reproduction because of its putative effect on FSH secretion through removal of the negative feedback of 
estradiol [41]. A 5-day regimen of letrozole has been used for ovarian stimulation in women [42], and in higher or increasing doses to induce ovarian superstimulation in women [46, 47].

In an effort to develop an effective, safe, and steroid-free protocol for controlling ovarian follicular wave dynamics in cattle, the specific objectives of this experiment were to gain an understanding of the effects of an aromatase inhibitor (letrozole) on bovine ovarian function and to establish a minimum effective dose of letrozole in cattle. We tested the hypothesis that letrozole will terminate growth of the extant dominant follicle and result in a surge in circulating FSH concentrations followed by the emergence of a new wave of follicular growth at a predictable interval post-treatment.

\subsection{Materials and Methods}

\subsubsection{Cattle}

Hereford-cross beef heifers, 14 to 20 months of age and weighing between 295 and $450 \mathrm{~kg}$, were chosen from a herd of 50 heifers maintained in outdoor corrals at the University of Saskatchewan Goodale Research Farm $\left(52^{\circ}\right.$ North and $106^{\circ}$ West). Heifers were fed alfalfa/grass hay and grain to gain approximately $1.3 \mathrm{Kg}$ per day and had water ad libitum during the experimental period from July to October. Heifers were initially examined by transrectal ultrasonography (7.5 MHz linear-array transducer, Aloka SSD-900; Tokyo, Japan) to confirm that they were postpubertal by observing the presence of a CL [143].

\subsubsection{Treatments and examinations}

Heifers in which a CL was detected during the initial examination were given $500 \mu \mathrm{g}$ of cloprostenol (PGF, Estrumate $^{\mathrm{TM}}$, Schering-Plough Animal Health, Pointe-Claire, QC, Canada) intramuscularly (im) to induce regression of the CL and to synchronize ovulation [144]. Heifers 
were examined daily by transrectal ultrasonography to detect ovulation. Transvaginal ultrasoundguided follicular aspiration of follicles $\geq 5 \mathrm{~mm}$ was performed five to eight days after ovulation to synchronize wave emergence [145]. Heifers were examined daily by transrectal ultrasonography to detect follicular wave emergence, which was expected 1 to 1.5 days after follicular ablation [145]. Four days after follicular ablation (approximately 2.5 days after follicular wave emergence), and at the time follicular dominance becomes apparent [57], heifers were assigned randomly to the following treatment groups and given a single intravenous dose of 1) $500 \mu \mathrm{g} / \mathrm{kg}$ of letrozole (high dose group, $\mathrm{n}=9$ ), 2) $250 \mu \mathrm{g} / \mathrm{kg}$ of letrozole (medium dose group, $\mathrm{n}=10$ ), 3) $125 \mu \mathrm{g} / \mathrm{kg}$ of letrozole (low dose group, $\mathrm{n}=10$ ), or 4) $20 \mathrm{ml}$ of phosphate buffered saline (PBS control group, $\mathrm{n}=10$ ). For practical purposes, the dose of letrozole was calculated based on an average weight of $400 \mathrm{~kg}$ for all heifers. The average oral dose used in women $(2.5-$ $5 \mathrm{mg}$ per day for 5 days) was used to estimate the medium dose for cattle [41, 42]. The high and low doses were set as double and half the medium dose, respectively. The day of treatment was defined as Day 0. For intravenous injection, letrozole was prepared in $95 \%$ ethanol at a final concentration of $5 \mathrm{mg}$ per $\mathrm{ml}$, resulting in an injection volume of $10-40 \mathrm{ml}$. The experiment was performed in four replicates ( $\mathrm{n}=2-3$ per group per replicate) and each heifer was used only once.

\subsubsection{Ovarian ultrasonography}

The observations from ultrasound examination were recorded on a sketch sheet in which each ovary and its structures (CL and follicles $\geq 4 \mathrm{~mm}$ in diameter [54]) were represented in size and location. Ovulation was defined as the disappearance of any follicle $\geq 8 \mathrm{~mm}$ between two consecutive daily examinations, and was confirmed by the subsequent development of a CL [143]. Follicular wave emergence was defined retrospectively as the day when the dominant follicle was first identified at a diameter of 4 or $5 \mathrm{~mm}[48,57]$. If the dominant follicle was not 
identified until it reached 6 or $7 \mathrm{~mm}$, the previous day was considered day of the follicular wave emergence [66]. The dominant follicle of a wave was defined as the largest antral follicle of that wave after deviation, and the first subordinate follicle as the second largest antral follicle of that wave [146]. The day of onset of follicular and luteal regression was defined as the first day of an apparent constant decrease in follicular and luteal diameters, respectively [57].

\subsubsection{Collection of blood samples}

Blood samples were collected by jugular or coccygeal venipuncture into $10 \mathrm{ml}$ heparinized vacuum tubes (Becton Dickinson Vacutainer Systems, Franklin Lakes, NJ, USA). Blood samples were collected at $0,0.25,0.5,1,1.5,2,3,4,6,8,12,24,36,48$ hours post-treatment [111] using an indwelling jugular catheter as previously described [63] and daily thereafter to the first posttreatment ovulation. Blood samples were centrifuged at $1500 \mathrm{x}$ g for 20 minutes; plasma was separated and stored in plastic tubes at $-20^{\circ} \mathrm{C}$.

\subsubsection{Hormone assays}

Plasma LH concentrations were determined in duplicate using a double-antibody radioimmunoassay (NIDDK-bLH4) $[12,147]$. The minimum and maximum values along the standard curve were 0.06 and $8 \mathrm{ng} / \mathrm{mL}$, respectively. The intra- and inter-assay coefficients of variation were $10.2 \%$ and $8.8 \%$, respectively, for low reference samples (mean, $0.88 \mathrm{ng} / \mathrm{mL}$ ) and $9.4 \%$ and $9.1 \%$, respectively, for high reference samples (mean, $2.7 \mathrm{ng} / \mathrm{mL}$ ).

Plasma FSH concentrations were determined in duplicate using a double-antibody radioimmunoassay using NIDDK-anti-oFSH-1 primary antibody and expressed as USDA bovine FSH-Il units $[12,147]$. The minimum and maximum values along the standard curve were 0.12 and $16 \mathrm{ng} / \mathrm{mL}$, respectively. The intra- and inter-assay coefficients of variation were $11.2 \%$ and 
$10.0 \%$, respectively, for low reference samples (mean, $1.7 \mathrm{ng} / \mathrm{mL}$ ) and $12.0 \%$ and $12.4 \%$, respectively, for high reference samples (mean $4.4 \mathrm{ng} / \mathrm{mL}$ ).

Plasma estradiol concentrations were determined in duplicate by enzyme-linked immunosorbent assay (Cayman Chemical Company, Ann Arbor, MI, USA). In this competitive ELISA, plasma steroid competes with acetylcholinesterase-labelled steroid for the binding site on polyclonal rabbit anti-steroid antibody. The antiserum to estradiol was reported to cross-react with estradiol-3-glucoronide (14\%), estrone (12\%), and estriol $(0.3 \%)$. For all other steroid hormones, cross-reactivity was reported as $<0.1 \%$. The minimum and maximum values along the standard curve were 6.6 and $4000 \mathrm{pg} / \mathrm{well}$, respectively. The intra- and inter-assay coefficients of variation were $11.7 \%$ and $12.7 \%$, respectively, for reference samples analyzed in duplicate. A concentration procedure using diethyl ether extraction was performed prior to the assay in all samples to increase estrogen concentration to measurable levels [148] . A ${ }^{3} \mathrm{H}$-labeled steroid was added to each plasma sample before extraction as an internal recovery standard. After the extraction procedure, a fraction of the final extract was quantified in a liquid scintillation counter to test for recoveries [149]. To confirm the effectiveness of the ELISA in quantifying estradiol concentrations in plasma, a random sub-set of plasma samples $(\mathrm{n}=25)$ was also analyzed by high performance liquid chromatography mass spectrometry (LC/MS) and results were compared to those obtained by ELISA (Appendices 3 and 4).

\subsubsection{Plasma letrozole concentration}

Plasma concentrations of letrozole were determined using high performance liquid chromatography tandem mass spectrometry (LC/MS/MS). To extract letrozole from the samples, $250 \mu \mathrm{L}$ of a buffer solution ( $0.1 \mathrm{M}$ ammonium) were added to $250 \mu \mathrm{L}$ of plasma followed by the addition of $5 \mathrm{~mL}$ of methyl t-butyl ether (MTBE) and vortexed for $15 \mathrm{sec}$. The organic layer was 
removed by pipetting and transferred to a fresh $15 \mathrm{~mL}$ plastic tube. This second tube was dried by gentle nitrogen gas flow. The dried extract was reconstituted in $1 \mathrm{~mL}$ of $100 \%$ ethanol, sonicated for $5 \mathrm{~min}$ and transferred to a labelled vial for further analysis. Separation was accomplished by HPLC (Agilent 1200, Santa Clara, CA, USA) fitted with an analytical column (50x2.1 mm, $3 \mu \mathrm{m}$ particle size; Thermo Scientific Betasil C18, Waltham, MA, USA) operated at $35^{\circ} \mathrm{C}$. Gradient conditions were used at a flow rate of $250 \mu \mathrm{L} / \mathrm{min}$, starting at $85 \%$ A $(0.1 \%$ acetic acid $)$ and $15 \% \mathrm{~B}(0.1 \%$ acetic acid in acetonitrile). Initial conditions were held for 2 min and then ramped to $100 \% \mathrm{~B}$ at $6 \mathrm{~min}$, held until $9 \mathrm{~min}$, decreased to $0 \% \mathrm{~B}$ at $11 \mathrm{~min}$, and returned to initial conditions at $13 \mathrm{~min}$, and held constant until $15 \mathrm{~min}$. Mass spectra were collected using a tandem mass spectrometer (Applied Bioscience SCIEX 3000, Foster City, CA, USA) fitted with an electrospray ionization source, operated in the negative ionization mode. Chromatograms were recorded using multiple reaction monitoring (MRM) mode, where at least two transitions per-analyte were monitored. The following instrument parameters were used: desolvation temperature $450^{\circ} \mathrm{C}$, desolvation (curtain) gas 6.0 arbitrary units (AU), nebulizer gas flow 4 AU, ion spray voltage $4500 \mathrm{~V}$, collision gas 12 AU, collision energy 46 AU, declustering potential $30 \mathrm{AU}$, and a dwell time of $100 \mathrm{msec}$. Quantification using these transitions was performed using Analyst 1.4.1 software provided by SCIEX (Applied Bioscience, Foster City, CA, USA). The minimum and maximum values along the standard curve were 0.25 and 500 $\mu \mathrm{g} / \mathrm{mL}$ respectively. The limit of quantification used in this method was $250 \mathrm{ng} / \mathrm{L}$ and the mean recovery was $70 \%$. The plasma letrozole concentration vs. time $(\mathrm{C}-\mathrm{t})$ data for each heifer was analyzed by non-compartmental techniques using a computer modeling program (WinNonLin Standard Edition Version 2.1, Pharsight Corporation, Mountain View, CA, USA). Peak concentration in plasma ( $\operatorname{Cmax})$ and time to peak concentration (tmax) were determined using 
observed values. The apparent terminal rate constant $(\lambda)$ was determined by linear regression of the last 6-8 points on the terminal phase of the logarithmic plasma concentration vs. time curve. The area under the $\mathrm{C}-\mathrm{t}$ curve until the final plasma sample ( $\left.\mathrm{AUC}_{\text {last }}\right)$ was determined using the linear trapezoidal rule. The total area under the curve extrapolated to infinity $\left(\mathrm{AUC}_{0-\infty}\right)$ was calculated by adding the $\mathrm{C}_{\text {last obs }} / \lambda+\mathrm{AUC}_{\text {last }}$. The terminal half-life $\left(\mathrm{T}_{1 / 2 \lambda}\right)$ was calculated as $\ln 2$ $\lambda$. The mean residence time (MRT) was calculated as the area under the moment curve extrapolated to infinity $\left(\mathrm{AUMC}_{0-\infty}\right) / \mathrm{AUC}_{0-\infty}$. Systemic clearance $\left(\mathrm{Cl}_{\mathrm{S}}\right)$ was determined using the dose divided by $\mathrm{AUC}_{0 \text {-inf. }}$ The apparent volume of distribution $\left(\mathrm{V}_{\lambda} / f\right)$ was calculated by clearance divided by $\lambda$.

\subsubsection{Statistical analyses}

Statistical analyses were done using the Statistical Analysis System software package (SAS Learning Edition 9.1, 2006; SAS Institute Inc., Cary, NC, USA). Time-series hormone data, plasma letrozole concentration, and follicular diameter profiles were analyzed by repeated measures, using the PROC MIXED procedure. The main effects were treatment (high, medium and low dose, and control), time, and their interactions. When no differences were detected among doses of letrozole, data were combined and re-analyzed as a single letrozole treatment group. Single point measurements (intervals from ablation to wave emergence, treatment to wave emergence, treatment to ovulation, treatment to onset of follicular regression, and treatment to onset of CL regression) were analyzed by one-way analysis of variance. Paired t-test was used to compare estradiol concentration pre- and post-treatment within a treatment group and twosample t-test was used to compare estradiol concentration at a single data point between letrozole and control groups. An F-test was used to analyse if the variability in the interval from treatment to wave emergence was significantly different between letrozole-treated and control heifers. Due 
to individual variability in circulating concentrations of LH and FSH among heifers, and because our objective was to determine the effect of treatment within individuals, $\mathrm{LH}$ and FSH data were transformed to a percentage of the mean concentration of the first three samples (i.e., 0 , 15 , and 30 min post-treatment) for each individual heifer. Residuals from percent data were normally distributed, therefore, transformation of percent data was not required. All values are expressed as mean $\pm \mathrm{SEM}$.

Animal procedures were performed in accordance with the Canadian Council on Animal Care and were approved by University of Saskatchewan Protocol Review Committee.

\subsection{Results}

\subsubsection{Ovarian function}

The interval from follicular ablation to emergence of the new follicular wave did not differ among treatment groups $(1.7,1.6,1.7$ and 1.6 days for high-, medium- and low-dose letrozole, and control groups, respectively). Consequently, treatment was applied $2.4 \pm 0.1$ days after follicular wave emergence, when the growing dominant follicle was $7.1 \pm 0.3 \mathrm{~mm}$. The interval from ablation to treatment, and the diameter of the dominant follicle at the time of treatment did not differ among groups.

Although the dominant follicle diameter profiles after letrozole treatment followed a dosedependent pattern, differences among the letrozole dose groups were not significant $(\mathrm{P}=0.11$, Appendix 1). Therefore, data from all letrozole dose groups were combined for comparison with the control group. The dominant follicle diameter profile of letrozole-treated heifers was larger $(\mathrm{P}<0.04)$ than that of control heifers (Fig 4.1). The dominant follicle grew to a larger diameter 
$(11.0 \pm 0.32$ vs $9.7 \pm 0.55 \mathrm{~mm})$ and regressed later $(\mathrm{P}<0.05$; Table 1$)$ in letrozole-treated heifers with than in control heifers.

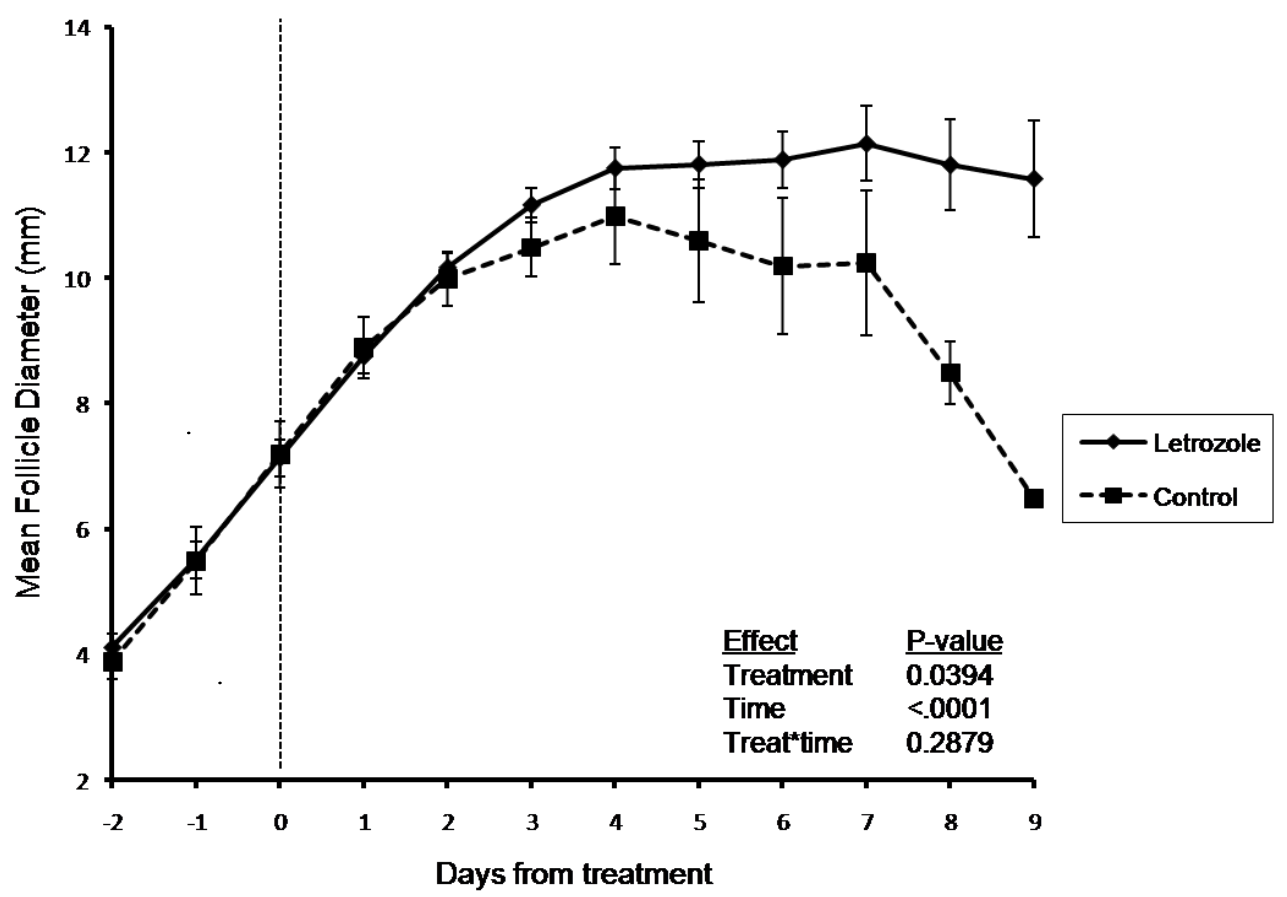

Figure 4.1. Diameter profile (mean \pm SEM) of the dominant follicle in heifers treated with letrozole (high-, medium- and low-dose groups combined; n=29) 4 days after follicular ablation (i.e., 2.5 days after wave emergence), compared to saline-treated controls $(\mathrm{n}=10)$.

The number of heifers in which the extant dominant follicle (i.e., the dominant follicle present at the time of treatment) ovulated did not differ among groups $(5 / 9,5 / 10,7 / 10$ and 4/10 heifers in high-, medium-, low-dose and control groups, respectively), but the interval to ovulation was longer in letrozole-treated heifers compared to controls (Table 4.1). In heifers that did not ovulate the extant dominant follicle, the intervals from treatment to onset of dominant follicle regression and to emergence of a new follicular wave were longer in those treated with letrozole than in controls $(\mathrm{P}<0.05$; Table 4.1). The variability (degree of synchrony) in intervals from treatment to wave emergence or dominant follicle regression was not different between letrozole-treated and control groups (F-value $=2.7, \mathrm{P}>0.05)$. 
Table 4.1. Effects of letrozole on interval to follicle wave emergence, ovulation, onset of follicular regression and onset of CL regression in cattle. Data from low-, medium- and highdose treatment groups were combined, and compared to saline-treated controls. Values are expressed as mean \pm SEM.

\begin{tabular}{|c|c|c|}
\hline Intervals (days) & Letrozole & Control \\
\hline Treatment to wave emergence* & $\begin{array}{l}7.5 \pm 0.27^{\mathrm{a}} \\
\quad(\mathrm{n}=29)\end{array}$ & $\begin{array}{l}5.9 \pm 0.46^{b} \\
\quad(n=10)\end{array}$ \\
\hline Treatment to ovulation of extant dominant follicle ${ }^{* *}$ & $\begin{array}{l}9.0 \pm 0.42^{a} \\
\quad(n=16)\end{array}$ & $\begin{array}{c}8.0 \pm 0.86^{a} \\
(n=4)\end{array}$ \\
\hline $\begin{array}{l}\text { Treatment to onset of regression of extant dominant } \\
\text { follicle** }\end{array}$ & $\begin{array}{l}8.7 \pm 0.47^{a} \\
\quad(n=13)\end{array}$ & $\begin{array}{l}5.2 \pm 0.65^{b} \\
\quad(n=6)\end{array}$ \\
\hline Treatment to onset of CL regression & $\begin{array}{l}6.1 \pm 0.35^{a} \\
\quad(n=29)\end{array}$ & $\begin{array}{l}5.1 \pm 0.62^{a} \\
\quad(n=10)\end{array}$ \\
\hline
\end{tabular}

${ }^{\mathrm{ab}}$ Within rows, values with different superscripts are different $(\mathrm{P}<0.05)$

*Differences in variability between groups were not significant

** Dominant follicle present at the time of treatment

\subsubsection{Circulating hormone concentrations}

Plasma FSH concentrations during the 4 days after treatment were not different among letrozole-dose groups; hence, data were combined for comparison with saline-treated controls. Plasma FSH levels tended to increase in both letrozole and control groups, but proportionately less in the letrozole-treated animals (Fig. 4.2). By 72 hours after treatment, plasma FSH concentrations were lower in heifers treated with letrozole than in controls $(\mathrm{P}<0.03)$. 


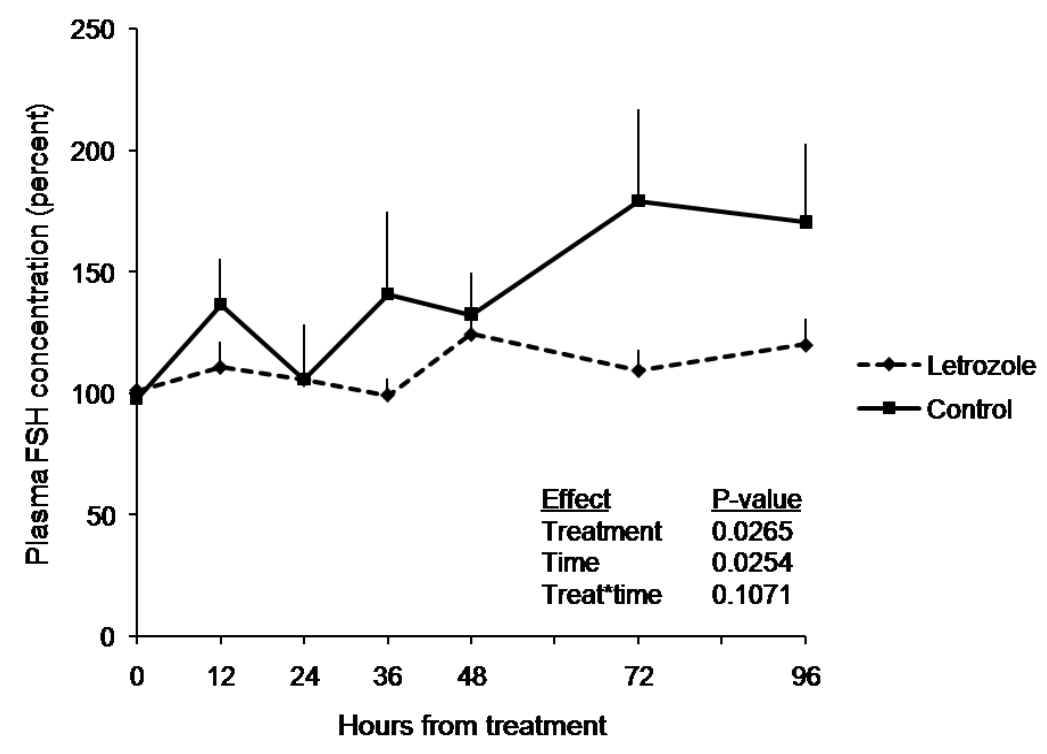

Figure 4.2. Plasma FSH concentrations (percent change after treatment; mean \pm SEM) in heifers treated with letrozole (high-, medium- and low-dose groups combined; $n=29$, ) 4 days after follicular ablation (i.e., 2.5 days after wave emergence), compared to saline-treated controls $(n=10)$.

Plasma LH concentrations during the 12-hour period after treatment did not differ among letrozole-treated groups; hence, data were combined for comparison with PBS-treated controls. Heifers treated with letrozole had higher plasma LH concentrations than saline-treated controls during the first 12 hours following treatment $(\mathrm{P}=0.05$; Fig. 4.3). Similarly, plasma LH concentrations during the 4-day period after treatment were not different among letrozole-treated groups and after combining data, heifers treated with letrozole had higher plasma LH concentrations than saline-treated controls ( $\mathrm{P}=0.01$; Fig. 4.3). 


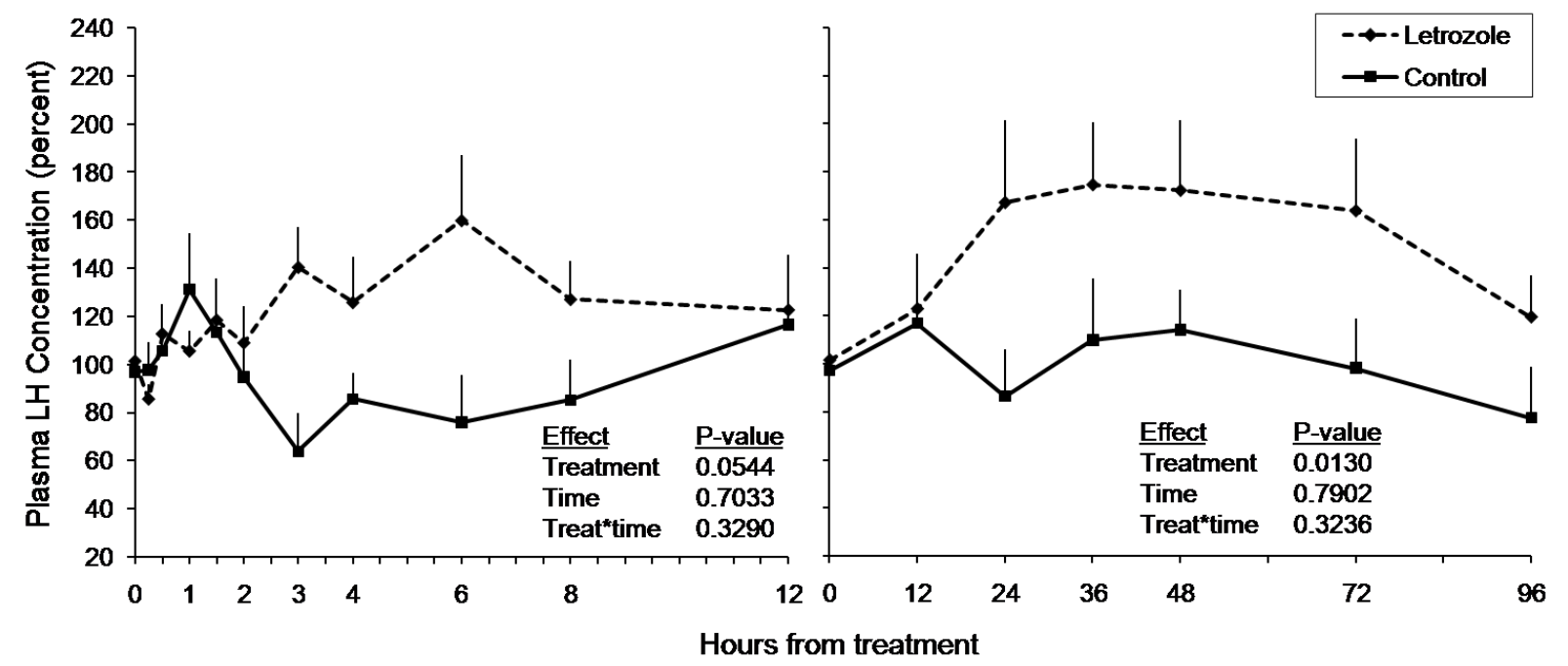

Figure 4.3. Plasma LH concentrations in heifers (percent change after treatment; mean \pm SEM) during the first 12 hours (left) and for 96 hours (right) after a single intravenous dose of letrozole (high-, medium- and low-dose groups combined; $\mathrm{n}=29$ ) given 4 days after follicular ablation (i.e., 2.5 days after wave emergence), compared to saline-treated controls $(\mathrm{n}=10)$.

Plasma estradiol concentrations did not differ among the letrozole-treated groups; hence, data were combined for comparison with saline-treated controls. Mean plasma concentrations of estradiol over the 4-day period after treatment tended to be higher in letrozole-treated heifers compared to control heifers $(\mathrm{P}=0.06)$, primarily as a result of an increase between 4 and 12 hours after treatment in letrozole-treated heifers (Fig. 4.4). Plasma estradiol concentrations decreased by nearly $50 \%$ from 0 to 24 hours after treatment in letrozole-treated heifers (from $15.2 \pm 3.01$ to $8.0 \pm 1.51 \mathrm{pg} / \mathrm{mL} ; \mathrm{P}=0.03$ ) while no change occurred in control heifers (from $11.0 \pm 3.16$ to 12.1 $\pm 3.43 \mathrm{pg} / \mathrm{mL}, \mathrm{P}=0.72)$. 


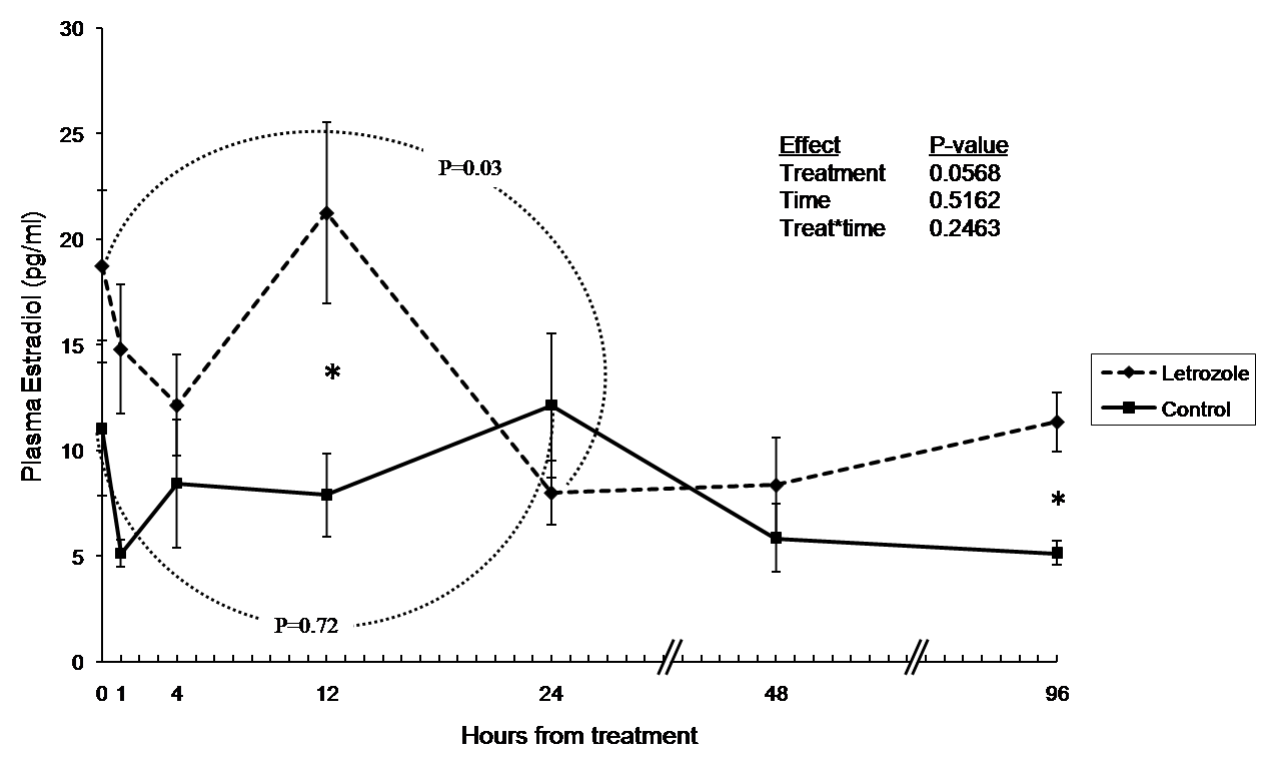

Figure 4.4. Plasma estradiol concentrations (mean \pm SEM) in heifers during the first 96 hours after a single intravenous dose of letrozole (high-, medium- and low-dose groups combined; $\mathrm{n}=29$ ) given 4 days after follicular ablation (i.e., 2.5 days after wave emergence), compared to PBS-treated controls $(n=10)$. Within groups, differences in estradiol concentrations between 0 and 24 hours after treatment were compared by paired t-test.

*Values differed between groups $(\mathrm{P}<0.03)$.

\subsubsection{Plasma letrozole concentration}

Plasma letrozole concentrations, as determined by LC/MS/MS, followed a dose-dependent pattern (Fig. 4.5). Mean plasma concentrations throughout the 8-day period were $0.63 \pm 0.04$ $\mu \mathrm{g} / \mathrm{mL}, 0.44 \pm 0.04 \mu \mathrm{g} / \mathrm{mL}$, and $0.27 \pm 0.04 \mu \mathrm{g} / \mathrm{mL}$ for high-, medium- and low-dose groups, respectively $(\mathrm{P}<0.0001)$. Pharmacokinetic parameters are summarized in Table 4.2. No significant differences were detected among dose-groups in the half-life $\left(\mathrm{T}_{1 / 2}\right)$, volume of distribution $\left(\mathrm{V}_{\mathrm{z}} / f\right)$, systemic clearance $\left(\mathrm{Cl}_{\mathrm{S}}\right)$ and mean residence time (MRT). Maximal concentration $\left(\mathrm{C}_{\mathrm{max}}\right)$ and area under the curve $\left(\mathrm{AUC}_{\text {last }}\right)$ differed between high, medium and low doses following a dose-dependent pattern $(\mathrm{P}=0.007$ and $\mathrm{P}<.0001$, respectively). 


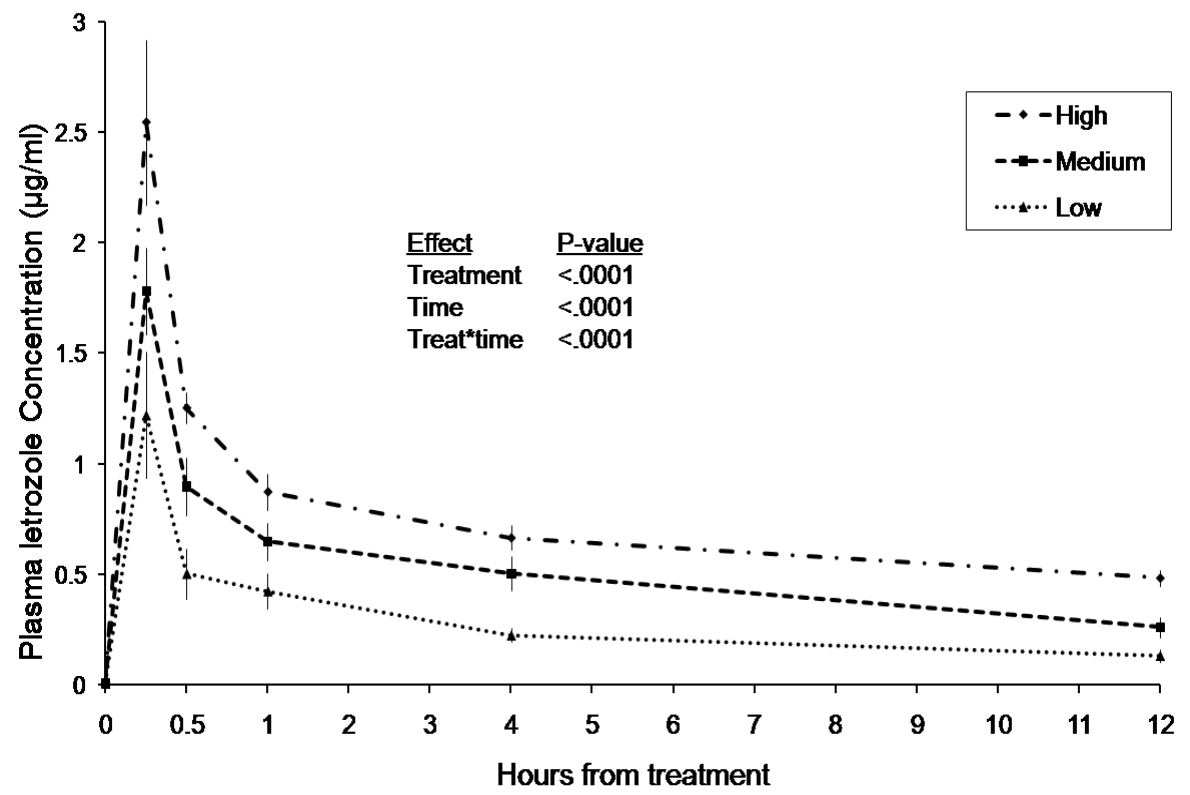

Figure 4.5. Plasma letrozole concentration (mean \pm SEM) as determined by HPLC/MS after administration of a single intravenous dose of 125,250 , or $500 \mu \mathrm{g} / \mathrm{kg}$. Data from Hour 0 to 12 hours after treatment are depicted.

Table 4.2. Pharmacokinetics of letrozole after administration of a single intravenous dose of 125 , 250 , or $500 \mu \mathrm{g} / \mathrm{kg}$ in postpubertal beef heifers, determined by non-compartmental analysis (mean \pm SEM).

\begin{tabular}{|c|c|c|c|c|}
\hline Parameter & $\begin{array}{c}125 \mu \mathrm{g} / \mathrm{kg} \\
(\mathrm{n}=9)\end{array}$ & $\begin{array}{c}250 \mu \mathrm{g} / \mathrm{kg} \\
(\mathrm{n}=9)\end{array}$ & $\begin{array}{c}500 \mu \mathrm{g} / \mathrm{kg} \\
(\mathrm{n}=9)\end{array}$ & Combined \\
\hline $\begin{array}{l}\text { Maximal concentration }\left(\mathrm{C}_{\max }\right) \\
(\mu \mathrm{g} / \mathrm{mL})\end{array}$ & $1.2 \pm 0.25^{\mathrm{a}}$ & $1.7 \pm 0.18^{\mathrm{b}}$ & $2.5 \pm 0.37^{c}$ & $1.8 \pm 0.27$ \\
\hline Half-life $\left(\mathrm{T}_{1 / 2}\right)$ (hours) & $26.9 \pm 0.95^{\mathrm{a}}$ & $26.6 \pm 1.18^{\mathrm{a}}$ & $28.5 \pm 1.05^{\mathrm{a}}$ & $27.3 \pm 0.42$ \\
\hline $\begin{array}{l}\text { Area under the curve }\left(\mathrm{AUC}_{\text {last }}\right) \\
\text { (hours } \times \mu \mathrm{g} / \mathrm{mL} \text { ) }\end{array}$ & $8.8 \pm 0.72^{\mathrm{a}}$ & $17.3 \pm 2.00^{\mathrm{b}}$ & $28.1 \pm 2.15^{\mathrm{c}}$ & $18.2 \pm 4.03$ \\
\hline $\begin{array}{l}\text { Volume of distribution }\left(\mathrm{V}_{\mathrm{z}} / f\right) \\
(\mathrm{mL} / \mathrm{kg})\end{array}$ & $566.2 \pm 43.95^{\mathrm{a}}$ & $592.9 \pm 66.06^{\mathrm{a}}$ & $\begin{array}{l}745.7 \pm \\
47.35^{\mathrm{a}}\end{array}$ & $634.9 \pm 39.54$ \\
\hline $\begin{array}{l}\text { Systemic clearance }\left(\mathrm{Cl}_{\mathrm{S}}\right) \\
(\mathrm{mL} / \mathrm{hour} / \mathrm{kg})\end{array}$ & $14.6 \pm 1.10^{\mathrm{a}}$ & $15.5 \pm 1.75^{\mathrm{a}}$ & $18.5 \pm 1.67^{\mathrm{a}}$ & $16.2 \pm 0.83$ \\
\hline $\begin{array}{l}\text { Mean residence time (MRT) } \\
\text { (hours) }\end{array}$ & $31.7 \pm 2.00^{\mathrm{a}}$ & $33.7 \pm 2.98^{\mathrm{a}}$ & $35.8 \pm 1.43^{\mathrm{a}}$ & $33.7 \pm 0.84$ \\
\hline
\end{tabular}

${ }^{\text {abc }}$ Within rows, values with no common superscript are different $(\mathrm{P}<0.05)$ 


\subsection{Discussion}

Letrozole has been used for several years for ovarian stimulation and induction of ovulation in women $[42-47,128-130,132,150]$; however, there are apparently no reports on the use of letrozole to control ovarian function in cattle. Based on clinical observations resulting from infertility treatments in women, it was hypothesized that letrozole would induce a drop in circulating E-17 $\beta$ concentrations followed by an increase in concentrations of FSH which would trigger the emergence of new follicular development [42, 43]. However, results of the present study in cattle did not support this hypothesis. On the contrary, a single treatment with letrozole on Day 3 post-ovulation in cattle, regardless of the dose, significantly lengthened the period of dominance of the extant dominant follicle, resulting in a prolonged interval to emergence of a new follicular wave. Furthermore, the mean diameter achieved by the dominant follicle was significantly larger in letrozole-treated heifers. Letrozole treatment was associated with elevated plasma LH concentrations, but had no apparent effect on FSH concentrations.

Mean plasma estradiol concentrations in letrozole-treated heifers tended to be higher than in controls for the first 4 days after treatment, but this was attributed primarily to a significant and sharp elevation at 12 hours after letrozole treatment. This acute elevation in estradiol has not been reported in women, but a similar increase was observed in rats, and was interpreted as the result of a gonadotrophin release caused by letrozole treatment [151]. Although in the present study plasma estradiol concentrations decreased by nearly $50 \%$ by 24 hours after letrozole treatment, concentrations were not significantly lower than controls.

The lack of an apparent suppressive effect of letrozole on estrogen concentrations in cattle in the present study may have been the result of insufficient assay sensitivity and/or an inadequate dose of letrozole. In women, basal and maximum circulating estradiol concentrations have been 
reported to be approximately 20 and $200 \mathrm{pg} / \mathrm{mL}$, respectively [137]. In the heifers examined in this study, basal plasma estradiol concentrations were below the detection limit (3 to $4 \mathrm{pg} / \mathrm{mL}$ ) and, on average, maximum concentrations did not exceed $25 \mathrm{pg} / \mathrm{mL}$ during the first 8 days after ovulation. In addition, the dose and duration of letrozole treatment used in our experiment may not have been sufficient to inhibit estradiol production in cattle, in contrast to other species in which treatment resulted in a marked reduction in circulating estradiol concentrations (97-99\% in post-menopausal women [42], and $88 \%$ in boars [152]).

Extended growth and delayed regression of the extant dominant follicle was attributed to letrozole-induced elevation in plasma LH concentrations [15, 18]. Endogenous concentrations of LH began to rise 2 hours after letrozole was administered and levels were elevated for at least 4 days after treatment. Increasing concentrations of LH during this time may also have elicited the surge in plasma estradiol concentrations observed 12 hours post-treatment.

Contrary to our expectations, plasma FSH concentrations were lower in letrozole-treated heifers than in controls. Follicular products other than estradiol also suppress FSH and may be responsible for the effect observed [3, 153, 154]. Inhibin is secreted by the dominant and subordinate follicles during the time of follicular deviation and, together with estradiol, has been associated with the suppressive effects involved in follicular selection and dominance $[139,155]$. However, letrozole treatment in the present study was associated with over-dominance (prolonged growth and maintenance of the dominant follicle) resulting in an extended period of FSH suppression and delayed emergence of the next follicular wave. It is noteworthy that inhibition of estradiol synthesis by an aromatase inhibitor did not adversely affect the extant dominant follicle, rather it indirectly enhanced follicular dominance by permitting elevated pituitary LH secretion. 
Although most of the studies in women in which letrozole was used to treat unexplained infertility are based on a 5-day treatment regimen (total dose of 12.5 to $20 \mathrm{mg}$ letrozole), single dose treatments of $20 \mathrm{mg}$ administered orally on the third day of the menstrual cycle have been reported to be equally effective in suppressing circulating estrogen concentrations. The half-life of letrozole in humans has been reported to be approximately 2 days which could result in effective suppression of estradiol production for 4 to 6 days after a single administration [130]. Although the pharmacokinetic parameters reported in the present study are preliminary, we estimated the half-life of letrozole in heifers to be 27 hours (as apposed to 48 hours in women $[111,112]$ ), the mean residence time (average duration of persistence in the body) to be 34 hours (as apposed to 59 hour in women [111]), and the volume of distribution to be $635 \mathrm{~mL} / \mathrm{kg}$ (as apposed to $1870 \mathrm{~mL} / \mathrm{kg}$ in women [111]). Taken together, we interpret these data to suggest that cattle may require a higher dose and a longer period of exposure to achieve effective concentrations in target tissues. This hypothesis is further supported by a study in which albendazole (another imidazole derivative used as an anthelminthic) significantly reduced follicular fluid estradiol concentrations in ewes when given orally at $11.5 \mathrm{mg} / \mathrm{kg}$ of body weight [156], which is a 46 times higher than the medium dose used in the present study.

In summary, letrozole treatment in heifers was associated with elevated circulating LH concentrations and an extended period of dominance of the dominant follicle present at the time of treatment, regardless of dose. Consequently, circulating concentrations of FSH remained suppressed and emergence of the next wave was delayed. These results were unexpected and provide impetus for additional studies to elucidate the differences in pharmacokinetics of letrozole between the bovine and human species, and to explore the potential of aromatase inhibitors as a non-steroidal approach to the control of ovarian function in cattle. 
Acknowledgements: We thank Jonathan Naile and Dr Al Chicoine for their help in obtaining and interpreting, respectively, plasma letrozole concentrations. We are thankful to Eric Higley and Dr Hong Chang from the Toxicology Center at the University of Saskatchewan for their help in the determination of estradiol concentrations. We also thank Brad Blackmore and the staff at Goodale Research Farm for assistance with handling and managing the cattle and our summer student Matthew Van Steelandt for help with data collection. The authors are thankful to the Natural Sciences and Engineering Research Council of Canada and Bioniche Animal Health Inc. for financial support. 


\subsection{EFFECTS OF A THREE-DAY REGIMEN OF LETROZOLE ON OVARIAN FUNCTION IN CATTLE}

\subsection{Abstract}

A study was designed to determine the effects of stage of the follicular wave on ovarian response to letrozole in cattle, and whether a 3-day regimen of letrozole treatment can be used to electively control ovarian function. Post-pubertal beef heifers $(\mathrm{N}=45)$ were assigned randomly to four treatment groups. One group received no treatment (control) and the other groups were given $85 \mu \mathrm{g} / \mathrm{kg}$ of letrozole per day (250 $\mu \mathrm{g} / \mathrm{kg}$ total dose) on Days 1 to 3, Days 3 to 5 , or Days 5 to 7 (Day $0=$ pre-treatment ovulation), corresponding to the period before, during and after selection of the dominant follicle, respectively. Follicular dynamics were monitored ultrasonographically and blood samples were collected for hormone assays. Follicle and CL diameter profiles, plasma concentrations of $\mathrm{LH}, \mathrm{FSH}$, estradiol, progesterone, and letrozole were analyzed. Regardless of the stage of the follicular wave in which treatments were initiated, multiple doses of letrozole lengthened the period of follicular dominance $(\mathrm{P}<0.01)$, delayed emergence of the next follicular wave $(\mathrm{P}<0.05)$, and resulted in a larger $\mathrm{CL}(\mathrm{P}<0.01)$. The effects on dominant follicle and CL diameters appeared to be the result of increased plasma concentrations of LH in letrozole-treated animals. No differences were found in mean plasma progesterone concentration among groups. Inconsistent inhibition of estradiol production and variable effects on FSH secretion may be a result of insufficient circulating levels of letrozole during the treatment period. Higher doses of letrozole may be necessary to consistently affect circulating concentrations of estradiol and gonadotropins, and predictably affect follicular wave dynamics in cattle. 


\subsection{Introduction}

Estradiol and its esters, in combination with a source of progesterone, have been used effectively for synchronizing follicle wave emergence and ovulation in cattle [9, 21]. Estradiol has a negative feedback effect on the hypothalamo-pituitary axis causing suppression of FSH secretion during the luteal phase [13], or under the influence of exogenous progesterone [74], and has been reported to decrease LH pulse amplitude in sheep [12] and cattle [13]. Furthermore, luteal or exogenous progesterone reduces LH secretion, and estradiol in combination with progesterone cause regression of the extant dominant follicle. Once the suppressive effects of estradiol are removed through metabolism $(42,110,120,170$ hours after treatment with estradiol-17ß [157], estradiol benzoate [158], estradiol valerate [159] and estradiol cypionate [158], respectively), FSH surges resulting in the emergence of a new wave of follicular development, approximately 4 days after estradiol treatment (with E17- $\beta$ and estradiol benzoate), regardless of the stage of development of the dominant follicle at the time of treatment $[9,20$, 21]. The degree of synchrony achieved with such treatments has made fixed-time artificial insemination feasible $[22,23]$ and improved the efficiency of multiple ovulation and embryo transfer programs $[9,24]$.

Estrogens have also been used for several decades by the beef industry as growth promotants [26] because of the key role they play in linear growth and closure of epiphyseal plates, and fat deposition [25]. However, the use of natural or synthetic estrogens in food producing animals, whether for anabolic purposes or for controlling reproductive function, has been the subject of considerable controversy (reviewed in [31, 32]). In January 1989, as a result of increasing concern about potential toxic and carcinogenic effects of hormonal preparations used in food producing animals [29-31], estradiol and other steroid hormones were banned for use as a growth 
promotant in animals designated for human consumption in all member states of the European Union [160]. In October 2006, the ban was extended to prohibit use of estradiol-17 $\beta$ and its esters for purposes of reproductive management [34]. In 2007, New Zealand and Australia banned use of estrogens in lactating dairy animals [161]. The use of estradiol and zeranol (an estrogen-like compound) as growth promotants is still permitted in the United States [119] and Canada [127], but no commercial preparations are available for the purposes of reproductive management. Hence, treatments for estrous synchronization must be custom-compounded and used by prescription only. Custom-compounding, however, has recently come under critical scrutiny in the USA [119]. This situation negatively impacts on the implementation of reproductive technologies in cattle production systems and limits reproductive efficiency and genetic improvement provided by the use of artificial insemination or embryo transfer programs [161]. In this context, the development of alternative methods for controlling ovarian function in cattle is needed.

Letrozole, a non-steroidal aromatase inhibitor, inactivates the aromatase enzyme responsible for the synthesis of estrogens by reversibly binding to the heme group of the P450 subunit. Letrozole is indicated as an adjuvant or first-line treatment for hormone-dependent breast cancer in post-menopausal women $[40,120]$, and it has also been used in assisted reproduction in women because of its potential effect on removing the negative feedback of estradiol on FSH secretion [41-43]. For ovarian stimulation in women, it is commonly used at a dose of 1 to $5 \mathrm{mg}$ per day for 5 days $[42,150]$, and it has been used in higher or increasing doses for ovarian superstimulation $[46,47]$.

Contrary to the proposed hypothesis based on observations in women [41], treatment of beef heifers with single intravenous dose of letrozole on Day 3 post-ovulation did not induce 
follicular atresia or hasten emergence of a new follicular wave (Chapter 4). Although circulating concentrations of estradiol were affected, letrozole treatment did not induce an elevation in circulating FSH concentrations. Rather, letrozole treatment increased mean plasma LH concentrations which resulted in a prolonged period of dominance of the extant dominant follicle and delayed emergence of the next follicular wave.

The objective of the present study was to test the hypothesis that an extended period of letrozole exposure will terminate dominant follicle growth and result in the emergence of a new follicular wave at a predictable interval thereafter, regardless of the stage of follicular development at the time of treatment. We examined the effects of letrozole on ovarian and endocrine function in cattle after treatment for 3 consecutive days beginning before, during, and after manifest selection of the dominant follicle of the first follicular wave of the cycle.

\subsection{Material and Methods}

\subsubsection{Cattle}

Hereford-cross beef heifers, 14 to 20 months of age and weighing between 233 and $404 \mathrm{~kg}$, were chosen from a herd of 50 animals maintained in outdoor corrals at the University of Saskatchewan Goodale Research Farm (52 North and $106^{\circ}$ West). Heifers were fed alfalfa/grass hay and grain to gain approximately $1.3 \mathrm{~kg}$ per day and had water ad libitum during the experimental period from May to July. Heifers were initially examined by transrectal ultrasonography (7.5 MHz linear-array transducer, Aloka SSD-900; Tokyo, Japan) to confirm that they were postpubertal by the presence of a CL [143]. 


\subsubsection{Treatments and examinations}

Heifers in which a CL was detected during the initial examination underwent transvaginal ultrasound-guided follicular ablation of the two largest ovarian follicles to synchronize follicular wave emergence, which was expected to occur 1 to 1.5 days later [145, 162]. Four days after follicular ablation, heifers were given $500 \mu \mathrm{g}$ of cloprostenol (PGF, Estrumate, Schering-Plough Animal Health, Pointe-Claire, QC, Canada) intramuscularly (im) to induce regression of the CL and to synchronize ovulation [144]. The experiment was performed in two replicates ( $n=20-27$ per replicate) and each heifer was used only once. In replicate 1 , heifers were assigned randomly at the time of ovulation (Day 0) to the following groups and given a 3-day regimen of letrozole on Days 1 to $3(n=5)$, Days 3 to $5(n=5)$, Days 5 to $7(n=5)$, or no treatment (control group, $n=5)$. In replicate 2, heifers were similarly assigned to groups and given letrozole from Days 1 to 3, $(n=5)$, Days 3 to $5(n=4)$, or Days 5 to $7(n=4)$, but untreated control heifers were arranged in three sub-groups to serve as contemporaneous controls for each letrozole-group during intensive blood sampling periods (i.e., control Days 1 to $3, \mathrm{n}=4$; control Days 3 to $5, \mathrm{n}=4$; and control Days 5 to $7, \mathrm{n}=5)$. For practical purposes, the total dose of letrozole $(250 \mu \mathrm{g} / \mathrm{kg})$ was calculated on the basis of an average weight of $350 \mathrm{~kg}$ for all heifers and administered intravenously in daily divided doses over 3 days $(85 \mu \mathrm{g} / \mathrm{kg}$ per day). For intravenous injection, letrozole was prepared in $95 \%$ ethanol to a final concentration of $5 \mathrm{mg} / \mathrm{ml}$, resulting in an injection volume of $6 \mathrm{~mL} /$ day.

\subsubsection{Ovarian ultrasonography}

Ultrasound examinations were recorded on a sketch sheet in which each ovary and its structures (CL [56] and follicles $\geq 4 \mathrm{~mm}$ in diameter [54]) were represented in size and relative location. Ovulation was defined as the disappearance of any follicle $\geq 8 \mathrm{~mm}$ between two 
consecutive daily examinations, and was confirmed by the subsequent development of a CL [137]. Follicular wave emergence was defined retrospectively as the day when the dominant follicle was first identified at a diameter of 4 or $5 \mathrm{~mm}[48,57]$. If the dominant follicle was not identified until it reached 6 or $7 \mathrm{~mm}$, the previous day was considered the day of follicular wave emergence [163]. The dominant follicle of a wave was defined as the largest antral follicle of that wave after deviation, and the first subordinate follicle as the second largest antral follicle originated from the same wave [146]. The day of onset of follicular and luteal regression was defined as the first day of an apparent constant decrease in follicular and luteal diameters, respectively [57].

\subsubsection{Computer-assisted ultrasound image analysis}

Ultrasound images from a subset of letrozole-treated ( $n=4-5$ per group) and control $(n=6)$ heifers were recorded throughout the duration of treatment for computer-assisted image analysis. Images were analyzed using a series of custom-developed computer algorithms optimized for ultrasonography (SYNERGYNE Version 2.8C Saskatoon, Saskatchewan) [164-166]. Echotexture was defined in terms of mean pixel value and pixel heterogeneity. Mean pixel values were quantified using a grey-scale ranging from 0 (black) to 255 (white). The pixel heterogeneity was the standard deviation of grey-scale values of all the pixels within the userdefined region of measurement. Spot analysis of the follicular antrum and corpus luteum, and line analysis of the peripheral antrum, follicular wall and stroma were done as previously described [167]. For spot analyses, the follicular antrum and the CL wall were divided into four quadrants and the sampling area encompassed 75 to $80 \%$ of each quadrant. For line analyses, a straight line was drawn transversing the follicular wall from peripheral antrum to stroma and the 
pixel values along that line were measured in areas located within the 10 and 2 o'clock position of the follicles [165].

\subsubsection{Collection of blood samples}

Blood samples were collected by jugular or coccygeal venipuncture into $10 \mathrm{ml}$ heparinised, vacuum tubes (Vacutainer tubes; Becton Dickinson Vacutainer Systems, Franklin Lakes, NJ, USA). Blood samples were collected daily from pre-treatment ovulation to post-treatment ovulation. In replicate 1, additional samples were collected from letrozole-treated heifers every 12 hours from the beginning of treatment to first wave emergence. In replicate 2 , heifers were sampled at 15 minute intervals for the first 8 hours after the second dose of letrozole (i.e., second day of treatment) using an indwelling jugular catheter, as described previously [63]. Blood samples were centrifuged at 1500 x g for 20 minutes, and plasma was separated and stored in plastic tubes at $-20^{\circ} \mathrm{C}$.

\subsubsection{Hormone assays}

Plasma LH concentrations were determined in duplicate using a double-antibody radioimmunoassay (NIDDK-bLH4) [12, 147]. The minimum and maximum values along the standard curve were 0.06 and $8 \mathrm{ng} / \mathrm{mL}$, respectively. The intra- and inter-assay coefficients of variation were $7.9 \%$ and $2.5 \%$, respectively, for low reference samples (mean, $0.85 \mathrm{ng} / \mathrm{mL}$ ) and $8.6 \%$ and $9.5 \%$, respectively, for high reference samples (mean, $2.5 \mathrm{ng} / \mathrm{mL}$ ).

Plasma FSH concentrations were determined in duplicate using a double-antibody radioimmunoassay using NIDDK-anti-oFSH-1 primary antibody and expressed as USDA bovine FSH-Il units $[12,147]$. The minimum and maximum values along the standard curve were 0.12 and $16 \mathrm{ng} / \mathrm{mL}$, respectively. The intra- and inter-assay coefficients of variation were $11.1 \%$ and 
$11.2 \%$, respectively, for low reference samples (mean, $1.9 \mathrm{ng} / \mathrm{mL}$ ) and $5.2 \%$ and $4.1 \%$, respectively, for high reference samples (mean $4.0 \mathrm{ng} / \mathrm{mL}$ ).

Plasma estradiol concentrations were determined in duplicate by enzyme-linked immunosorbent assay (Cayman Chemical Company, Ann Arbor, MI, USA). In this competitive ELISA, plasma steroid competes with acetylcholinesterase labelled steroid for the binding site on the polyclonal rabbit anti-steroid antibody. The antiserum to estradiol was reported to cross-react with estradiol-3-glucoronide (14\%), estrone (12\%), and estriol (0.3\%). For all other steroids cross-reactivities were reported as $<0.1 \%$. The minimum and maximum values along the standard curve were 6.6 and $4000 \mathrm{pg} / \mathrm{well}$, respectively. The intra- and inter-assay coefficients of variation for reference sample $(100 \mathrm{pg} / \mathrm{ml})$ assayed in duplicate were $11.7 \%$ and $12.7 \%$, respectively. A concentration procedure using diethyl ether extraction was performed prior to the assay in all samples to increase estrogen concentration to measurable levels [148]. A ${ }^{3} \mathrm{H}$-labeled steroid was added to each plasma sample before extraction as an internal recovery standard. After the extraction procedure, a fraction of the final extract was quantified in a liquid scintillation counter to test for recoveries [149]. To confirm the effectiveness of the ELISA in quantifying estradiol concentrations in plasma, a random sub-set of plasma samples $(n=25)$ was also analyzed by high performance liquid chromatography mass spectrometry (HPLC/MS) and results were compared to those obtained by ELISA (Appendices 3 and 4).

Plasma progesterone concentrations were determined in duplicate using a commercial solidphase kit (Coat-A-Count; Diagnostic Products Corporation, Los Angeles, CA, USA). The range of the standard curve was 0.1 to $40.0 \mathrm{ng} / \mathrm{mL}$. The intra- and inter-assay coefficients of variation for samples assayed in duplicates were $10.1 \%$ and $15 \%$, respectively, for low reference samples 
(mean, $1.8 \mathrm{ng} / \mathrm{mL}$ ) and $5.5 \%$ and $7.7 \%$, respectively, for high reference samples (mean, 17.5 $\mathrm{ng} / \mathrm{mL})$.

\subsubsection{Plasma letrozole concentration}

Plasma concentrations of letrozole were determined from samples collected every 12 hours from pre-treatment to one day after cessation of treatment using high performance liquid chromatography tandem mass spectrometry (LC/MS/MS) as described in Chapter 4, Section 4.3.6.

\subsubsection{Statistical analyses}

Statistical analyses were done using the Statistical Analysis System software package (SAS Learning Edition 9.1, 2006; SAS Institute Inc., Cary, NC, USA). Time-series hormone data, plasma letrozole concentration, follicular and luteal diameter profiles, were analysed by repeated measures, using the PROC MIXED procedure. The same test was used to compare pixel values and pixel heterogeneity for the dominant follicles and CL using mean values of two pretreatment images taken 24 hours and immediately before treatment and mean values of two posttreatment images taken 24 and 48 hours after the end of treatment. The main effects were treatment, time, and their interactions. Initial inspection of $\mathrm{LH}$ data revealed an apparent difference between morning and afternoon values, so LH data were examined by analysis of variance for repeated measures to determine the main effects of treatment (During and After), stage of follicular development (Days 1 to 3, Days 3 to 5, and Days 5 to 7), time of the day (AM vs PM), and day of treatment $\left(1^{\text {st }}, 2^{\text {nd }}\right.$, and $3^{\text {rd }}$ dose). Single point measurements (interwave and interovulatory intervals, interval from ovulation to onset of CL regression, mean and basal LH concentrations, LH pulse amplitude and frequency, and pharmacokinetic parameters for 
letrozole) were analysed by analysis of variance. If no differences were detected among letrozole-treated groups, data were combined and re-analysed as a single letrozole treatment group for comparison with non-treated controls. If significant main effects or interactions $(\mathrm{P} \leq$ 0.05) were detected, Tukey's post-hoc test was used for multiple comparisons.

Due to individual variability in circulating hormone concentrations among heifers, and because our objective was to determine the effect of treatment within individuals, data on LH and FSH concentrations were transformed to a percentage of the mean concentration of the two first data points collected (Days 0 and 1) for each individual heifer before analysis of variance for repeated measures. For the same reasons, estradiol concentrations were transformed to a percentage of the mean concentration of two pre-treatment data points (i.e. for each individual heifer) before statistical analysis.

For analysis of LH pulsatility from raw LH data, a pulse was defined as the presence of two consecutive samples (taken at 15 minute intervals) which were greater than the mean of the two previous samples (basal value) and one or both exceeding the mean basal value by more than twice the coefficient of variation of the assay [168]. The basal concentration of LH for individual heifers was defined as the mean of all the concentrations excluding those that were included in the definition of a pulse. Pulse amplitude was determined by the difference between LH pulse height (the highest concentration of LH within a pulse) and the basal concentration [169]. All values are expressed as mean \pm SEM.

Animal procedures were performed in accordance with the Canadian Council on Animal Care and were approved by University of Saskatchewan Protocol Review Committee. 


\subsection{Results}

\subsubsection{Circulating concentrations of letrozole}

Plasma letrozole concentrations in all three treatment groups were elevated by 12 hours after initiation of treatment and reached peak levels by 60 hours, followed by a decline to approximately half peak values by 108 hours (time effect, $\mathrm{P}<0.001$; Fig. 5.1). Heifers treated from Days 1 to 3 had higher circulating letrozole concentrations than those treated from Days 3 to 5, while those treated from Days 5 to 7 were intermediate (overall means, $68.6 \pm 4.79$, $43.9 \pm 4.75$ and $55.6 \pm 4.75 \mathrm{ng} / \mathrm{ml}$, respectively, $\mathrm{P}<0.01$; Fig. 5.1).

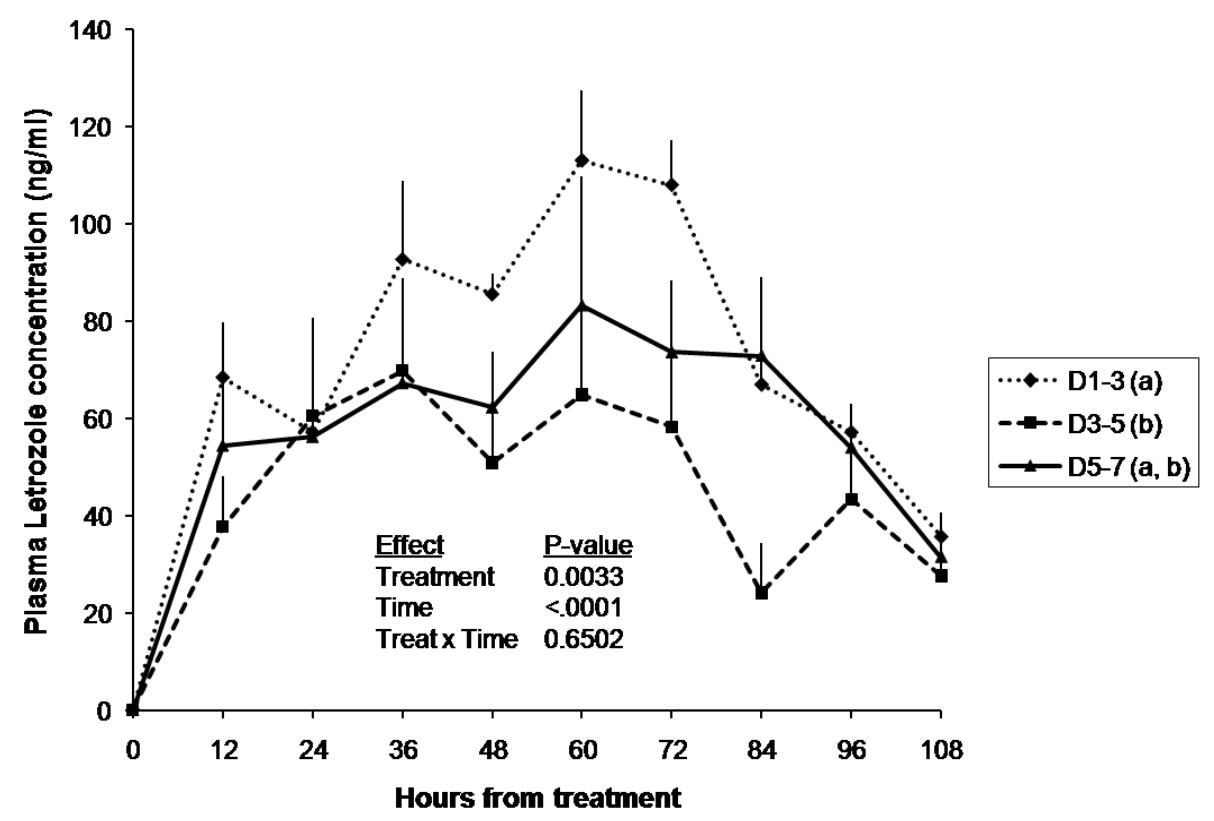

Figure 5.1. Plasma letrozole concentration (mean \pm SEM) in heifers treated with letrozole ( 85 $\mu \mathrm{g} / \mathrm{kg} /$ day) from Days 1 to 3, Days 3 to 5 or Days 5 to 7 (Day $0=$ ovulation).

${ }^{a b c}$ Overall means for treatment groups with no common superscript were different $(\mathrm{P}<0.05)$.

\subsubsection{Ovarian follicles and estradiol}

The diameter profile of the extant dominant follicle (i.e., the dominant follicle present at the time of treatment) was similar among letrozole treatment groups (Appendix 2); hence, data were 
combined for comparison with controls. The dominant follicle grew to a greater diameter in letrozole-treated heifers than in controls $(\mathrm{P}<0.01$; Fig. 5.2). The inter-wave interval was longer in letrozole-treated heifers than in controls $(\mathrm{P}<0.05$; Table 5.1). However, the inter-ovulatory interval did not differ between groups.

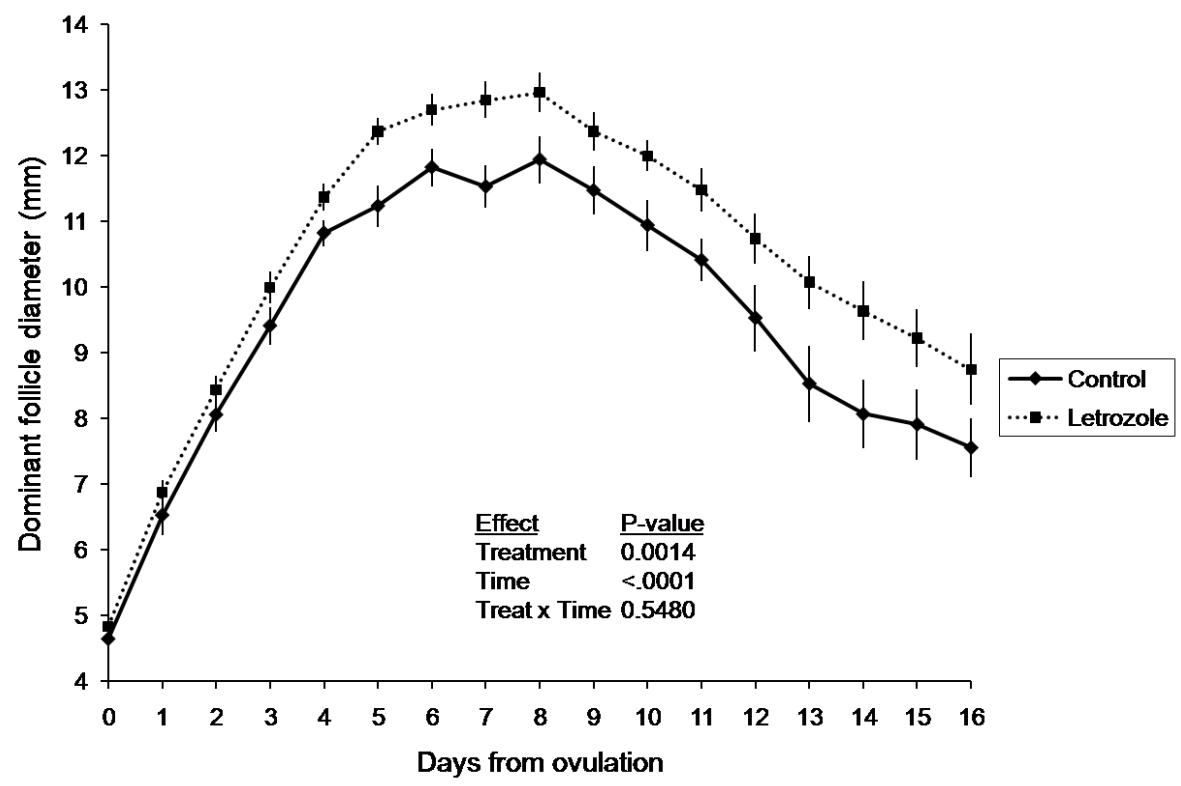

Figure 5.2. Diameter profile (mean \pm SEM) of the dominant follicle in heifers treated with letrozole on Days 1 to 3, 3 to 5 or 5 to 7 (Day $0=$ ovulation; treatment groups combined, $n=28$ ) compared to untreated controls $(n=17)$.

Table 5.1. Effects (mean \pm SEM) of a 3 -day regimen of letrozole given at three different stages of the follicular wave in heifers on the intervals to new wave emergence and ovulation.

\begin{tabular}{|c|c|c|c|c|}
\hline & \multicolumn{3}{|c|}{ Letrozole treatment } & \multirow{2}{*}{$\begin{array}{l}\text { Control } \\
(n=17)\end{array}$} \\
\hline & $\begin{array}{c}\text { Days } 1 \text { to } 3 \\
(n=10)\end{array}$ & $\begin{array}{c}\text { Days } 3 \text { to } 5 \\
(n=9)\end{array}$ & $\begin{array}{c}\text { Days } 5 \text { to } 7 \\
(n=9)\end{array}$ & \\
\hline Inter-wave interval (days) & $8.9 \pm 0.35^{\mathrm{a}}$ & $10.0 \pm 0.37^{\mathrm{ab}}$ & $10.7 \pm 0.37^{\mathrm{b}}$ & $7.6 \pm 0.27^{\mathrm{c}}$ \\
\hline $\begin{array}{l}\text { Inter-ovulatory interval } \\
\text { (days) }\end{array}$ & $20.9 \pm 0.46^{\mathrm{a}}$ & $20.1 \pm 0.49^{\mathrm{a}}$ & $21.2 \pm 0.49^{\mathrm{a}}$ & $20.5 \pm 0.35^{\mathrm{a}}$ \\
\hline $\begin{array}{l}\text { Dominant follicle diameter } \\
\text { at treatment }(\mathrm{mm})^{*}\end{array}$ & $6.8 \pm 0.36^{\mathrm{a}}$ & $10.1 \pm 0.45^{b c}$ & $12.1 \pm 0.43^{\mathrm{d}}$ & $\begin{array}{c}6.5 \pm 0.27(\text { Day } 1)^{\mathrm{a}} \\
9.4 \pm 0.32(\text { Day } 3)^{\mathrm{b}} \\
11.2 \pm 0.30(\text { Day } 5)^{\mathrm{cd}}\end{array}$ \\
\hline
\end{tabular}

${ }^{a b c d}$ Within rows, values with no common superscript are different $(\mathrm{P}<0.05)$.

* Compared to respective controls at the same stage of follicular development. 
The diameter profile of the largest subordinate follicle in heifers treated with letrozole from Days 1 to 3 was larger than that of control heifers $(\mathrm{P}<0.05$; Fig. 5.3). The diameter profiles of the largest subordinate follicle in heifers treated with letrozole from Days 3 to 5 were intermediate and did not differ from either of the other two groups.

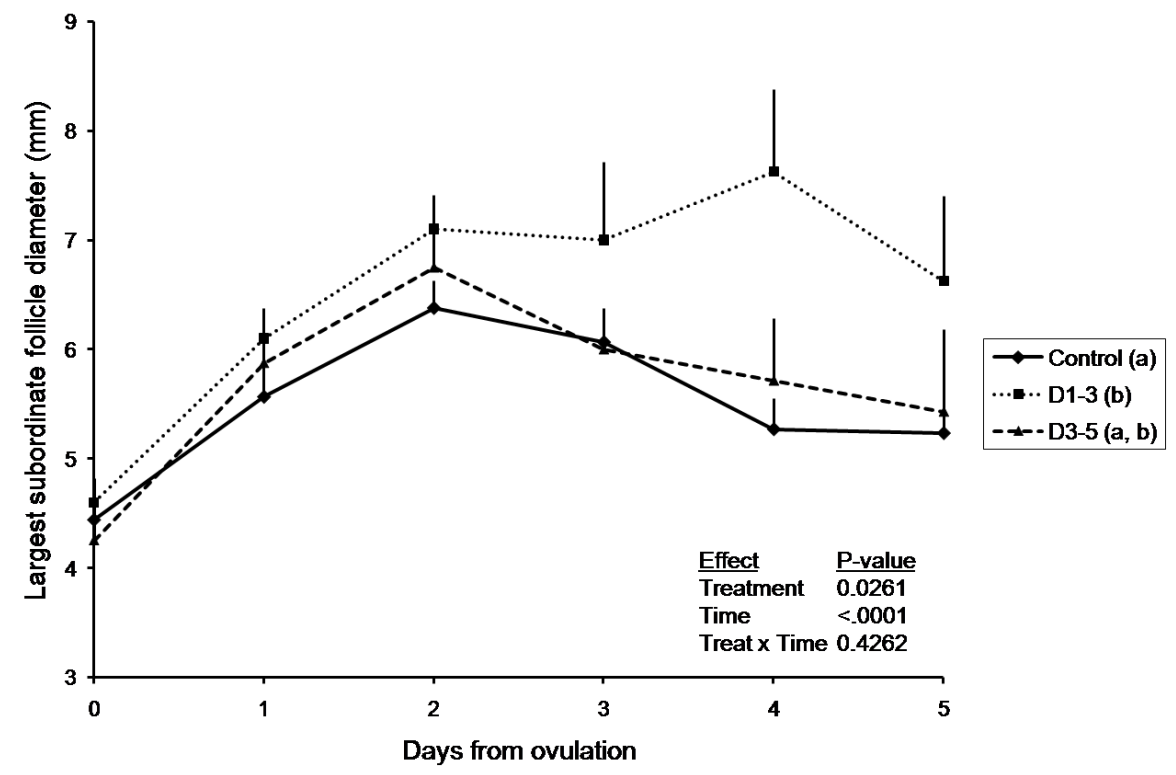

Figure 5.3. Diameter profile (mean $\pm \mathrm{SEM}$ ) of the largest subordinate follicle in heifers treated with letrozole on Days 1 to $3(n=10)$, or Days 3 to $5(n=9)$, compared to untreated controls $(n=17)$. Heifers treated with letrozole from Days 5 to 7 were not included in the analysis since the largest subordinate follicle was no longer detectable at initiation of treatment on Day 5. ${ }^{a b c}$ Overall means for treatment groups with no common superscript were different $(\mathrm{P}<0.05)$.

Plasma estradiol concentrations for each treatment group were compared independently with the respective control subgroup for each treatment period (data from replicate 2; Fig. 5.4). Estradiol concentrations were not different between letrozole-treated and control heifers, regardless of the stage of follicular development at the time of treatment (Fig. 5.4). 


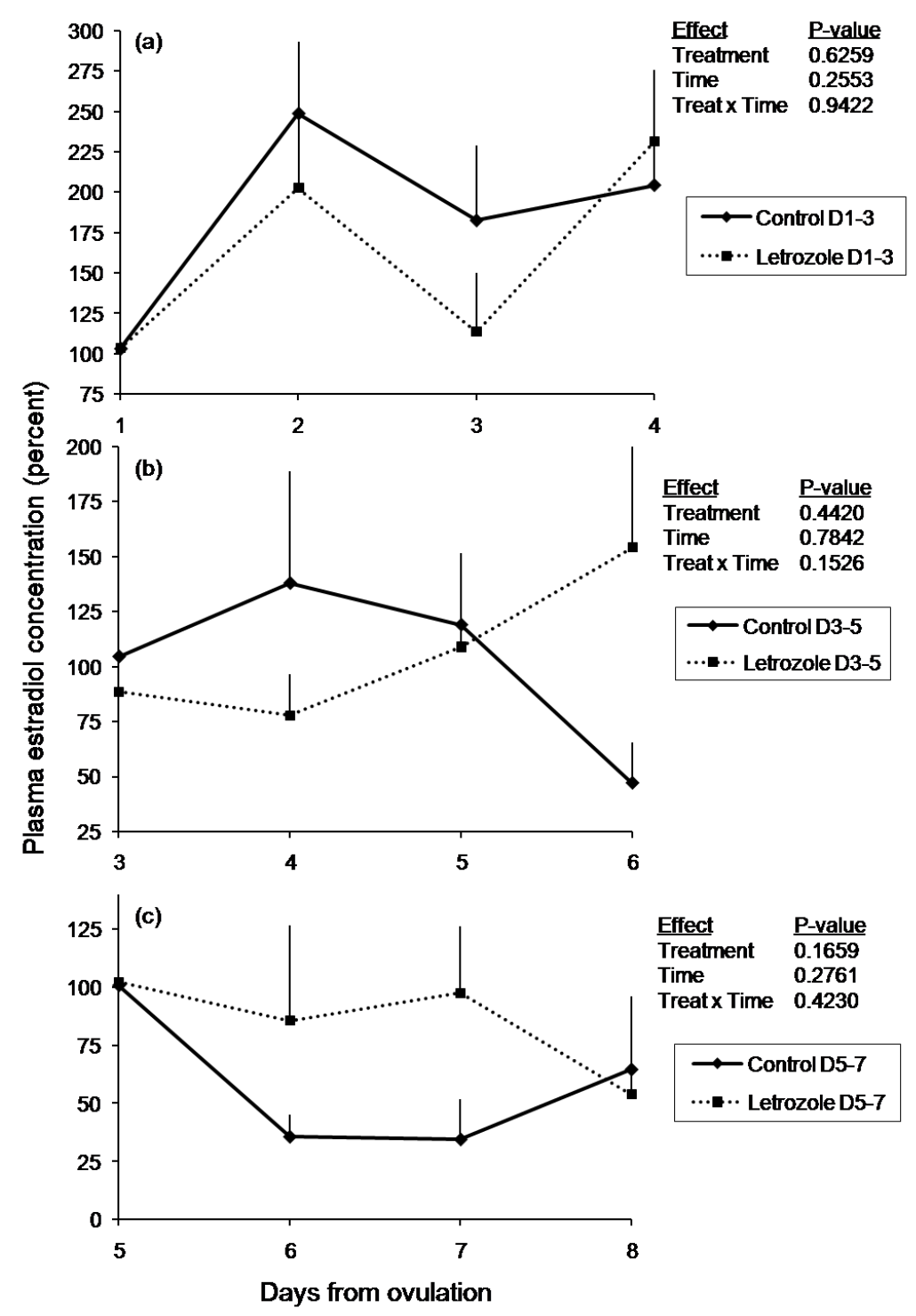

Figure 5.4. Plasma estradiol concentrations, expressed as a percent of the mean of two pretreatment samples (i.e. taken 24 hours before and immediately before treatment; mean \pm SEM); in heifers following daily treatment with letrozole from Days 1 to 3 (a), Days 3 to 5 (b) and Days 5 to 7 (c) of the first follicular wave $(n=4-5$ per group; Day $0=$ ovulation).

\subsubsection{Corpus luteum and plasma progesterone}

No differences in CL diameter were detected among letrozole-treated groups; hence, data for the three treatment groups were combined for comparison with untreated controls. The day-today CL diameter profile of heifers treated with letrozole was larger than that of controls $(\mathrm{P}<0.004$; Fig. 5.5). Plasma progesterone concentrations did not differ among treatment groups, 
and data were combined for comparison with controls (Fig. 5.5). Though numerically higher throughout the sampling period in the letrozole-treated group than in the control group, differences in plasma progesterone concentrations were not significant (Fig. 5.5).
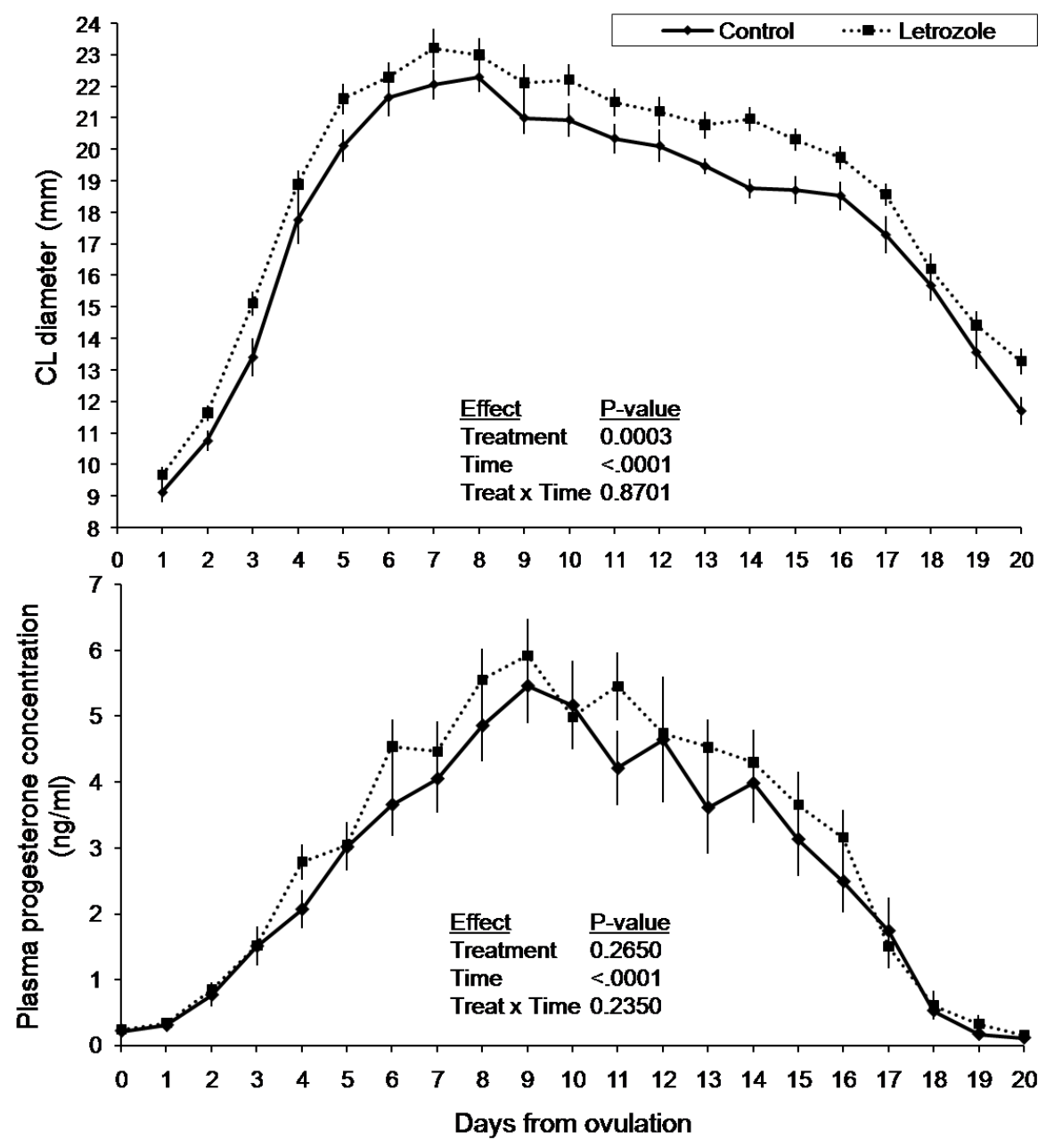

Figure 5.5. Diameter profile of the corpus luteum and plasma progesterone concentration (mean \pm SEM) in heifers treated with letrozole $(85 \mu \mathrm{g} / \mathrm{kg} /$ day for 3 days; data from treatment periods of Days 1 to 3, 3 to 5, and 5 to 7 combined; $n=18)$, compared to untreated controls $(n=17)$.

\subsubsection{Computer-assisted ultrasound image analysis}

Spot analysis of the CL: Mean pixel values and pixel heterogeneity of images of the CL were not affected by letrozole treatment compared to controls. No significant changes in mean 
pixel values or in heterogeneity were detected between pre- and post-treatment periods (Appendix 5).

Spot analysis of the dominant follicle antrum: Although post-treatment values were consistently lower than pre-treatment values in all groups, mean pixel values and heterogeneity were not affected significantly by treatment during any of the three periods of the first follicular wave, nor was there a significant interaction of treatment and time (Appendix 5).

Line analysis of the dominant follicle wall: Mean pixel values recorded in heifers treated with letrozole from Days 1 to 3 after ovulation increased (treatment by time interaction $\mathrm{P}<0.06$ ) between pre- and post-treatment evaluation while it remained unchanged in control heifers. However, significantly lower pre-treatment samples were observed in the letrozole-treated group and that might account for the difference observed between controls and heifers treated from Days 1 to 3 . There was no effect of letrozole on pre- and post-treatment mean pixel values or heterogeneity along the follicular wall in heifers treated on Days 3 and 5, and Days 5 and 7, compared to controls (Appendix 5).

\subsubsection{Gonadotropins}

No differences were detected in plasma FSH levels between letrozole-treated heifers compared with their respective controls (Fig. 5.6). 


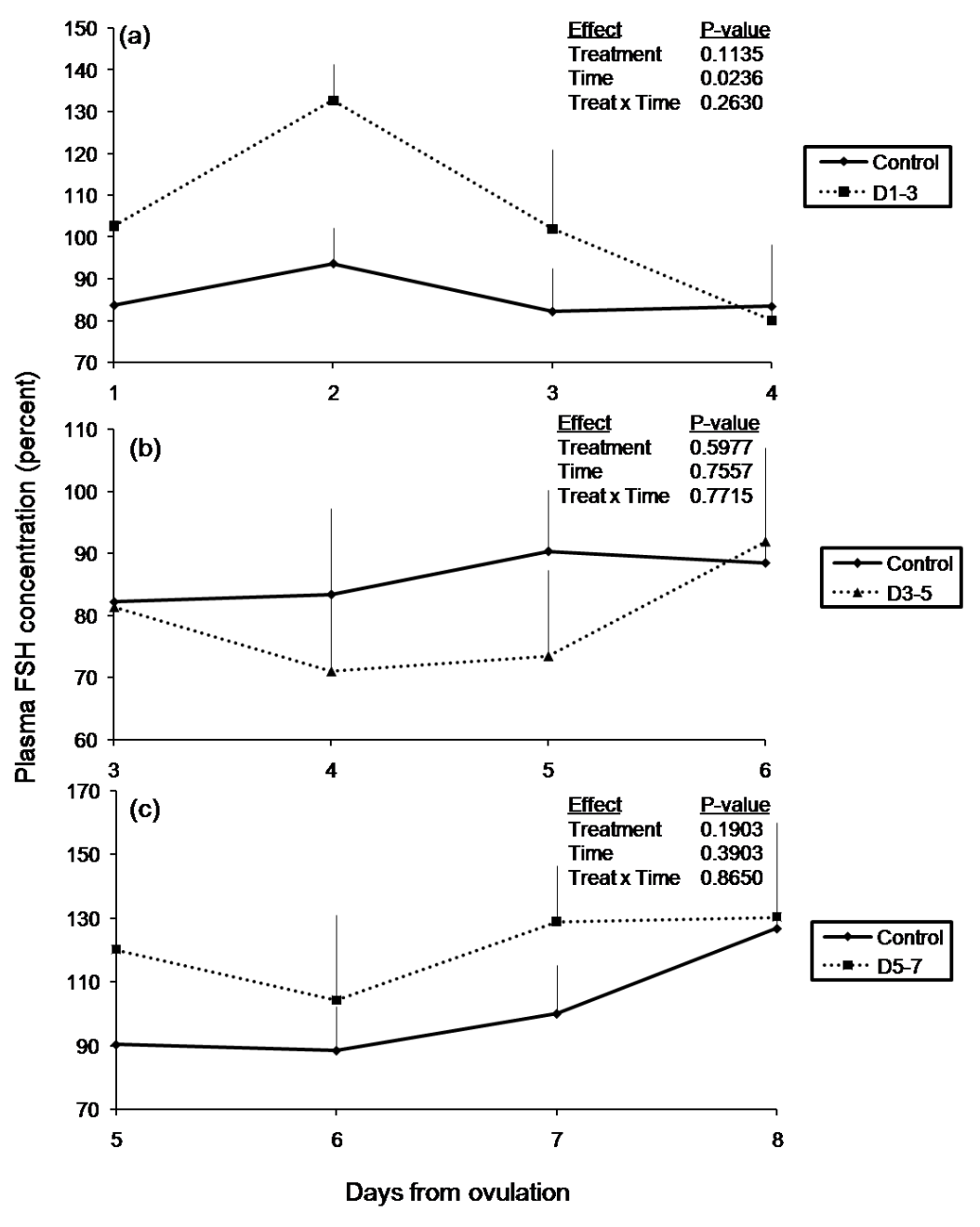

Figure 5.6. Plasma FSH concentration, expressed as a percent of the mean of Days 0 and 1 (mean \pm SEM), in heifers treated with letrozole on Days 1 to $3(n=10)$, Days 3 to $5(n=9)$, or Days 5 to $7(n=9$; Day $0=$ ovulation $)$, compared to untreated controls $(n=17)$.

No differences in plasma LH concentrations were detected among groups using daily samples $(\mathrm{P}=0.78)$. To examine the effects on LH more critically, additional 12-hour samples (i.e., PM samples), originally taken in letrozole-treated heifers for measurement of letrozole, were also analyzed. Since PM samples were not obtained from control animals, the control group was not included in the analysis. Plasma LH concentrations were analyzed to determine the effect of time of sampling (AM vs PM), day $\left(1^{\text {st }}, 2^{\text {nd }}\right.$, and $\left.3^{\text {rd }}\right)$, period ( 3 days of treatment vs 3 
days after treatment), and the follicular stage when treatment was initiated (Days 1 to 3, Days 3 to 5 , or Days 5 to 7). The overall model revealed no significant effect or interaction involving follicular stage; hence, the effect of follicular stage was removed from the model before further analysis (Fig. 5.7). Interactions between day $\left(1^{\text {st }}, 2^{\text {nd }}, 3^{\text {rd }}\right)$ and time (AM vs PM), and between treatment period (during vs after treatment) and time (AM vs PM) were significant. All PM samples collected during treatment were significantly higher $(188.5 \pm 28.50 \%)$ than AM samples collected during treatment $(93.6 \pm 14.85 \%)$ and AM and PM samples collected after cessation of treatment (79.3 \pm 14.64 and $78.9 \pm 27.91 \%$, respectively; Fig. 5.8).

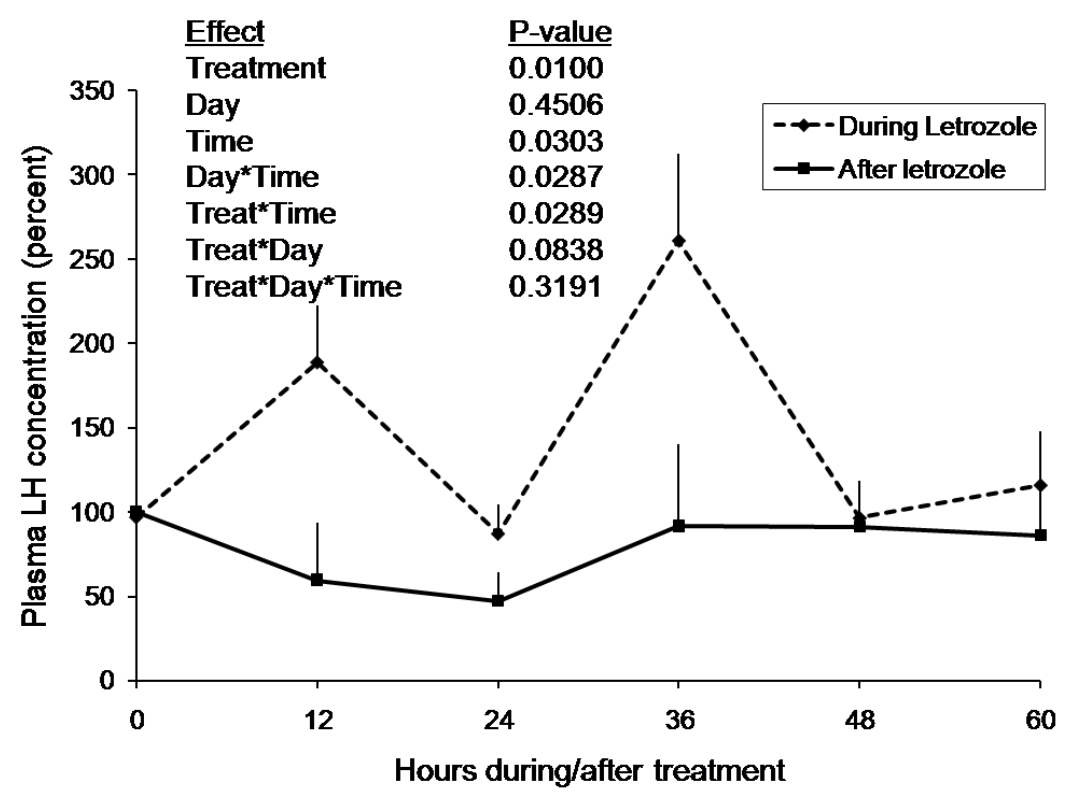

Figure 5.7. Comparison of plasma LH concentrations in heifers for a 60-hour period from the start of treatment and from the end of treatment with letrozole. Values (mean \pm SEM) are expressed as a percent of the mean of Days 0 and 1 in heifers treated with letrozole in the morning (AM) on Days 1 to $3(n=10)$, Days 3 to $5(n=9)$, or Days 5 to $7(n=9$; Day $0=$ ovulation). Data obtained during the 3 days of letrozole treatment and the 3 days after treatment were analyzed for effects of Treatment (during vs after), Time of data collection (AM vs PM), Day $\left(1^{\text {st }}, 2^{\text {nd }}\right.$, and $\left.3^{\text {rd }}\right)$, and their interactions. 


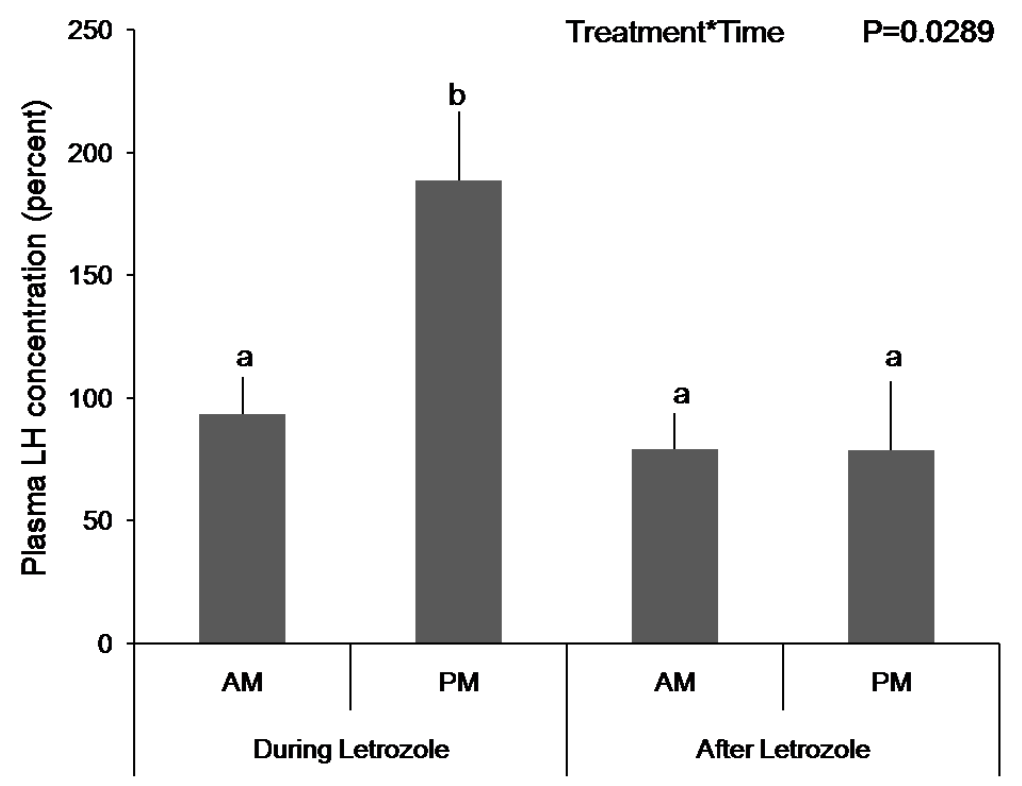

Figure 5.8. Effect of letrozole on plasma LH concentrations (expressed as a percent of the mean of Days 0 and 1 post-ovulation; mean \pm SEM) in heifers treated in the morning for 3 consecutive days (letrozole-groups combined $n=28$ ) during the 3 days of treatment and after the 3 days following treatment.

Plasma LH values determined in samples taken at 15 minute intervals for 8 hours after the second dose of letrozole were compared to their respective controls to determine the effect of treatment on mean and basal concentrations, pulse amplitude, and pulse frequency for each treatment interval (Table 5.2). No differences between letrozole vs controls groups were found for any of the parameters analyzed in any of the treatment periods.

Table 5.2. Effect of 3-day letrozole treatment at three different stages of the follicular wave on LH secretory activity compared to corresponding controls as measured in 15 min samples collected over 8 hours.

\begin{tabular}{|c|c|c|c|c|c|}
\hline $\begin{array}{l}\text { Treatment } \\
\text { period }\end{array}$ & Group & $\begin{array}{c}\text { Mean LH } \\
(\mathrm{ng} / \mathrm{mL})\end{array}$ & $\begin{array}{c}\text { Basal LH } \\
(\mathrm{ng} / \mathrm{mL})\end{array}$ & $\begin{array}{l}\text { LH pulse } \\
\text { amplitude } \\
\text { (ng/mL) }\end{array}$ & $\begin{array}{l}\text { LH pulse } \\
\text { frequency } \\
\text { (pulses/h) }\end{array}$ \\
\hline \multirow{2}{*}{ Days 1-3 } & control & $0.58 \pm 0.12$ & $0.41 \pm 0.09$ & $0.65 \pm 0.20$ & $0.92 \pm 0.04$ \\
\hline & treated & $0.52 \pm 0.15$ & $0.38 \pm 0.11$ & $0.46 \pm 0.15$ & $0.95 \pm 0.08$ \\
\hline \multirow{2}{*}{ Days 3-5 } & control & $0.15 \pm 0.03$ & $0.1 \pm 0.03$ & $0.21 \pm 0.04$ & $0.66 \pm 0.08$ \\
\hline & treated & $0.15 \pm 0.5$ & $0.08 \pm 0.03$ & $0.40 \pm 0.18$ & $0.53 \pm 0.03$ \\
\hline \multirow{2}{*}{ Days 5-7 } & control & $0.15 \pm 0.06$ & $0.09 \pm 0.03$ & $0.45 \pm 0.11$ & $0.41 \pm 0.06$ \\
\hline & treated & $0.21 \pm 0.04$ & $0.13 \pm 0.02$ & 0.88 & $0.41 \pm 0.08$ \\
\hline
\end{tabular}




\subsection{Discussion}

In the present study, a 3-day letrozole treatment of post-pubertal beef heifers at different stages of development of the dominant follicle of the first follicular wave did not consistently decrease circulating estradiol concentrations, nor did it induce a surge in FSH, or hasten emergence of a new follicular wave as was hypothesized. On the contrary, letrozole treatment caused the extant dominant follicle to grow larger and prolonged its period of dominance, extending the interval to emergence of the next follicular wave. In women, treatment with letrozole from Days 3 to 7 after the beginning of menses has been reported to cause emergence of a new wave of follicular development shortly after the initiation of treatment [42]. The mechanism responsible for this effect was hypothesized to involve removal of the negative feedback effect of estradiol on pituitary FSH secretion resulting in an endogenous surge in plasma FSH which recruits a new cohort of growing follicles [41-43]. The reason(s) for these differences between species are not immediately clear.

The dominant follicle diameter profiles reported herein document that $85 \mu \mathrm{g} / \mathrm{kg} / \mathrm{day}$ of letrozole given intravenously in a 3-day regimen $(250 \mu \mathrm{g} / \mathrm{kg}$ total $)$ did not terminate dominant follicle growth, regardless of whether treatment was initiated before, during or after selection of the dominant follicle. Continued growth of the dominant follicle, as well as the CL, was attributed to increased circulating concentrations of LH in letrozole-treated heifers [170]. Results from computerized image analysis supported the notion that dominant follicle viability was not modified by letrozole treatment during any of the treatment stages assessed in the present study.

Another unexpected finding was the continued growth of the largest subordinate follicle in heifers treated with letrozole from Days 1 to 3 after ovulation; it grew larger and for longer 
period of time compared to controls. Although this observation resembled an FSH-dependent superstimulatory effect $[57,78]$, it was not associated with an increase in circulating concentrations of FSH. Perhaps elevated LH was responsible for continued growth of subordinate follicles during treatment on Days 1 to 3 . Growing follicles within a follicular wave are FSH-dependent to approximately 3 days after wave emergence when LH receptors begin to express, leading to a shift in gonadotrophin responsiveness [48, 49, 57, 61, 139]. As this shift to LH responsiveness is not an all-or-nothing phenomenon, as subordinate follicles are capable of assuming dominance [171], it is plausible that growing subordinate follicles become responsive to LH before selection is complete (e.g., Day 2 of the follicular wave) and that elevated LH concentrations induced by letrozole treatment were stimulatory to the growth of the largest subordinate follicle [172].

A treatment-induced-cycle-like pattern of LH secretion was observed in the three letrozoletreated groups; an elevation of LH concentrations occurred by 12 hours after treatment followed by a decline to baseline within 24 hours. Although the understanding of ultradian or circadian variations on LH secretion in cattle and other mammals is contradictory $[166,173,174]$; the fact that evening increases in circulating LH concentrations were present only during letrozole treatment tends to rule out a diurnal-nocturnal variation as a cause for such increases.

The effect of letrozole treatment on mean plasma estradiol concentrations was inconsistent among the three treatment periods assessed in this experiment. Although not significant, it appeared that heifers receiving letrozole from Days 5 to 7 after ovulation had higher plasma estradiol concentrations compared to controls. This third treatment period encompassed the early/late static phase of the dominant follicle, a time when estrogen synthesis might be expected to start declining. However, after treatment with letrozole from Days 5 to 7 post-ovulation, the 
dominant follicle remained viable and produced estradiol for a longer period of time; thus, wave emergence did not occurred, on average, until Day 10.7 post-ovulation (vs Day 7 in control heifers).

Unexpectedly, letrozole concentrations were lower in heifers treated from Days 3 to 5 than those treated from Days 1 to 3, although this observation may be due to differences in real body weight among heifers within each treatment group. The mean circulating concentrations of letrozole 96 hours after $250 \mu \mathrm{g} / \mathrm{kg}$ given in a 3-day regimen or as a single dose were similar $(51.6 \pm 4.33 \mathrm{ng} / \mathrm{mL}$ vs $43.7 \pm 8.79 \mathrm{ng} / \mathrm{mL}$, respectively). However, during the first 96 hours after initiation of treatment, the mean circulating levels of letrozole in the 3-day protocol were lower compared to those of heifers given the same dose in a single application $(60.8 \pm 3.36$ vs $112 \pm 16.26 \mathrm{ng} / \mathrm{ml})$. It could be speculated that the single injection of letrozole at a dose of 250 $\mu \mathrm{g} / \mathrm{kg}$ was marginal in suppressing estradiol production, while splitting this dose into three daily injections resulted in sub-thresh-hold doses that failed to inhibit estradiol production in this study.

In summary, $250 \mu \mathrm{g} / \mathrm{kg}$ of letrozole, given in a 3-day regimen, elevated $\mathrm{LH}$ secretion resulting in larger dominant follicle and CL profiles and prolonged interwave intervals, regardless the stage of follicular development during which treatment was applied. Follicle stimulating hormone levels in plasma were not affected by letrozole administration during any of the treatment periods. We speculate that the inconsistent and minimal inhibition of estradiol production accounts for the lack of effect on FSH secretion. Based on the circulating concentrations of letrozole achieved in this study, it could be concluded that a total dose of 250 $\mu \mathrm{g} / \mathrm{kg}$ of letrozole divided into three doses of $85 \mu \mathrm{g} / \mathrm{kg}$ is insufficient to consistently inhibit aromatase activity and estradiol secretion. Thus, the results continue to support the notion that 
higher levels of letrozole may be needed to achieve a consistent and durable inhibition of estradiol production necessary to predictably affect gonadotropin secretion and follicular dynamics in cattle.

Acknowledgements: We thank Jonathan Naile and Dr Al Chicoine for their help in obtaining and interpreting, respectively, plasma letrozole concentrations. We are thankful to Eric Higley and Dr Hong Chang from the Toxicology Center at the University of Saskatchewan for their help in the determination of estradiol concentrations. We also thank Brad Blackmore and the staff at Goodale Research Farm for assistance with handling and managing the cattle, and our summer students Cody Creelman, Rand Davis and Druvtej Ambati for help with data collection. The authors are thankful to the Natural Sciences and Engineering Research Council of Canada and Bioniche Animal Health Inc. for financial support. 


\section{GENERAL DISCUSSION}

Letrozole is a non-steroidal aromatase inhibitor that has been used for treatment of hormonedependent breast cancer in women [120]. When administered to premenopausal women, letrozole has been reported to have a stimulatory effect on ovarian function, and has been used for the purpose of follicular stimulation and induction of ovulation [41] and ovarian superstimulation [46, 47]. We hypothesized that letrozole could be used to manipulate and synchronize ovarian follicular wave dynamics in cattle.

Two experiments were conducted to determine the effects of letrozole treatment on endocrine function and follicular dynamics in cattle. We examined: 1) the effects of three doses of letrozole administered as a single intravenous injection on follicular dynamics, gonadotropin release and estradiol production (Chapter 4); and, 2) the effect of a 3-day regimen of letrozole on follicular and luteal dynamics, gonadotropin release, and estradiol and progesterone production when given before, during or after dominant follicular selection (Chapter 5).

The objective of this section is to summarize and integrate the results obtained from the experiments presented in Chapters 4 and 5 of this thesis to current information available in the literature. Although most of the studies in which letrozole has been used as a fertility therapy have been conducted in women, the validated bovine model allows for the comparison of results reported in this thesis with those reported in humans $[136,140]$. However, the limitations of these comparisons will be acknowledged when pertinent.

In women, it has been proposed that letrozole treatment interrupts dominant follicle maturation and by eliminating the negative feedback effects of estradiol on the pituitary gland, induces a surge in circulating FSH concentrations resulting in the emergence of a wave of follicular growth $[41-43,150]$. However, there does not appear to be any scientific reports where 
such effects on follicular dynamics in women were critically determined. The studies included in this thesis failed to show that a single treatment of letrozole on Day 3 post-wave emergence (Chapter 4), or a 3-day-regimen of letrozole given before, during or after dominant follicle selection (Chapter 5) would induce the regression of the dominant follicle and the emergence of a new follicular wave. Conversely, letrozole treatments in both studies effectively lengthened the period of dominance of the extant dominant follicle and resulted in a prolonged interval to emergence of the next follicular wave. Further, the mean diameters achieved by the extant dominant follicle and CL were significantly larger in letrozole-treated heifers.

Contrary to our hypothesis, none of the letrozole-treated groups examined in Chapters 4 and 5 had significantly increased circulating concentrations of FSH compared to controls. This observation explained the failure to induce a wave of follicular development after letrozole treatment. Studies conducted in rats [151] and bonnet monkeys [175] provided evidences to support the notion that letrozole treatment would increase FSH levels. Despite clinical impressions to the contrary, no such results have been documented in women. Cortinez et al. [45] found no effect of a 5-day letrozole treatment protocol from Days 3 to 7 after onset of menses on FSH levels compared to control cycles, and Fisher et al. [131] found no effect of a 5-day regimen of letrozole from Days 5 to 9 after onset of menses. Our observations suggest that letrozole treatment does not have an effect on pituitary FSH secretion in cattle at the doses evaluated in the two trials included in this thesis. The immediate reasons for the unchanged FSH levels are not remain poorly elucidated. Although estradiol production may have been at least marginally affected by letrozole treatment given once (Chapter 4) or in a 3-day regimen (Chapter 5), follicle growth continued. In addition, rather that regressing, the dominant follicle had an extended lifespan. Thus, the suppressive effect of inhibin and other follicular products that would be produced 
by the persistent follicle may account for the unchanged FSH levels reported herein [115, 155, $168,176-178]$.

It must be accepted that the lack of a marked suppressive effect of letrozole on estrogen concentrations in cattle in the studies reported in this thesis may have been due to an inadequate dosage. To our knowledge, there are no published data comparing different doses or regimens of letrozole treatment for ovarian stimulation in cattle. The medium dose $(250 \mu \mathrm{g} / \mathrm{kg})$ of letrozole used in Chapter 4 was determined by calculations based on a study conducted in women in which a single dose of $20 \mathrm{mg}$ of letrozole seemed to be comparable to a 5-day regimen of letrozole for ovarian stimulation [130]. We calculated that the amount of letrozole administered to a woman weighting, on average, $75 \mathrm{~kg}$ was about $250 \mu \mathrm{g} / \mathrm{kg}$; we determined the high and low doses as twice and a half of the medium dose, respectively, using this study as reference. We speculated that $250 \mu \mathrm{g} / \mathrm{kg}$ of letrozole divided in a 3-day regimen (Chapter 5) should be able to induce the hypothesized changes on ovarian function. In Chapter 4, mean plasma estradiol concentrations in letrozole-treated heifers tended to be higher than in controls for the first 4 days after treatment, although plasma estradiol concentrations decreased by nearly $50 \%$ by 24 hours after a single treatment with letrozole. This result was attributed to a significant and sharp elevation in circulating estradiol concentrations 12 hours after letrozole administration. The increase in estradiol synthesis may have been caused by increased LH secretion induced by the initial decrease in estradiol concentrations following letrozole treatment. The rebound in estradiol production may also have been triggered by substrate accumulation (androgens) after letrozole-induced aromatase inhibition.

The inconsistent effect of letrozole treatment on estradiol production may have been responsible for the unchanged FSH concentrations observed in both trials. Additionally, 
treatment with letrozole during Days 1 to 3 after ovulation (Chapter 5) resulted in the synchronous development of two follicles (dominant follicle plus largest subordinate) for the duration of treatment, both of which may have been actively secreting estrogens. Thus, the amount of estradiol secreted "per follicle" in this treatment group may have been reduced by letrozole administration, however the total amount measured in plasma did not differ due to the additive effect of both follicles.

Letrozole treatment reduced estrogen levels by $90 \%$ at 24 hours and levels remained low for at least 168 hours post-treatment when given to boars at a dose of $0.1 \mathrm{mg} / \mathrm{kg}$ body weight [152]. Rats treated with 0.5 to $5 \mathrm{mg} / \mathrm{kg} /$ day of letrozole had an $80 \%$ reduction in ovarian tissue estradiol levels compared to untreated controls [151]. In humans, estrogen suppression was 97 to $99 \%$ in post-menopausal women $[114,120]$, and $30 \%$ and $90 \%$, respectively, with the lowest $(0.02 \mathrm{mg})$ and the highest $(30 \mathrm{mg}$ ) dose of letrozole tested in healthy male volunteers [109]. It is important to highlight, however, that levels of inhibition of about $50 \%$ were reported in premenopausal bonnet monkeys treated with $3.5 \mathrm{mg}$ of letrozole over 7 days (from Days 7 to 14 of the menstrual cycle) [175] and in premenopausal women treated with $5 \mathrm{mg} /$ day of letrozole from Days 3 to 7 of the menstrual cycle [45]. Collectively, it appears that estradiol inhibition by letrozole treatment is more profound in males (boars and men) and in post-menopausal women than in premenopausal women and non-human primates. It is recognized that differences in doses and regimens of administration of letrozole, as well as methods used for determination of estradiol levels in plasma, serum or ovarian tissue must be taken into consideration in the interpretation of these results. It is also recognized that the inherently low estradiol concentration in non-pregnant cattle and the sensitivity of the estradiol assay used in these experiments may have made it difficult to demonstrate an effect of letrozole treatment in the experiments reported herein. However, these 
results also lead one to the conclusion that higher levels of letrozole are needed to effectively suppress estradiol production in cattle, especially with the greater amount of estradiol produced by the ovaries of cyclic cattle.

The continued growth of the dominant follicle (Chapter 4 and 5) and enhanced development of the CL (Chapter 5) following letrozole treatment were probably the result of the higher plasma LH concentrations observed in letrozole-treated animals [15, 18]. It has been shown that increased LH pulse frequency can maintain and extend follicular dominance, delaying the emergence of a new wave of follicular development. The results of several studies have led to the conclusion that LH levels are suppressed by luteal concentrations of progesterone $[15,18]$ in conjunction with the feedback effect of estradiol on gonadotrophin secretion during progesterone influence [13]. Hence, if letrozole treatment did reduce estradiol production in the present studies, the pituitary secretion of LH may have been released from the negative feedback effect of estradiol and been responsible for the increased plasma LH concentrations we observed. Our results are in agreement with the study by Cortinez et al. in which a larger follicular size in letrozole-treated women was also attributed to the higher levels of LH found in circulation [45]. Similar effects of prolonged dominance have been observed in postpartum beef cows following exogenous pulsatile administration of LH [179]. An interesting observation was that despite prolonged dominance in letrozole-treated animals, there was no difference in the interovulatory interval between letrozole-treated and control heifers during the 3-day treatment regimen (Chapter 5). We therefore speculate that the increased LH concentrations following letrozole treatment occurred too early in the luteal phase (last letrozole treatment was given on Day 7 postovulation) to affect the life-span of the CL. Letrozole treatment later in the luteal phase may very 
well delay luteolysis by maintaining higher circulating levels of LH, thereby lengthening the interovulatory interval.

The elevated levels of LH reported in letrozole-treated animals may also have also been responsible for the sustained growth of the second largest follicle in heifers treated with letrozole from Days 1 to 3 post-ovulation (Chapter 5). Although this observation resembled an FSHdependent superstimulatory effect $[57,78]$, it was not associated with an increase in circulating concentrations of FSH. Growing follicles are FSH-dependent until approximately 3 days after wave emergence when $\mathrm{LH}$ receptors begin to express $[48,49,57,61,139]$. As the shift to LH responsiveness is not an all-or-none phenomenon (subordinate follicles are capable of assuming dominance [171]), it is plausible that growing subordinate follicles become responsive to LH before selection is complete (e.g., Day 2 of the follicular wave). Therefore, elevated LH concentrations resulting from letrozole treatment may have been stimulatory to the growth of the largest subordinate follicle [172]. This same mechanism may be responsible for the growth of more than one dominant follicle observed in women undergoing letrozole ovarian superstimulation [45-47]. The same results (more than one pre-ovulatory sized follicle) potentially could be achieved in cattle by extending the period of letrozole treatment. However, it is unclear whether the stimulatory effects of LH on follicular maturation involve increased estradiol production or if $\mathrm{LH}$ is able to directly stimulate mitosis and differentiation of granulosa and thecal cells without steroid hormones as mediators.

The pharmacokinetic study of plasma from heifers treated intravenously with a single dose of 125,250 or $500 \mu \mathrm{g} / \mathrm{kg}$ of letrozole resulted in circulating concentrations of letrozole that differed from that reported in humans. Letrozole seemed to have a shorter half-life in heifers than in humans (on average, 27 vs 48 hours) and the mean residence time (MRT) value (representing 
the average duration of persistence of the drug in the body) was almost half that reported in humans (33.7 hours in heifers vs 58.7 hours in women [111]). The volume of distribution observed in the heifers $(635 \mathrm{~mL} / \mathrm{kg})$ was also lower than that reported in women $(1870 \mathrm{~mL} / \mathrm{kg})$ [111]. Collectively, these data may be interpreted to mean that letrozole appears to be more rapidly cleared from circulation in cattle than in humans. Thus, higher or more frequent doses of letrozole may be needed to achieve effective circulating levels in cattle as compared to women. The method for measurement of letrozole in plasma in these studies was not completely validated; therefore, the pharmacokinetic parameters must be interpreted with caution. Further pharmacologic determinations need to be performed to confirm these findings.

Determining the minimal effective dose of letrozole that results in consistent inhibition of estradiol production in cattle is essential to explore the endocrine and paracrine mechanisms affected by estrogen deprivation. The hypothesis proposed to explain the effects of letrozole treatment on FSH secretion and ovarian function in humans was not supported, but quite unexpectedly, an effect on LH secretion was observed. Ovarian function was affected by letrozole treatment and it is now important to investigate the various endocrine inter-relationship that are involved and how this unexpected finding might be used for the expressed purpose of controlling ovarian function. Aromatase inhibitors represent a potentially safe, steroid-free method to control ovarian function in cattle. The observed effects should be confirmed and pursued, and the putative mechanisms of action of letrozole on follicular dynamics in women may need to be reconsidered.

We propose a new mechanism of action of the aromatase inhibitor letrozole on ovarian stimulation in cattle in which estradiol inhibition affects $\mathrm{LH}$ secretion without altering FSH release. The increased LH concentrations resulting from letrozole treatment caused continued 
growth of the extant dominant follicle, which could result in improved ovulatory response after hCG or GnRH treatment. Furthermore, increased LH levels apparently stimulated the development of subordinate follicles to a state of maturation in which they may have gained responsiveness to an LH pre-ovulatory surge, potentially leading to multiple ovulations. 


\section{GENERAL CONCLUSIONS}

The results of the experiments included in this thesis and the related literature have led to the conclusion that the general hypothesis that letrozole treatment would terminate growth of dominant follicle by suppressing estradiol production, followed by a surge in FSH secretion and the emergence of a new wave of follicular development was not supported. However, results are supportive of an alternative hypothesis relating to the control of ovarian function through increased LH secretion following letrozole treatment.

The specific conclusions of this thesis are:

1) Chapter 4: Effects of letrozole on ovarian function in cattle

a. Letrozole given once intravenously at a dose of 125,250 or $500 \mu \mathrm{g} / \mathrm{kg}$ on Day 4 post-follicular ablation in postpubertal beef heifers is not able to significantly reduce plasma estradiol concentrations.

b. Letrozole given once intravenously at a dose of 125,250 or $500 \mu \mathrm{g} / \mathrm{kg}$ on Day 4 post-follicular ablation in postpubertal beef heifers is not able to significantly reduce dominant follicle growth.

c. Letrozole given once intravenously at a dose of 125,250 or $500 \mu \mathrm{g} / \mathrm{kg}$ on Day 4 post-follicular ablation in postpubertal beef heifers does not induce a surge on FSH secretion, but significantly increases circulating LH levels.

d. Higher circulating levels of LH observed following the intravenous administration of letrozole at a dose of 125,250 or $500 \mu \mathrm{g} / \mathrm{kg}$ in heifers on Day 4 post-follicular ablation can stimulate continued growth of the extant dominant follicle and prolong the interwave interval. 
e. Based on the apparent 20 hours shorter half-life of letrozole in the circulation of heifers compared to humans, a more prolonged treatment (i.e., multiple doses) may be necessary to effectively suppress estradiol production in cattle.

2) Chapter 5: Effect of a 3-day regimen of letrozole on ovarian function in cattle

a. A dose of $250 \mu \mathrm{g} / \mathrm{kg}$ of letrozole given in a 3-day regimen $(85 \mu \mathrm{g} / \mathrm{kg} / \mathrm{day})$ to postpubertal beef heifers does not significantly reduce estrogen production.

b. Letrozole given in a 3-day regimen of $85 \mu \mathrm{g} / \mathrm{kg} / \mathrm{day}$ to postpubertal beef heifers does not terminate growth of the extant dominant follicle regardless of the stage of follicular development at the time of initiation of treatment.

c. Letrozole given in a 3-day regimen of $85 \mu \mathrm{g} / \mathrm{kg} /$ day to postpubertal beef heifers, regardless the stage of follicular development at the time of initiation of treatment does not directly affect FSH secretion, but significantly increases circulating LH levels.

d. Higher circulating levels of LH observed in heifers after a 3-day regimen of 85 $\mu \mathrm{g} / \mathrm{kg} / \mathrm{day}$ of letrozole result in a larger mean dominant follicle and CL diameters and the prolonged interwave intervals.

e. Data suggest that it may be possible to induce ovarian superstimulation by continuing treatment with letrozole to maintain the growth of the dominant and larger subordinate follicles. 


\section{FUTURE STUDIES}

Based on observations made in this thesis, I propose that the following research questions need to be addressed:

- Would a higher dose of letrozole (i.e., $1 \mathrm{mg} / \mathrm{kg}$ ) be more efficacious in reducing circulating levels of estradiol?

- Are the pharmacokinetic parameters of letrozole reported herein accurate? Can the vehicle or route of administration significantly alter those pharmacokinetic parameters?

- If estradiol production is effectively inhibited, would that cause increased FSH secretion?

- Which non-steroidal follicular factors, if any, are preventing the increase in FSH secretion before and after follicular selection?

- Can a long-term treatment with letrozole stimulate the growth of subordinate follicles to ovulatory size? Can these subordinate follicles be induced to ovulate?

- Can letrozole treatment prevent the pre-ovulatory estradiol surge? Could this be used in women as emergency contraception treatment?

- Is estradiol required for the normal growth and maturation of the dominant follicle?

- Does the inhibition of estradiol affect oocyte competence?

- How can letrozole be used for the synchronization of ovarian function in cattle?

- Is bovine model an effective method to study the effects of letrozole on ovarian function in humans?

- Can the effects of letrozole on LH secretion be used to manipulate ovarian function in cattle, or humans? 


\section{BIBLIOGRAPHY}

1. Savio JD, Keenan L, Boland MP, Roche JF. Pattern of growth of dominant follicles during the oestrous cycle of heifers. J Reprod Fertil 1988; 83: 663-671.

2. Rajakoski E. The ovarian follicular system in sexually mature heifers with special reference to seasonal, cyclical and left-right variations. Acta Endocrinol (Copenh) 1960; 52: $1-68$.

3. Adams GP, Matteri RL, Kastelic JP, Ko JCH, Ginther OJ. Association between surges of follicle-stimulating hormone and the emergence of follicular waves in heifers. J Reprod Fertil 1992; 94: 177-188.

4. Ginther OJ, Bergfelt DR, Kulick LJ, Kot K. Pulsatility of systemic FSH and LH concentrations during follicular-wave development in cattle. Theriogenology 1998; 50: 507-519.

5. Kulick LJ, Kot K, Wiltbank MC, Ginther OJ. Follicular and hormonal dynamics during the first follicular wave in heifers. Theriogenology 1999; 52: 913-921.

6. Colazo MG, Kastelic JP, Davis H, Rutledge MD, Martinez MF, Small JA, Mapletoft RJ. Effects of plasma progesterone concentrations on LH release and ovulation in beef cattle given GnRH. Domest Anim Endocrinol 2008; 34: 109-117.

7. Ginther OJ, Bergfelt DR, Kulick LJ, Kot K. Selection of the Dominant Follicle in Cattle: Role of Estradiol1. Biol Reprod 2000; 63: 383-389.

8. Bo GA, Adams GP, Caccia M, Martinez M, Pierson RA, Mapletoft RJ. Ovarian follicular wave emergence after treatment with progestogen and estradiol in cattle. Animal Reproduction Science 1995; 39: 193-204.

9. Bo GA, Adams GP, Pierson RA, Mapletoft RJ. Exogenous control of follicular wave emergence in cattle. Theriogenology 1995; 43: 31-40.

10. Bo GA, Bergfelt DR, Brogliatti GM, Pierson RA, Adams GP, Mapletoft RJ. Local versus systemic effects of exogenous estradiol-17[beta] on ovarian follicular dynamics in heifers with progestogen implants. Anim Reprod Sci 2000; 59: 141-157.

11. Ginther OJ, Bergfelt DR, Kulick LJ, Kot K. Selection of the dominant follicle in cattle: Role of estradiol. Biol Reprod 2000; 63: 383-389.

12. Rawlings NC, Jeffcoate IA, Rieger DL. The influence of estradiol-17[beta] and progesterone on peripheral serum concentrations of luteinizing hormone and follicle stimulating hormone in the ovariectomized ewe. Theriogenology 1984; 22: 473-488.

13. Price CA, Webb R. Steroid control of gonadotropin secretion and ovarian function in heifers [published erratum appears in Endocrinology 1989 Feb;124(2):604]. Endocrinology 1988; 122: 2222-2231.

14. Ireland JJ, Roche JF. Effect of progesterone on basal LH and episodic LH and FSH secretion in heifers. J Reprod Fertil 1982; 64: 295-302.

15. Adams GP, Matteri RL, Ginther OJ. Effect of progesterone on ovarian follicles, emergence of follicular waves and circulating follicle-stimulating hormone in heifers. $\mathbf{J}$ Reprod Fertil 1992; 96: 627-640.

16. Savio JD, Thatcher WW, Badinga L, de la Sota RL, Wolfenson D. Regulation of dominant follicle turnover during the oestrous cycle in cows. J Reprod Fertil 1993; 97: 197-203. 
17. Savio JD, Thatcher WW, Morris GR, Entwistle K, Drost M, Mattiacci MR. Effects of induction of low plasma progesterone concentrations with a progesterone-releasing intravaginal device on follicular turnover and fertility in cattle. J Reprod Fertil 1993; 98: 77-84.

18. Stock AE, Fortune JE. Ovarian follicular dominance in cattle: relationship between prolonged growth of the ovulatory follicle and endocrine parameters. Endocrinology 1993; 132: 1108-1114.

19. Sanchez T, Wehrman ME, Kojima FN, Cupp AS, Bergfeld EG, Peters KE, Mariscal V, Kittok RJ, Kinder JE. Dosage of the synthetic progestin, norgestomet, influences luteinizing hormone pulse frequency and endogenous secretion of 17 beta-estradiol in heifers. Biol Reprod 1995; 52: 464-469.

20. Adams GP. Control of ovarian follicular wave dynamics in cattle: Implications for synchronization \& superstimulation. Theriogenology 1994; 41: 19-24.

21. Bo GA, Adams GP, Caccia M, Martinez M, Pierson RA, Mapletoft RJ. Ovarian follicular wave emergence after treatment with progestogen and estradiol in cattle. Anim Reprod Sci 1995; 39: 193-204.

22. Bridges PJ, Lewis PE, Wagner WR, Inskeep EK. Follicular growth, estrus and pregnancy after fixed-time insemination in beef cows treated with intravaginal progesterone inserts and estradiol benzoate. Theriogenology 1999; 52: 573-583.

23. Martinez MF, Adams GP, Kastelic JP, Bergfelt DR, Mapletoft RJ. Induction of follicular wave emergence for estrus synchronization and artificial insemination in heifers. Theriogenology 2000; 54: 757-769.

24. Mapletoft RJ, Martinez MF, Colazo MG, Kastelic JP. The use of controlled internal drug release devices for the regulation of bovine reproduction. J Anim Sci 2003; 81: E28-36.

25. Berne R, Levy M, Koeppen B, Stanton B. Physiology. St. Louis, Missouri: Mosby; 1998.

26. Preston RL. Hormone containing growth promoting implants in farmed livestock. Adv Drug Deliv Rev 1999; 38: 123-138.

27. Heinrich H. D M. Biochemistry and physiology of anabolic hormones used for improvement of meat production. APMIS 2001; 109: 1-8.

28. Lee CY, Henricks DM, Skelley GC, Grimes LW. Growth and hormonal response of intact and castrate male cattle to trenbolone acetate and estradiol. J Anim Sci 1990; 68: 2682-2689.

29. Fritsche S, Steinhart H. Occurrence of hormonally active compounds in food: a review. Eur Food Res Technol 1999; 209: 153-179.

30. Daxenberger A, Ibarreta D, Meyer HHD. Possible health impact of animal oestrogens in food. Hum Reprod Update 2001; 7: 340-355.

31. Andersson A, Skakkebaek N. Exposure to exogenous estrogens in food: possible impact on human development and health. Eur J Endocrinol 1999; 140: 477-485.

32. Umberger EJ. Products marketed to promote growth in food-producing animals: Steroid and hormone products. Toxicology 1975; 3: 3-21.

33. US Department of Agriculture. Foreign Agricultural Service 2003. Historic overview and chronology of EU's hormone ban. GAIN Report E23206. Available from http://www.fas.usda.gov/scriptsw/attacherep/gain_display_report.asp?Rep_ID=14598677 $\underline{3}$ 
34. Official Journal of the European Union. L 262, 14/10/2003. Directive 2003/74/EC of the European Parliament and of the Council on 22 September 2003 amending Council Directive 96/22/EC concerning the prohibition on the use in stockfarming of certain substances having a hormonal or thyristatic action and of beta-agonist. pp. 17-21. Brussels, Belgium, 2003.

35. Lane EA, Austin EJ, Crowe MA. Oestrous synchronisation in cattle--Current options following the EU regulations restricting use of oestrogenic compounds in food-producing animals: A review. Animal Reproduction Science 2008; 109: 1-16.

36. US Food and Drug Administration. 2002. The use of steroid hormones for growth promotion in food-producing animals. Center for Veterinary Medicine. Accesed January 25th, 2009. Available from http://www.fda.gov/cvm/hormones.htm

37. Health Canada. Drugs and Health Products. Veterinary Products. Questions and answer: Hormonal growth promoters. Accessed 25th January, 2009. Available from http://www.hc-sc.gc.ca/dhp$\mathrm{mps} / \mathrm{vet} / \mathrm{faq} / \mathrm{growth}$ hormones_promoters_croissance hormonaux_stimulateurs-eng.php

38. Gibbs JN. Is veterinary compounding illegal under federal law? IJPC 2004; 8: 449-451.

39. US Food and Drug Administration. 2003. Compliance Policy Guides Manual, Sec. 608.400. Compounding of drugs for use in animals. Department of Health and Human Services. Available from http://www.fda.gov/ora/compliance_ref/cpg/cpgvet/cpg608400compounding.pdf

40. Novartis. 2006. Femara®, Product Monograph. Available from http://www.femarainfo.com/pdf/femara_global_monograph.pdf

41. Requena A, Herrero J, Landeras J, Navarro E, Neyro JL, Salvador C, Tur R, Callejo J, Checa MA, Farre M, Espinos JJ, Fabregues F, Grana-Barcia M. Use of letrozole in assisted reproduction: A systematic review and meta-analysis. Hum Reprod Update 2008; 14: 571-582.

42. Mitwally MF, Casper RF. Aromatase inhibition for ovarian stimulation: future avenues for infertility management. Curr Opin Obstet Gynecol 2002; 14: 255-263.

43. Mitwally MF, Casper RF. Use of aromatase inhibitor for induction of ovulation in patients with an inadequate response to clomiphene citrate. Fertil Steril 2001; 75: 305309.

44. Mitwally MFM, Casper RF. Aromatase inhibition reduces the dose of gonadotropin required for controlled ovarian hyperstimulation. J Soc Gynecol Investig 2004; 11: 406415.

45. Cortínez A, De Carvalho I, Vantman D, Gabler F, Iñiguez G, Vega M. Hormonal profile and endometrial morphology in letrozole-controlled ovarian hyperstimulation in ovulatory infertile patients. Fertil Steril 2005; 83: 110-115.

46. Al-Fadhli R, Sylvestre C, Buckett W, Tan SL, Tulandi T. A randomized trial of superovulation with two different doses of letrozole. Fertil Steril 2006; 85: 161-164.

47. Mitwally MF, Said T, Galal A, Chan S, Cohen M, Casper RF, Magarelli PC. Letrozole step-up protocol: A successful superovulation protocol. Fertil Steril 2008; 89: S23-S24.

48. Ginther OJ, Kot K, Kulick LJ, Wiltbank MC. Emergence and deviation of follicles during the development of follicular waves in cattle. Theriogenology 1997; 48: 75-87.

49. Ginther OJ, Beg MA, Bergfelt DR, Donadeu FX, Kot K. Follicle selection in monovular species. Biol Reprod 2001; 65: 639-647. 
50. Lucy MC, Savio JD, Badinga L, De La Sota RL, Thatcher WW. Factors that affect ovarian follicular dynamics in cattle. J Anim Sci 1992; 70: 3615-3626.

51. Sirois J, Fortune JE. Ovarian follicular dynamics during the estrous cycle in heifers monitored by real-time ultrasonography. Biol Reprod 1988; 39: 308-317.

52. Ginther OJ, Kastelic JP, Knopf L. Composition and characteristics of follicular waves during the bovine estrous cycle. Anim Reprod Sci 1989; 20: 187-200.

53. Mihm M, Crowe MA, Knight PG, Austin EJ. Follicle wave growth in cattle. Reprod Domest Anim 2002; 37: 191-200.

54. Knopf L, Kastelic JP, Schallenberger E, Ginther OJ. Ovarian follicular dynamics in heifers: Test of two-wave hypothesis by ultrasonically monitoring individual follicles. Domest Anim Endocrinol 1989; 6: 111-119.

55. Noseir W. Ovarian follicular activity and hormonal profile during estrous cycle in cows: the development of 2 versus 3 waves. Reprod Biol Endocrinol 2003; 1: 50.

56. Ginther OJ, Knopf L, Kastelic JP. Temporal associations among ovarian events in cattle during oestrous cycles with two and three follicular waves. J Reprod Fertil 1989; 87: 223230.

57. Adams P, Kot K, Smith C, Ginther O. Selection of a dominant follicle and suppression of follicular growth in heifers. Anim Reprod Sci 1993; 30: 259-271.

58. Fortune JE, Rivera GM, Evans ACO, Turzillo AM. Differentiation of dominant versus subordinate follicles in cattle. Biol Reprod 2001; 65: 648-654.

59. Ginther OJ, Bergfelt DR, Kulick LJ, Kot K. Selection of the dominant follicle in cattle: establishment of follicle deviation in less than 8 hours through depression of fsh concentrations. Theriogenology 1999; 52: 1079-1093.

60. Beg MA, Bergfelt DR, Kot K, Ginther OJ. Follicle selection in cattle: Dynamics of follicular fluid factors during development of follicle dominance. Biol Reprod 2002; 66: 120-126.

61. Ginther OJ, Bergfelt DR, Beg MA, Kot K. Follicle Selection in Cattle: Role of Luteinizing Hormone1. Biol Reprod 2001; 64: 197-205.

62. Ginther OJ, Beg MA, Kot K, Meira C, Bergfelt DR. Associated and Independent Comparisons Between the Two Largest Follicles Preceding Follicle Deviation in Cattle1. Biol Reprod 2003; 68: 524-529.

63. Bergfelt DR, Smith CA, Adams GP, Ginther OJ. Surges of FSH during the follicular and early luteal phases of the estrous cycle in heifers. Theriogenology 1997; 48: 757-768.

64. Taft R, Ahmad N, Inskeep EK. Exogenous pulses of luteinizing hormone cause persistence of the largest bovine ovarian follicle. J. Anim Sci. 1996; 74: 2985-2991.

65. Lauderdale JW, Seguin BE, Stellflug JN, Chenault JR, Thatcher WW, Vincent CK, Loyancano AF. Fertility of cattle following PGF2 \{alpha\} injection. J Anim Sci 1974; 38: 964-967.

66. Kastelic JP, Knopf L, Ginther OJ. Effect of day of prostaglandin F2[alpha] treatment on selection and development of the ovulatory follicle in heifers. Anim Reprod Sci 1990; 23: 169-180.

67. Stevenson JS, Britt JH. Detection of Estrus by Three Methods. J Dairy Sci 1977; 60: 1994-1998. 
68. Pursley JR, Wiltbank MC, Stevenson JS, Ottobre JS, Garverick HA, Anderson LL. Pregnancy Rates Per Artificial Insemination for Cows and Heifers Inseminated at a Synchronized Ovulation or Synchronized Estrus. J Dairy Sci 1997; 80: 295-300.

69. Pursley JR, Mee MO, Wiltbank MC. Synchronization of ovulation in dairy cows using PGF2[alpha] and GnRH. Theriogenology 1995; 44: 915-923.

70. Pursley JR, Kosorok MR, Wiltbank MC. Reproductive management of lactating dairy cows using synchronization of ovulation. J Dairy Sci 1997; 80: 301-306.

71. Macmillan KL, Thatcher WW. Effects of an agonist of gonadotropin-releasing hormone on ovarian follicles in cattle. Biol Reprod 1991; 45: 883-889.

72. Tribulo HE, Bo GA, Kastelic JP, Pawlyshyn V, Barth AD, Mapletoft RJ. Estrus synchronization in cattle with estradiol-17[beta] and CIDR-B vaginal devices. Theriogenology 1995; 43: 340-340.

73. Bó GA, Baruselli PS, Moreno D, Cutaia L, Caccia M, Tríbulo R, Tríbulo H, Mapletoft RJ. The control of follicular wave development for self-appointed embryo transfer programs in cattle. Theriogenology 2002; 57: 53-72.

74. Bergfeld EG, Kojima FN, Cupp AS, Wehrman ME, Peters KE, Mariscal V, Sanchez T, Kinder JE. Changing dose of progesterone results in sudden changes in frequency of luteinizing hormone pulses and secretion of 17 beta-estradiol in bovine females. Biol Reprod 1996; 54: 546-553.

75. Martínez MF, Kastelic JP, Colazo MG, Mapletoft RJ. Effects of estradiol on gonadotrophin release, estrus and ovulation in CIDR-treated beef cattle. Domest Anim Endocrinol 2007; 33: 77-90.

76. Colazo MG, Kastelic JP, Mapletoft RJ. Effects of estradiol cypionate (ECP) on ovarian follicular dynamics, synchrony of ovulation, and fertility in CIDR-based, fixed-time AI programs in beef heifers. Theriogenology 2003; 60: 855-865.

77. Colazo MG, Kastelic JP, Martínez MF, Whittaker PR, Wilde R, Ambrose JD, Corbett R, Mapletoft RJ. Fertility following fixed-time AI in CIDR-treated beef heifers given GnRH or estradiol cypionate and fed diets supplemented with flax seed or sunflower seed. Theriogenology 2004; 61: 1115-1124.

78. Nasser LF, Adams GP, Bo GA, Mapletoft RJ. Ovarian superstimulatory response relative to follicular wave emergence in heifers. Theriogenology 1993; 40: 713-724.

79. Bergfelt DR, Bo GA, Mapletoft RJ, Adams GP. Superovulatory response following ablation-induced follicular wave emergence at random stages of the oestrous cycle in cattle. Anim Reprod Sci 1997; 49: 1-12.

80. Bao B, Garverick HA. Expression of steroidogenic enzyme and gonadotropin receptor genes in bovine follicles during ovarian follicular waves: a review. J Anim Sci 1998; 76: 1903-1921.

81. Bao B, Garverick HA, Smith GW, Smith MF, Salfen BE, Youngquist RS. Changes in messenger ribonucleic acid encoding luteinizing hormone receptor, cytochrome P450side chain cleavage, and aromatase are associated with recruitment and selection of bovine ovarian follicles. Biol Reprod 1997; 56: 1158-1168.

82. Ginther OJ, Wiltbank MC, Fricke PM, Gibbons JR, Kot K. Selection of the dominant follicle in cattle. Biol Reprod 1996; 55: 1187-1194. 
83. Fitzpatrick SL, Carlone DL, Robker RL, Richards JS. Expression of aromatase in the ovary: Down-regulation of mRNA by the ovulatory luteinizing hormone surge. Steroids 1997; 62: 197-206.

84. Mellin TN, Erb EB. Estrogens in the bovine-A review. J Dairy Sci 1965; 48: 687-700.

85. Lange IG, Hartel A, Meyer HHD. Evolution of oestrogen functions in vertebrates. J Steroid Biochem Mol Biol 2002; 83: 219-226.

86. Rico AG. Metabolism of endogenous and exogenous anabolic agents in cattle. J Anim Sci 1983; 57: 226-232.

87. Simpson ER, Davis SR. Minireview: Aromatase and the Regulation of Estrogen Biosynthesis--Some New Perspectives. Endocrinology 2001; 142: 4589-4594.

88. Bulun SE, Rosenthal IM, Brodie AM, Inkster SE, Zeller WP, DiGeorge AM, Frasier SD, Kilgore MW, Simpson ER. Use of tissue-specific promoters in the regulation of aromatase cytochrome P450 gene expression in human testicular and ovarian sex cord tumors, as well as in normal fetal and adult gonads [corrected and republished in J Clin Endocrinol Metab 1994 Feb;78(2):1616-21]. J Clin Endocrinol Metab 1993; 77: 16161621.

89. Honda S, Harada N, Takagi Y. Novel Exon I of the Aromatase Gene Specific for Aromatase Transcripts in Human Brain. Biochem Biophys Res Commun 1994; 198: 1153-1160.

90. Jakimiuk AJ, Weitsman SR, Brzechffa PR, Magoffin DA. Aromatase mRNA expression in individual follicles from polycystic ovaries. Mol Hum Reprod 1998; 4: 1-8.

91. Mahendroo MS, Mendelson CR, Simpson ER. Tissue-specific and hormonally controlled alternative promoters regulate aromatase cytochrome P450 gene expression in human adipose tissue. J Biol Chem 1993; 268: 19463-19470.

92. Toda K, Simpson ER, Mendelson CR, Shizuta Y, Kilgore MW. Expression of the gene encoding aromatase cytochrome P450 (CYP19) in fetal tissues. Mol Endocrinol 1994; 8: 210-217.

93. Zhao Y, Mendelson CR, Simpson ER. Characterization of the sequences of the human CYP19 (aromatase) gene that mediate regulation by glucocorticoids in adipose stromal cells and fetal hepatocytes. Mol Endocrinol 1995; 9: 340-349.

94. Simpson ER, Michael MD, Agarwal VR, Hinshelwood MM, Bulun SE, Zhao Y. Cytochromes P450 11: expression of the CYP19 (aromatase) gene: an unusual case of alternative promoter usage. FASEB J 1997; 11: 29-36.

95. Means GD, Mahendroo MS, Corbin CJ, Mathis JM, Powell FE, Mendelson CR, Simpson ER. Structural analysis of the gene encoding human aromatase cytochrome P- 450, the enzyme responsible for estrogen biosynthesis. J Biol Chem 1989; 264: 19385-19391.

96. Reinhardt C. Growth-promotant implants: Managing the tools. Vet Clin North Am Food Anim Pract 2007; 23: 309-319.

97. Buttery PJ, Dawson JM. Growth promotion in farm animals. Proc Nutr Soc 1990; 49: 459-466.

98. Daston GP, Gooch JW, Breslin WJ, Shuey DL, Nikiforov AI, Fico TA, Gorsuch JW. Environmental estrogens and reproductive health: A discussion of the human and environmental data. Reprod Toxicol 1997; 11: 465-481. 
99. Aksglaede L, Juul A, Leffers H, Skakkebaek NE, Andersson A-M. The sensitivity of the child to sex steroids: possible impact of exogenous estrogens. Hum Reprod Update 2006; 12: 341-349.

100. Nayga RM, Jr. Sociodemographic influences on consumer concern for food safety: The case of irradiation, antibiotics, hormones, and pesticides. Rev Agr Econ 1996; 18: 467475.

101. Bibbo M, Gill W, Azizi F, Blough R, Fang V, Rosenfield R, Schumacher G, Sleeper K, Sonek M, Wied G. Follow-up study of male and female offspring of DES-exposed mothers. Obstet Gynecol 1977; 49: 1-18.

102. Hartmann S, Lacorn M, Steinhart H. Natural occurrence of steroid hormones in food. Food Chem 1998; 62: 7-20.

103. Foreign Agricultural Service USDA. Historic Overview and Chronology of EU's Hormone Ban. In: GAIN Report E23206; 2003.

104. Lane EA, Austin EJ, Crowe MA. Oestrous synchronisation in cattle--Current options following the EU regulations restricting use of oestrogenic compounds in food-producing animals: A review. Anim Reprod Sci 2008; 109: 1-16.

105. Hong Y, Chen S. Aromatase inhibitors, structural features and biochemical characterization. Ann N Y Acad Sci 2006; 1089: 237-251.

106. Haynes BP, Dowsett M, Miller WR, Dixon JM, Bhatnagar AS. The pharmacology of letrozole. J Steroid Biochem Mol Biol 2003; 87: 35-45.

107. Lønning PE. Pharmacology of new aromatase inhibitors. The Breast 1996; 5: 202-208.

108. Bhatnagar AS, Häusler A, Schieweck K, Lang M, Bowman R. Highly selective inhibition of estrogen biosynthesis by CGS 20267, a new non-steroidal aromatase inhibitor. J Steroid Biochem Mol Biol 1990; 37: 1021-1027.

109. Trunet PF, Mueller P, Bhatnagar AS, Dickes I, Monnet G, White G. Open dose-finding study of a new potent and selective nonsteroidal aromatase inhibitor, CGS 20 267, in healthy male subjects. J Clin Endocrinol Metab 1993; 77: 319-323.

110. Pfister CU, Martoni A, Carlo Z, Lelli G, De Braud F, Souppart C, Duval M, Hornberger U. Effect of age and single versus multiple dose pharmacokinetics of letrozole (Femara $\left.{ }^{\circledR}\right)$ in breast cancer patients. Biopharm Drug Dispos 2001; 22: 191-197.

111. Sioufi A, Gauducheau N, Pineau V, Marfil F, Jaouen A, Cardot JM, Godbillon J, Czendlik C, Howald H, Pfister CH, Vreeland F. Absolute bioavailability of letrozole in healthy postmenopausal women. Biopharm Drug Dispos 1997; 18: 779-789.

112. Sioufi A, Sandrenan N, Godbillon J, Trunet P, Czendlik C, Howald H, Pfister C, Ezzet F. Comparative bioavailability of letrozole under fed and fasting conditions in 12 healthy subjects after a 2.5 mg single oral administration. Biopharm Drug Dispos 1997; 18: 489497.

113. Iveson TJ, Smith IE, Ahern J, Smithers DA, Trunet PF, Dowsett M. Phase I study of the oral nonsteroidal aromatase inhibitor CGS 20267 in healthy postmenopausal women. J Clin Endocrinol Metab 1993; 77: 324-331.

114. Dowsett M, Jones A, Johnston SR, Jacobs S, Trunet P, Smith IE. In vivo measurement of aromatase inhibition by letrozole (CGS 20267) in postmenopausal patients with breast cancer. Clin Cancer Res 1995; 1: 1511-1515. 
115. Danforth DR, Sinosich MJ, Anderson TL, Cheng CY, Bardin CW, Hodgen GD. Identification of gonadotropin surge-inhibiting factor (GnSIF) in follicular fluid and its differentiation from inhibin. Biol Reprod 1987; 37: 1075-1082.

116. Beatson GT. On the treatment of inoperable cases of carcinoma of the mamma: Suggestions for a new method of treatment, with illustrative cases. CA Cancer J Clin 1983; 33: 108-121.

117. Njar VCO, Brodie AMH. Comprehensive pharmacology and clinical efficacy of aromatase inhibitors. Review article Drugs 1999; 58: 233-255.

118. Brodie A, Lu Q, Long B. Aromatase and its inhibitors. J Steroid Biochem Mol Biol 1999; 69: 205-210.

119. US Food and Drug Administration. 2007. Drug approval package: Femara (Letrozole) Tablets. Available from: www.fda.gov/cder/foi/nda/2001/20-726S006_Femara.htm

120. Cohen MH, Johnson JR, Li N, Chen G, Pazdur R. Approval summary: Letrozole in the treatment of postmenopausal women with advanced breast cancer. Clin Cancer Res 2002; 8: 665-669.

121. Bhatnagar A. The discovery and mechanism of action of letrozole. Breast Cancer Res Treat 2007; 105: 7-17.

122. Hefler LA, Grimm C, van Trotsenburg M, Nagele F. Role of the vaginally administered aromatase inhibitor anastrozole in women with rectovaginal endometriosis: a pilot study. Fertil Steril 2005; 84: 1033-1036.

123. de Ziegler D. Associate editor's commentary: The dawning of the non-cancer uses of aromatase inhibitors in gynaecology. Hum Reprod 2003; 18: 1598-1602.

124. Brodie AMH. Aromatase inhibition and its pharmacologic implications. Biochemical Pharmacology 1985; 34: 3213-3219.

125. Verma A, Konje JC. Successful treatment of refractory endometriosis-related chronic pelvic pain with aromatase inhibitors in premenopausal patients. Eur J Obstet Gynecol Reprod Biol 2009; 143: 112-115.

126. Ebert AD, Bartley J, David M. Aromatase inhibitors and cyclooxygenase-2 (COX-2) inhibitors in endometriosis: New questions--old answers? Eur J Obstet Gynecol Reprod Biol 2005; 122: 144-150.

127. Health Canada. 2005. Contraindication of Femara* (letrozole) in premenopausal women. Available from: $\quad$ http://www.hc-sc.gc.ca/dhp-mps/alt_formats/hpfbdgpsa/pdf/medeff/femara_hpc-cps-eng.pdf

128. Bayar U, TanrIverdi HA, Barut A, Ayoglu F, Özcan O, Kaya E. Letrozole vs. clomiphene citrate in patients with ovulatory infertility. Fertil Steril 2006; 85: 1045-1048.

129. Jee BC, Ku SY, Suh CS, Kim KC, Lee WD, Kim SH. Use of letrozole versus clomiphene citrate combined with gonadotropins in intrauterine insemination cycles: a pilot study. Fertil Steril 2006; 85: 1774-1777.

130. Mitwally MFM, Casper RF. Single-dose administration of an aromatase inhibitor for ovarian stimulation. Fertil Steril 2005; 83: 229-231.

131. Fisher SA, Reid RL, Van Vugt DA, Casper RF. A randomized double-blind comparison of the effects of clomiphene citrate and the aromatase inhibitor letrozole on ovulatory function in normal women. Fertil Steril 2002; 78: 280-285.

132. Mitwally MF, Casper RF. Aromatase Inhibition improves ovarian response to folliclestimulating hormone in poor responders. Fertil Steril 2002; 77: 776-780. 
133. Biljan MM, Hemmings R, Brassard N. The outcome of 150 babies following the treatment with letrozole or letrozole and gonadotropins. Fertil Steril 2005; 84: S95-S95.

134. Tulandi T, Martin J, Al-Fadhli R, Kabli N, Forman R, Hitkari J, Librach C, Greenblatt E, Casper RF. Congenital malformations among 911 newborns conceived after infertility treatment with letrozole or clomiphene citrate. Fertil Steril 2006; 85: 1761-1765.

135. Badawy A, Shokeir T, Allam AF, Abdelhady H. Pregnancy outcome after ovulation induction with aromatase inhibitors or clomiphene citrate in unexplained infertility. Acta Obstet Gynecol Scand 2009; 88: 187 - 191.

136. Adams GP, Pierson RA. Bovine model for study of ovarian follicular dynamics in humans. Theriogenology 1995; 43: 113-120.

137. Baerwald A, Adams G, Pierson R. Characterization of ovarian follicular wave dynamics in women. Biol Reprod 2003; 69: 1023-1031.

138. Baerwald AR, Adams GP, Pierson RA. A new model for ovarian follicular development during the human menstrual cycle. Fertil Steril 2003; 80: 116-122.

139. Ginther OJ, Beg MA, Donadeu FX, Bergfelt DR. Mechanism of follicle deviation in monovular farm species. Anim Reprod Sci 2003; 78: 239-257.

140. Mihm M, Evans ACO. Mechanisms for dominant follicle selection in monovulatory species: A comparison of morphological, endocrine and intraovarian events in cows, mares and women. Reprod Domest Anim 2008; 43: 48-56.

141. Malhi PS, Adams GP, Singh J. Bovine model for the study of reproductive aging in women: Follicular, luteal, and endocrine characteristics. Biol Reprod 2005; 73: 45-53.

142. Malhi PS, Adams GP, Mapletoft RJ, Singh J. Oocyte developmental competence in a bovine model of reproductive aging. Reproduction 2007; 134: 233-239.

143. Pierson RA, Ginther OJ. Reliability of diagnostic ultrasonography for identification and measurement of follicles and detecting the corpus luteum in heifers. Theriogenology 1987; 28: 929-936.

144. Hafs HD, Louis TM, Noden PA, Oxender WD. Control of the estrous cycle with prostaglandin F2\{alpha\} in cattle and horses. J Anim Sci 1974; 38: 10-21.

145. Berfelt DR, Lightfoot KC, Adams GP. Ovarian synchronization following ultrasoundguided transvaginal follicle ablation in heifers. Theriogenology 1994; 42: 895-907.

146. Peter AT, Levine H, Drost M, Bergfelt DR. Compilation of classical and contemporary terminology used to describe morphological aspects of ovarian dynamics in cattle. Theriogenology 2009; 71: 1343-1357.

147. Evans ACO, Adams GP, Rawlings NC. Endocrine and ovarian follicular changes leading up to the first ovulation in prepubertal heifers. J Reprod Fertil 1994; 100: 187-194.

148. Valentini F, Compagnoneb D, Gentilic A, Palleschia G. An electrochemical ELISA procedure for the screening of 17-estradiol in urban waste waters. Analyst 2002; 127: 1333-1337.

149. Hecker M, Park J-W, Murphy MB, Jones PD, Solomon KR, Van Der Kraak G, Carr JA, Smith EE, du Preez L, Kendall RJ, Giesy JP. Effects of atrazine on CYP19 gene expression and aromatase activity in testes and on plasma sex steroid concentrations of male african clawed frogs (Xenopus laevis). Toxicol Sci 2005; 86: 273-280.

150. Casper RF. Letrozole: ovulation or superovulation? Fertil Steril 2003; 80: 1335-1337. 
151. Sinha S, Kaseta J, Santner SJ, Demers LM, Bremmer WJ, Santen RJ. Effect of CGS 20267 on ovarian aromatase and gonadotropin levels in the rat. Breast Cancer Res Treat 1998; 48: 45-51.

152. At-Taras EE, Conley AJ, Berger T, Roser JF. Reducing estrogen synthesis does not affect gonadotropin secretion in the developing boar. Biol Reprod 2006; 74: 58-66.

153. Miller KF, Critser JK, Rowe RF, Ginther OJ. Ovarian effects of bovine follicular fluid treatment in sheep and cattle. Biol Reprod 1979; 21: 537-544.

154. Miller KF, Wesson JA, Ginther OJ. Interaction of estradiol and a nonsteroidal follicular fluid substance in the regulation of gonadotropin secretion in the mare. Biol Reprod 1981; 24: 354-358.

155. Bleach ECL, Glencross RG, Feist SA, Groome NP, Knight PG. Plasma inhibin A in heifers: Relationship with follicle dynamics, gonadotropins, and steroids during the estrous cycle and after treatment with bovine follicular fluid. Biol Reprod 2001; 64: 743752.

156. Mamali P, Samartzi F, Batzias GC, Theodosiadou E, Vainas E, Goulas P, Belibasaki S, Saratsis F. The effect of albendazole administration on the concentration of ovarian steroids in the follicular fluid and the maturation of oocytes in the ewe. In: 16th International Conference of Animal Reproduction; 2008; Budapest, Hungary. Reprod Domest Anim Vol $43: 192$.

157. Bo GA, Adams GP, Pierson RA, Tribulo HE, Caccia M, Mapletoft RJ. Follicular wave dynamics after estradiol-17[beta] treatment of heifers with or without a progestogen implant. Theriogenology 1994; 41: 1555-1569.

158. Vynckier L, Debackere M, Kruif A, Coryn M. Plasma estradiol-17\{beta\} concentrations in the cow during induced estrus and after injection of estradiol-17\{beta\} benzoate and estradiol-17\{beta\} cypionate -a preliminary study. J Vet Pharmacol Therap 1990; 13: 3642.

159. Bo GA, Adams GP, Nasser LF, Pierson RA, Mapletoft RJ. Effect of estradiol valerate on ovarian follicles, emergence of follicular waves and circulating gonadotropins in heifers. Theriogenology 1993; 40: 225-239.

160. Foreign Agricultural Service USDA. 2003. Historic overview and chronology of EU's hormone ban. GAIN Report E23206. Available from $\underline{\text { http://www.fas.usda.gov/scriptsw/attacherep/gain_display_report.asp?Rep_ID }=14598677}$ $\underline{3}$

161. Lane EA, Austin EJ, Roche JF, Crowe MA. The effect of estradiol benzoate on synchrony of estrus and fertility in cattle after removal of a progesterone-releasing intravaginal device. Theriogenology 2001; 55: 1807-1818.

162. Baracaldo MI, Martinez MF, Adams GP, Mapletoft RJ. Superovulatory response following transvaginal follicle ablation in cattle. Theriogenology 2000; 53: 1239-1250.

163. Pierson RA, Kastelic JP, Ginther OJ. Basic principles and techniques for transrectal ultrasonography in cattle and horses. Theriogenology 1988; 29: 3-20.

164. Singh J, Pierson RA, Adams GP. Ultrasound image attributes of the bovine corpus luteum: structural and functional correlates. J Reprod Fertil 1997; 109: 35-44.

165. Singh J, Pierson RA, Adams GP. Ultrasound image attributes of bovine ovarian follicles and endocrine and functional correlates. J Reprod Fertil 1998: 19-29. 
166. Chen S, Zhang F, Sherman MA, Kijima I, Cho M, Yuan Y-C, Toma Y, Osawa Y, Zhou D, Eng ET. Structure-function studies of aromatase and its inhibitors: a progress report. The Journal of Steroid Biochemistry and Molecular Biology 2003; 86: 231-237.

167. Pierson RA, Adams GP. Computer-assisted image analysis, diagnostic ultrasonography and ovulation induction: Strange bedfellows. Theriogenology 1995; 43: 105-112.

168. Campbell BK, Picton HM, Mann GE, McNeilly AS, Baird DT. Effect of steroid- and inhibin-free ovine follicular fluid on ovarian follicles and ovarian hormone secretion. J Reprod Fertil 1991; 93: 81-96.

169. Marongiu M, Gulinati A. Opioid inhibition if the pulsatile luteinizing hormone release as assessed by naloxone treatment in the lactanting rabbit. In: 9th World Rabbit Congress; 2008; Verona, Italy. Available from http://world-rabbit-science.com/WRSAProceedings/Congress-2008-Verona/Papers/R-Marongiu2001.pdf.

170. Taft R, Ahmad N, Inskeep EK. Exogenous pulses of luteinizing hormone cause persistence of the largest bovine ovarian follicle. J Anim Sci 1996; 74: 2985-2991.

171. Adams G, Kot K, Smith CA, Ginther OJ. Effect of the dominant follicle on regression of its subordinates in heifers. Can J Anim Sci 1993; 73: 267-275.

172. Bodensteiner KJ, Wiltbank MC, Bergfelt DR, Ginther OJ. Alterations in follicular estradiol and gonadotropin receptors during development of bovine antral follicles. Theriogenology 1996; 45: 499-512.

173. Gombe S, Hall WC, McEntee K, Hansel W, Pickett BW. Regulation of blood levels of LH in bulls: influence of age, breed, sexual stimulation and temporal fluctuations. J Reprod Fertil 1973; 35: 493-503.

174. Wilks JW, Hansel W. Oxytocin and the secretion of luteinizing hormone in cattle. J Anim Sci 1971; 33: 1048-1052.

175. Shetty G, Krishnamurthy H, Krishnamurthy HN, Bhatnagar AS, Moudgal RN. Effect of estrogen deprivation on the reproductive physiology of male and female primates. J Steroid Biochem Mol Biol 1997; 61: 157-166.

176. Welschen R, Hermans WP, Dullaart J, de Jong FH. Effects of an inhibin-like factor present in bovine and porcine follicular fluid on gonadotrophin levels in ovariectomized rats. J Reprod Fertil 1977; 50: 129-131.

177. Law AS, Baxter G, Logue DN, O'Shea T, Webb R. Evidence for the action of bovine follicular fluid factor(s) other than inhibin in suppressing follicular development and delaying oestrus in heifers. J Reprod Fertil 1992; 96: 603-616.

178. Kaneko H, Nakanishi Y, Akagi S, Arai K, Taya K, Watanabe G, Sasamoto S, Hasegawa Y. Immunoneutralization of inhibin and estradiol during the follicular phase of the estrous cycle in cows. Biol Reprod 1995; 53: 931-939.

179. Duffy P, Crowe MA, Boland MP, Roche JF. Effect of exogenous LH pulses on the fate of the first dominant follicle in postpartum beef cows nursing calves. J Reprod Fertil 2000; 118: 9-17. 


\section{APPENDICES}

APPENDIX 1: Diameter profile (mean \pm SEM) of the dominant follicle in heifers treated with a

high- $(n=9)$, medium- $(n=10)$ or low-dose $(n=10)$ of letrozole 4 days after follicular ablation (i.e., 2.5 days after wave emergence), compared to saline-treated controls $(n=10)$.

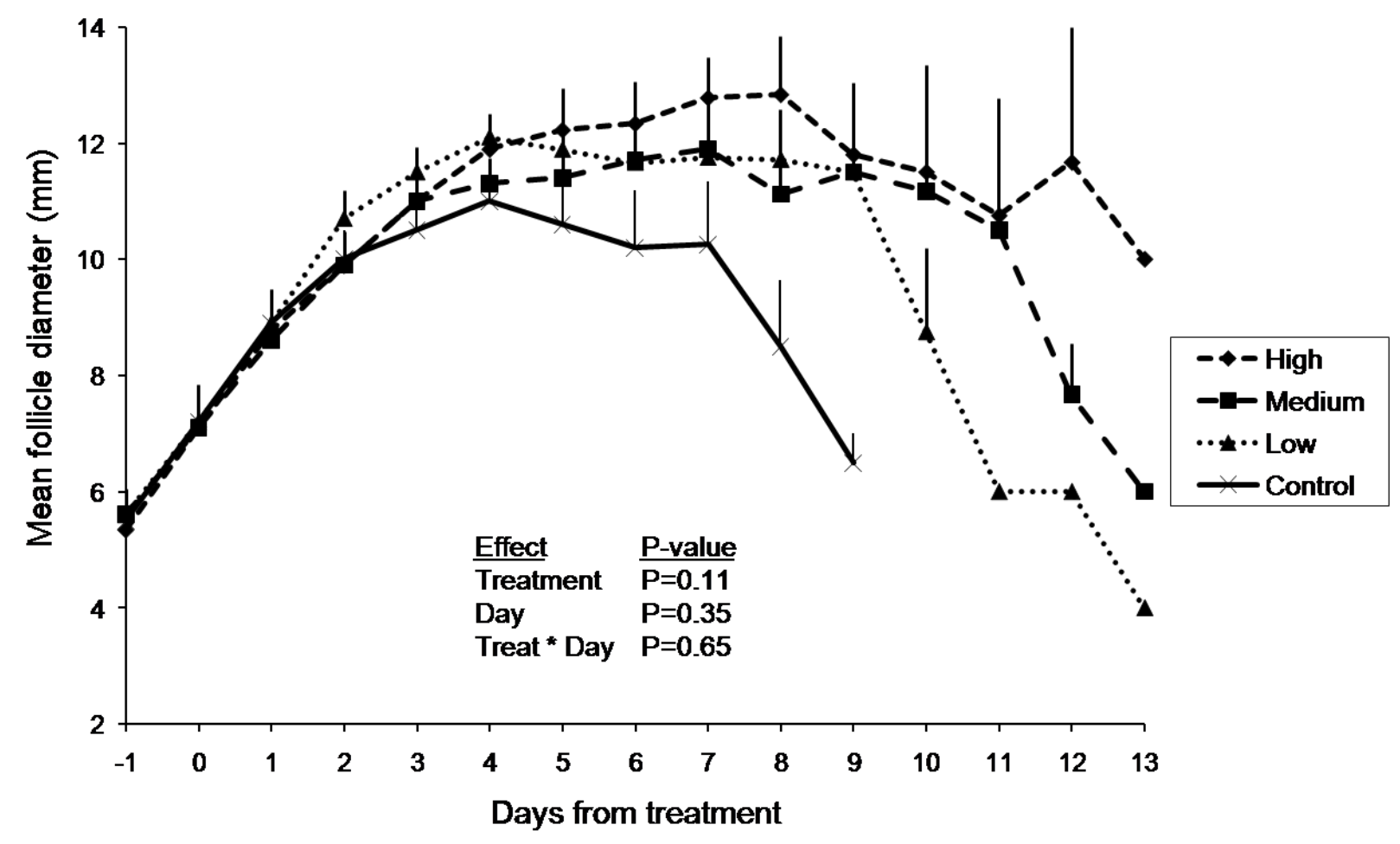


APPENDIX 2: Diameter profile (mean \pm SEM) of the dominant follicle in heifers treated with letrozole on Days 1 to $3(n=10), 3$ to $5(n=9)$ or 5 to $7(n=9)$ (Day $0=$ ovulation) compared to untreated controls $(n=17)$.

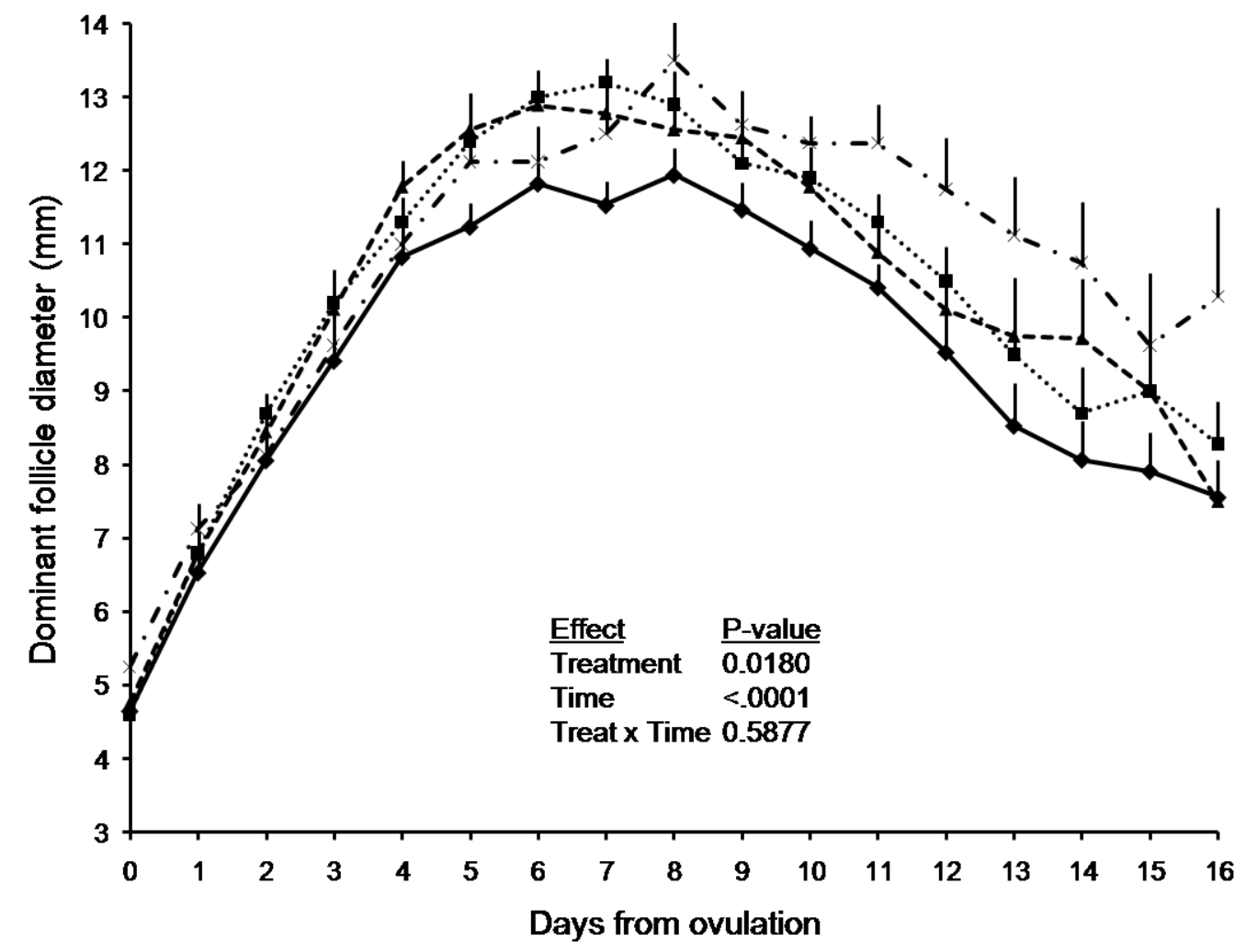


APPENDIX 3: Determination of plasma estradiol-17 $\beta$ concentrations by liquid chromatography/mass spectrometry

Plasma concentrations of estradiol were determined using high performance liquid chromatography/mass spectrometry (HPLC/MS). To extract estradiol from the samples, $100 \mu \mathrm{L}$ of surrogate standard $\left(500 \mathrm{pg} / \mathrm{mL} \mathrm{d}_{4}-\mathrm{E} 2\right.$, deuterated form of estradiol-17 $\left.\beta\right)$ were added to $1.5 \mathrm{~mL}$ of plasma followed by the addition of $3 \mathrm{~mL}$ of methanol. The mixture was diluted $(10 \% \mathrm{v} / \mathrm{v}$ methanol) with nanopure water. A solid phase extraction of the samples was accomplish using Oasis ${ }^{\circledR}$ HLB cartridges (hydrophilic lipophilic balance; Waters, Milford, MA, USA). Prior to extraction, the cartridges were fitted onto a solid-phase extraction (SPE) vacuum manifold and were sequentially conditioned with $6 \mathrm{~mL}$ of ethyl acetate, $6 \mathrm{~mL}$ of acetonitrile and finally $12 \mathrm{~mL}$ of nanopure water. After conditioning, samples were loaded, and after passing trough, the cartridges were dried by negative pressure. The retained compounds were eluted with $12 \mathrm{~mL}$ of ethyl acetate. After dried under gentle nitrogen flow, the residues were dissolved in $4 \mathrm{~mL}$ of hexane/ethyl acetate (v/v, 9:1) and transferred to a $12 \mathrm{~mL}$ glass bottle. Additional $2 \mathrm{~mL}$ of nanopure water were added to the $12 \mathrm{~mL}$ bottle and after shaking and separation, the organic layer was removed by pipetting and transferred to a $4 \mathrm{~mL}$ glass bottle. After drying the organic solvents, addition of hexane/ethyl acetate (v/v, 9:1) and transfer of organic layer to the same 4 $\mathrm{mL}$ bottle was repeated twice. This second tube was dried by gentle nitrogen gas flow. The dried extract was resolved with $\mathrm{NaHCO}_{3}$ buffer $(0.1 \mathrm{~mL})$ and dansyl chloride agent $(1 \mathrm{mg} / \mathrm{mL}, 0.1 \mathrm{~mL})$ for derivatization, and it was shaken for 1 minute and heated at $60^{\circ} \mathrm{C}$ for 5 minutes. After it cooled, $1 \mathrm{~mL}$ of nanopure water and $2 \mathrm{~mL}$ of hexane/ethyl acetate (v/v, 9:1) were added and the organic layer were transferred to a fresh $4 \mathrm{~mL}$ glass bottle. This last liquid extraction was repeated two more times. Finally, the extract was dried under nitrogen gas flow and the residues 
were reconstituted in $80 \mu \mathrm{L}$ of acetonitrile plus $20 \mu \mathrm{L}$ of nanopure water prior analysis using LCMS/Ms. Separation was accomplished by HPLC (Agilent 1200, Santa Clara, CA, USA) fitted with an analytical column (100x2.1 mm, $5.0 \mu \mathrm{m}$ particle size; Thermo Scientific Betasil C18, Waltham, MA, USA) operated at $30^{\circ} \mathrm{C}$. The mobile phase consisting of acetonitrile (solvent A) and $0.1 \%$ formic acid in water (solvent $\mathrm{B}$ ) was used with a gradient elution of $\mathrm{A}: \mathrm{B}=80: 20$ to 95:5 (0-15 $\mathrm{min})$ and 80:20 (15-20 $\mathrm{min})$ at a flow rate of $0.25 \mathrm{~mL} / \mathrm{min}$. Mass spectra were collected using a tandem mass spectrometer (Applied Bioscience SCIEX 3000, Foster City, CA, USA) fitted with an electrospray ionization source, operated in the positive ionization mode. Chromatograms were recorded using multiple reaction monitoring (MRM) mode, where at least two transitions per-analyte were monitored. The following instrument parameters were used: desolvation temperature $475^{\circ} \mathrm{C}$, desolvation (curtain) gas 8.0 arbitrary units (AU), nebulizer gas flow $12 \mathrm{AU}$, ion spray voltage $3750 \mathrm{~V}$, collision gas $12 \mathrm{AU}$, collision energy $48 \mathrm{AU}$, declustering potential $70 \mathrm{AU}$, and a dwell time of $200 \mathrm{msec}$. Quantification using these transitions was performed using Analyst 1.4.1 software provided by SCIEX (Applied Bioscience, Foster City, CA, USA). The minimum and maximum values along the standard curve were 40 and $20000 \mathrm{pg} / \mathrm{mL}$ respectively. The limit of quantification used in this method was $10 \mathrm{pg} / \mathrm{mL}$ and the mean recovery was $70 \%$. The LOD and LOQ in the plasma are $0.8 \mathrm{pg} / \mathrm{mL}$ and $2 \mathrm{pg} / \mathrm{mL}$. CV was less than $5 \%$. 
APPENDIX 4: Comparison of plasma estradiol-17 $\beta$ concentration as determined by high performance liquid chromatography (HPLC/MS) and enzyme-linked immunosorbent assay (ELISA).

A sub-set of plasma samples $(n=20)$ was analyzed by HPLC/MS to determine plasma estradiol-17 $\beta$ concentration and to be compared with the results obtained by ELISA. Unexpectedly, two plasma samples failed to induce a peak on the mass spectrometer and they could not be measured. The data obtained by HPLC/MS and ELISA, together with the coefficient of variation $(\mathrm{CV})$ between the two methods of determination are summarized in the following table:

\begin{tabular}{lccc} 
& \multicolumn{2}{c}{ Plasma E-17 $\beta$ concentration } & \\
\cline { 2 - 3 } Sample & LC/MS & Elisa & CV \\
\hline $\mathrm{A}$ & 164 & 160.2 & 1.7 \\
$\mathrm{~B}$ & 66.4 & 58.5 & 9.0 \\
$\mathrm{C}$ & 3.0 & 3.4 & 7.9 \\
$\mathrm{D}$ & 10.9 & 12.9 & 11.9 \\
$\mathrm{E}$ & 330 & 296.6 & 7.5 \\
$\mathrm{~F}$ & 4.9 & 3.4 & 26.9 \\
$\mathrm{G}$ & 4.34 & 6.0 & 22.9 \\
$\mathrm{H}$ & 4.5 & 3.4 & 20.4 \\
$\mathrm{I}$ & 10.2 & 11.4 & 7.7 \\
$\mathrm{~J}$ & 5.08 & 5.3 & 3.0 \\
$\mathrm{~K}$ & 6.2 & 5.4 & 9.4 \\
$\mathrm{~L}$ & 11.8 & 11.3 & 3.1 \\
$\mathrm{M}$ & 17.3 & 18.3 & 3.6 \\
$\mathrm{~N}$ & 15.1 & 15.1 & 0.2 \\
$\mathrm{O}$ & 8.7 & 7.0 & 15.3 \\
$\mathrm{P}$ & 12.5 & 12.0 & 2.9 \\
$\mathrm{Q}$ & 70.1 & 73.6 & 3.4 \\
$\mathrm{R}$ & 11.9 & 16.9 & 24.2 \\
\hline & & Mean CV & 10.1
\end{tabular}


APPENDIX 5: Results from computer-assisted image analysis of CL and dominant follicle
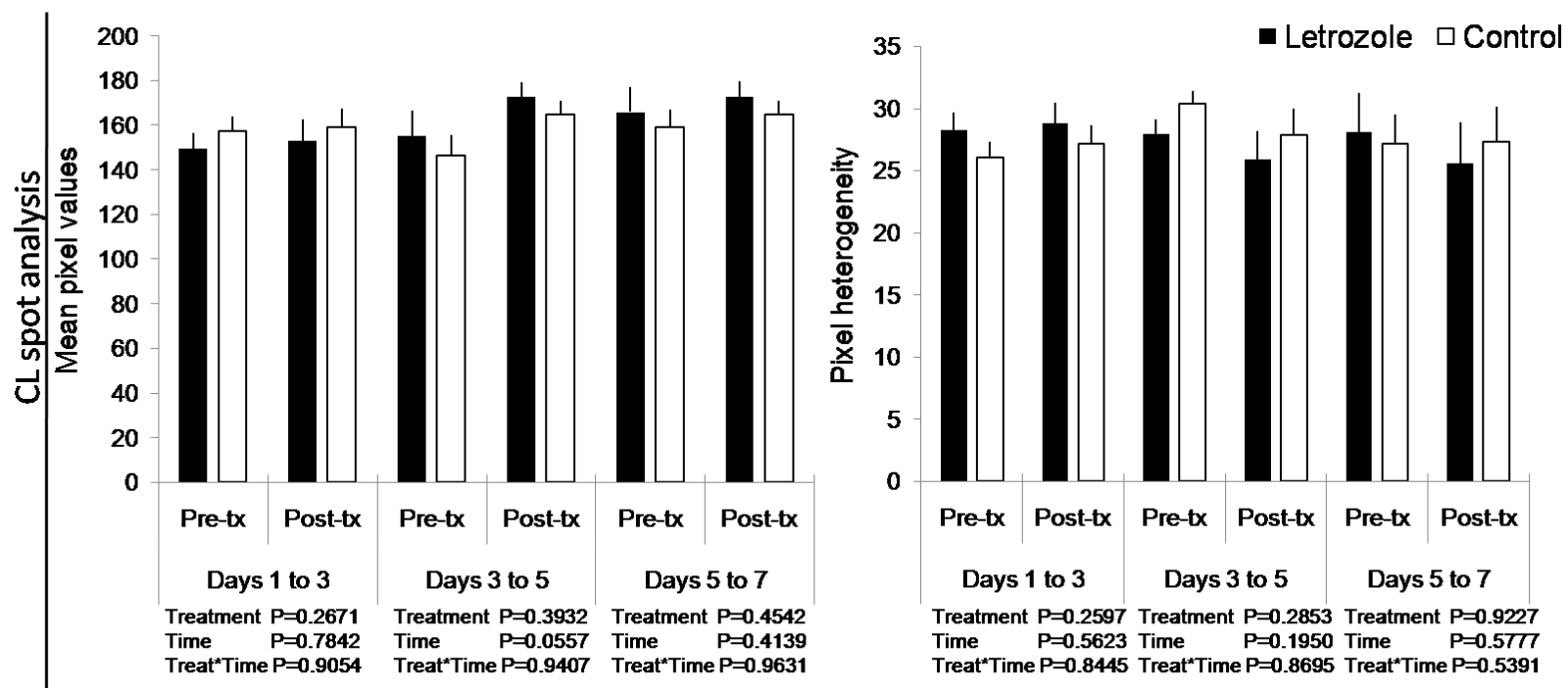

Mean pixel values (mean \pm SEM) and pixel heterogeneity (mean \pm SEM) of the CL recorded by spot analysis. Pre- and post-treatment values were compared within each treatment period (Days 1 to 3 , Days 3 to 5 or Days 5 to 7) with contemporary controls.
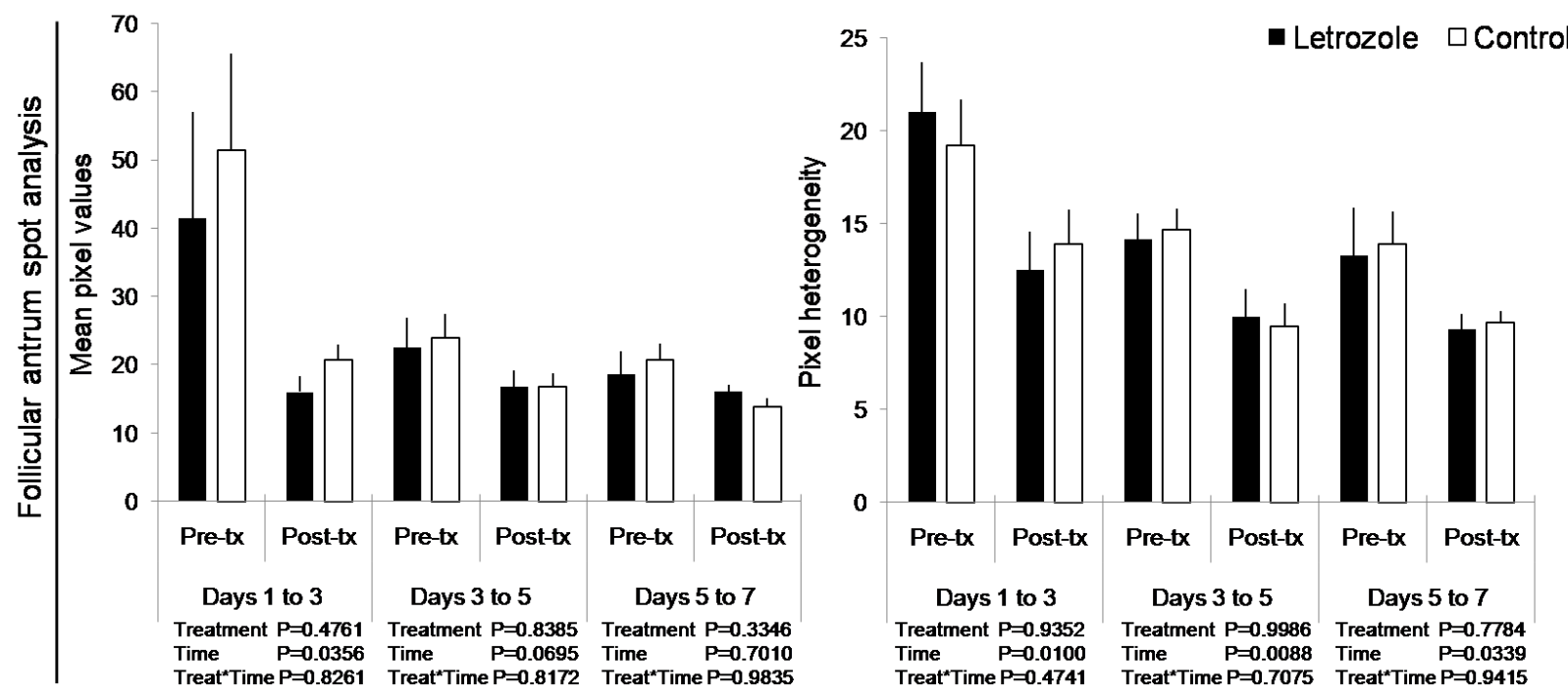

Mean pixel values (mean \pm SEM) and pixel heterogeneity (mean \pm SEM) of the follicular antrum recorded by spot analysis. Pre- and post-treatment values were compared within each treatment period (Days 1 to 3, Days 3 to 5 or Days 5 to 7) with contemporary controls. 

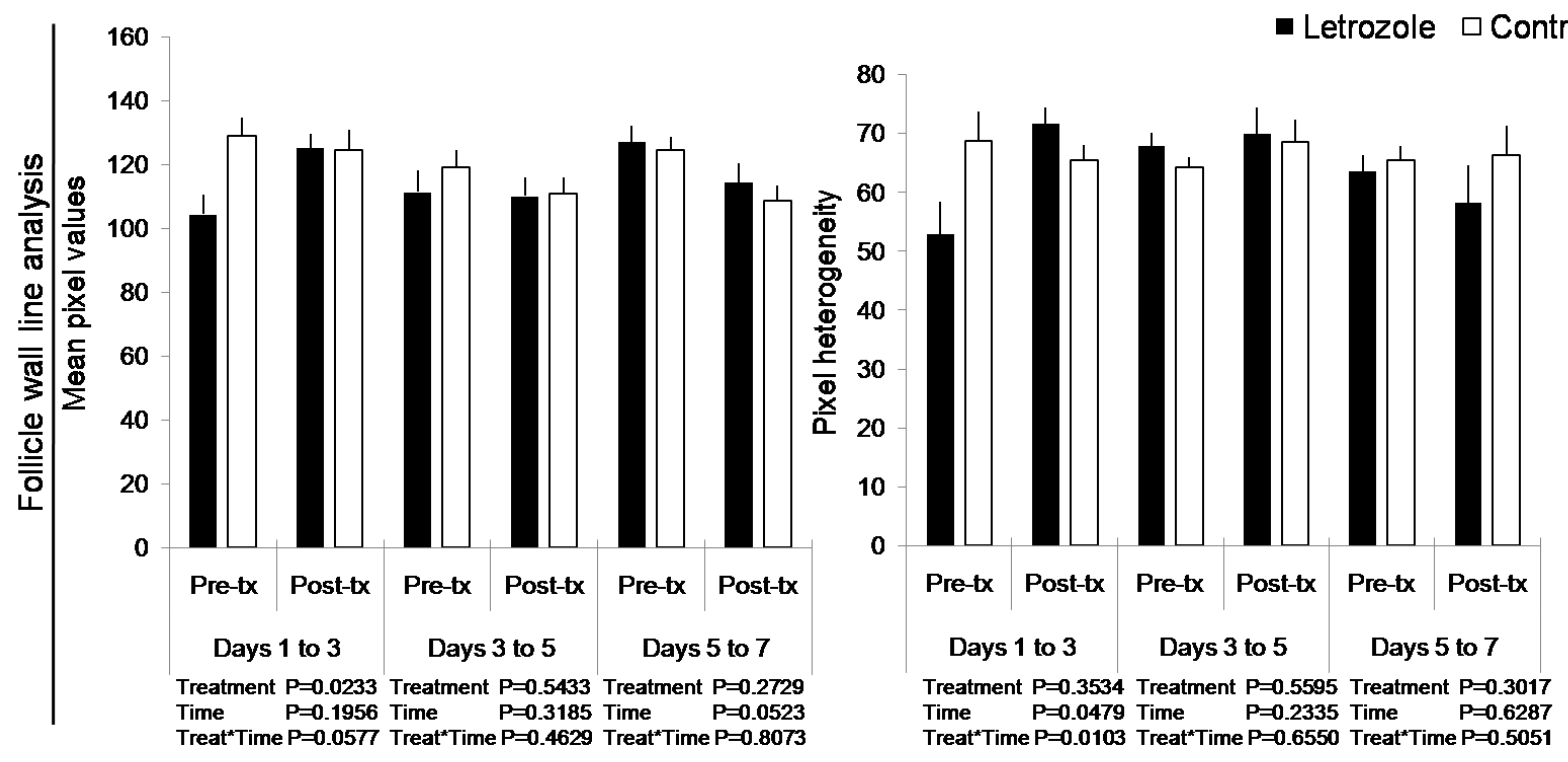

Mean pixel values (mean \pm SEM) and pixel heterogeneity (mean \pm SEM) along the follicular wall recorded by line analysis. Pre- and post-treatment values were compared within each treatment period (Days 1 to 3, Days 3 to 5 or Days 5 to 7) with contemporary controls. 